\title{
MANAGING IDENTITIES DURING SOCIAL CHANGE
}

A dissertation presented to the Faculty of the Graduate School

University of Missouri

Department of Communication

\author{
In Partial Fulfillment \\ of the Requirements for the Degree \\ Doctor of Philosophy
}

by

ANNA VALIAVSKA

Dr. Rebecca Meisenbach, Dissertation Supervisor

JULY 2019 
The undersigned, appointed by the dean of the Graduate school have examined the dissertation entitled:

MANAGING IDENTITIES DURING SOCIAL CHANGE

Presented by Anna Valiavska

A Candidate for the degree of

Doctor of Philosophy

And hereby certify that, in their opinion, it is worthy of acceptance.

Rebecca J. Meisenbach, PhD.

Debbie S. Dougherty, PhD.

Brian Houston, PhD.

Candace Kuby, PhD. 


\section{Acknowledgements}

"the thing you are most

afraid to write

write that

- advice to young writers"

Nayyirah Waheed

It takes a village to write a dissertation. I am fortunate beyond reason to have all the people who supported me, helped me think through ideas, brought me food and poetry books, and cheered me on. I will take this space to speak to those who have made this project possible.

First, I wanted to thank my participants. For sharing your experiences, for trusting me in sharing your stories, and for providing meaningful feedback.

Next, I want to thank my generous, rigorous, and giving committee. You believed in me and this work, and without your careful attention to detail and thoughtful questions this project would not be possible. Rebecca, you are an amazing advisor - your mentorship, encouragement, and humor made this PhJourney a smooth one. I have deeply appreciated your consistent ability to believe in me and the many directions I wanted to travel. Thank you for pushing me and seeing what I could not yet see as possible. To committee members Debbie Dougherty, Brian Houston, and Candace Kuby -Your questions and conversation made this project real and possible. Thank you for inviting me to think critically, play, and make a meaningful, practical contribution.

Finally, I wanted to thank my family and friends. To my mom who taught me that working hard should be balanced with adventure (and an occasional glass of wine). 
Thank you for encouraging me to cultivate my creativity, my writing voice, and my resilience. I am grateful for my family that I am always connected to no matter how far I am from home. Thank you all my friends for encouragement, phone calls, ongoing advice, and so much cheer. To officemates and cohort mates: I have learned so much from you! \#TheFutureIsSwitzler106

Lastly, I want to thank the communities that have been home near and far. Thank you to Columbia for trails and Ragtag and the gem of imagination that is $\mathrm{T} / \mathrm{F}$. Thank you to many kitchens and living rooms for hosting potlucks and creating community. I am grateful for the online community of Academic Twitter for all that it gives freely and for a greater good. 


\section{Table of Contents}

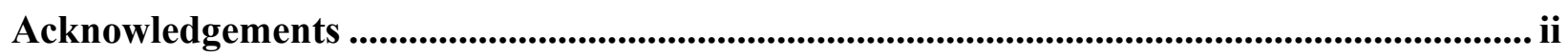

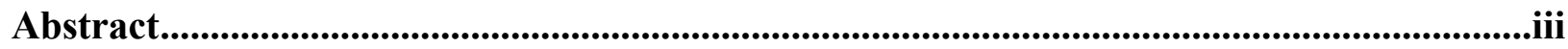

Chapter I: Rationale and Justification .............................................................................. 1

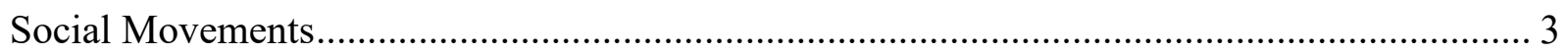

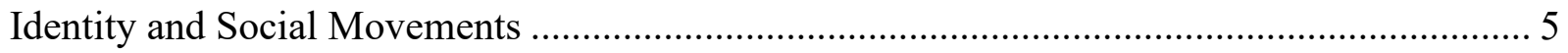

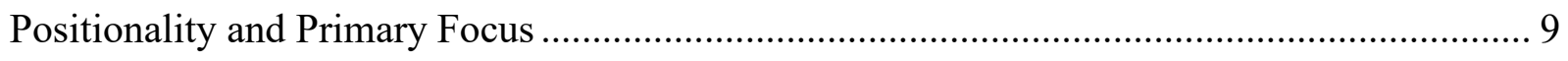

Project Overview and Conclusion ............................................................................. 12

Chapter 2: Literature Review.................................................................................. 14

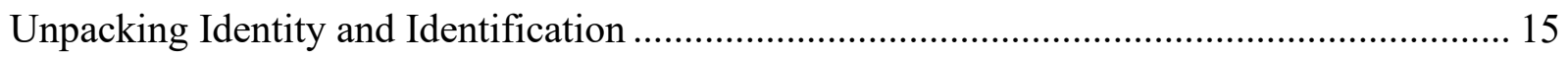

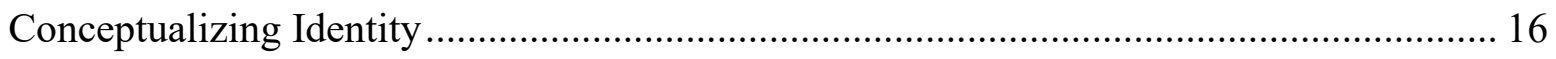

Identification, Identity and Organizational Control .................................................. 18

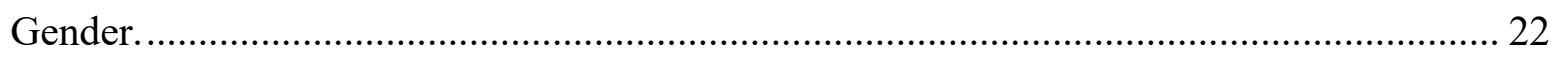

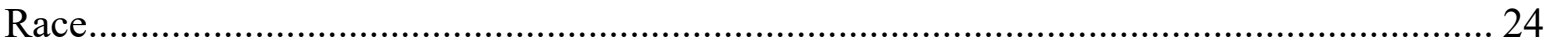

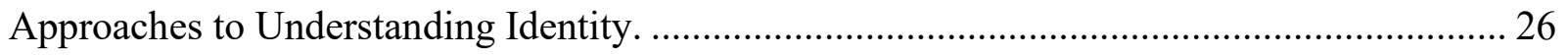

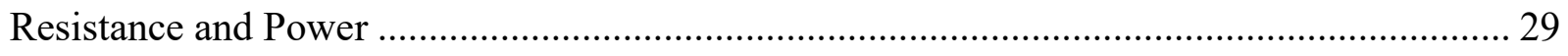

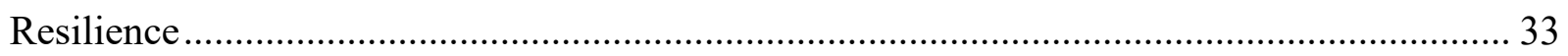

Towards Identity Management during a Social Change................................................. 37

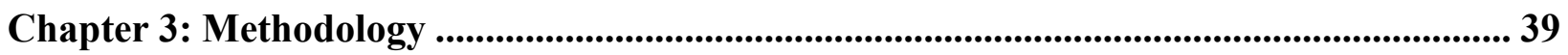

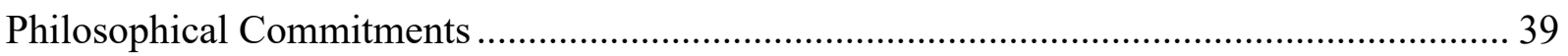




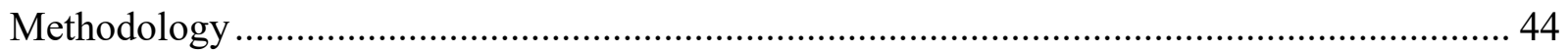

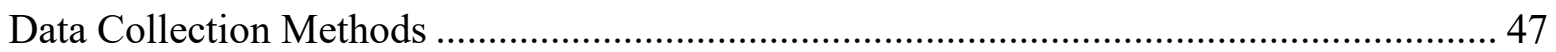

Initial sampling, theoretical sampling, and participants. ................................................. 47

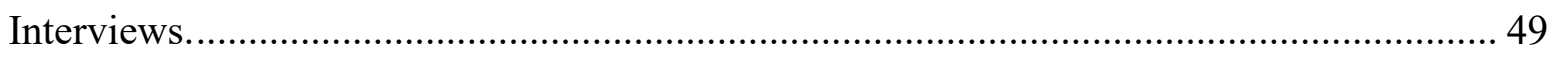

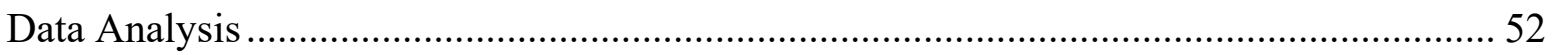

Chapter 4: Findings .................................................................................................................................... 55

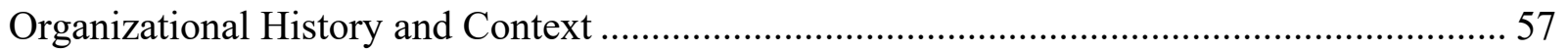

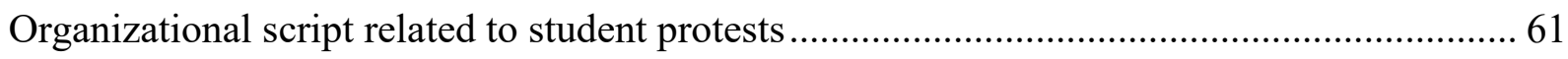

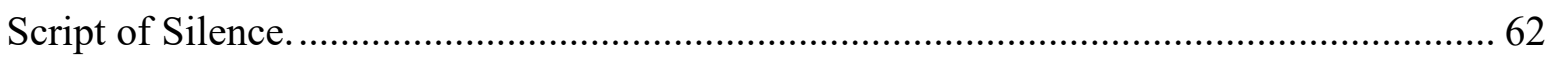

"We have discovered the performance by making it": Navigating identity building through

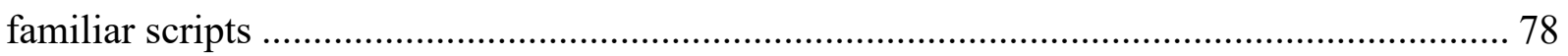

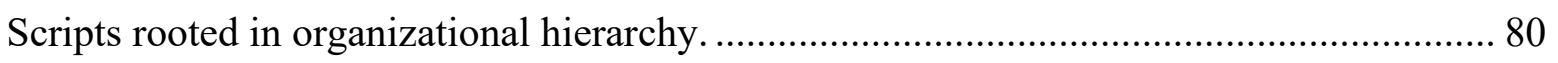

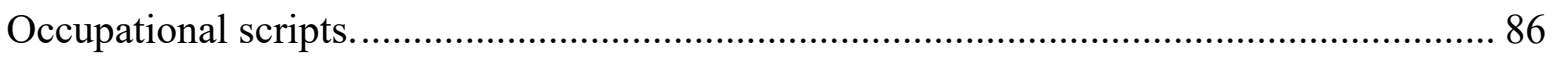

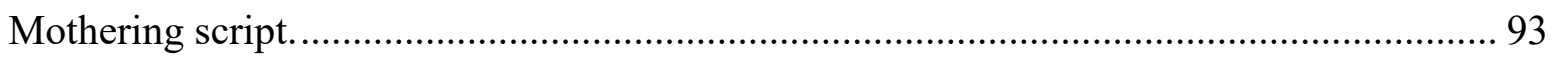

Roles of culture and community in developing scripts...................................................... 99

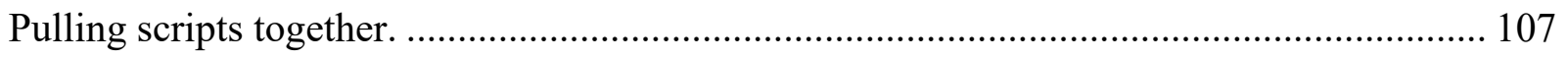

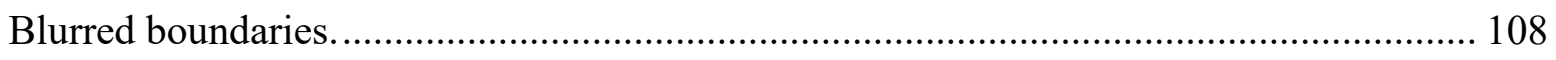

Managing identity as managing visibility/invisibility. .................................................... 112

Chapter 5: Discussion ............................................................................................................................. 116

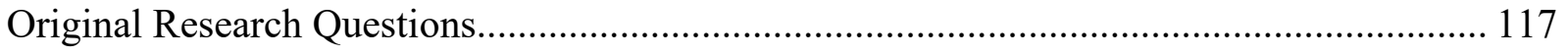


Research question 1: How do individuals craft identities in resilient ways in moments of social change?

Research question 2: How, if at all, do people manage identity conflicts in moments of social change?

Research question 3: What role does embodiment play in the process of identity creation and maintenance during social change?.

Primary Research Question: How do administrators, faculty, and staff manage identity during student led protests on a university campus?

Theoretical Implications 125

Identity Literature 126

Resilience literature. 140

Methodological implications 141

Implications for Practice.

Strengths 146

Limitations . 147

Future Directions 148

Conclusion 152

Coda 153

References. 155

Appendix A: Recruitment Script. 175

MU Info blurb 175 


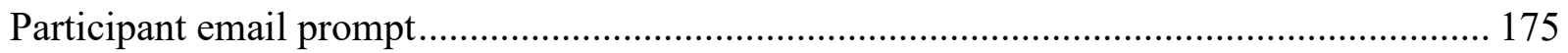

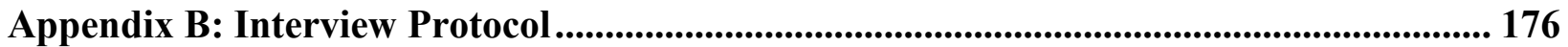

Appendix C: Demographic Survey ................................................................................ 178

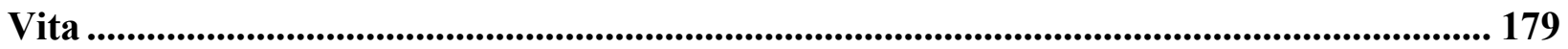




\begin{abstract}
Protests and social movements are a part of the history of Higher Education in the United States. In this study I use grounded theory to understand the process of identity management for administrators, faculty, and staff during student-led protests on a university campus. To gather data for this project I have conducted 26 interviews with faculty, administrators and staff. I theorize that the process of identity management was a discursive and embodied process of interweaving familiar scripts in response to a limited and limiting organizational script of silence. Many participants found the organizational script insufficient and, therefore, turned to following other familiar scripts: organization roles, occupational knowledge, motherhood, and cultural background. The identity management process engaged and was informed by specific cultural, historic, and geographic realities. This overall process is described as a rhizomatic identity negotiation process. My project extends the theorizing on identity work and on feminist grounded theory, with a specific focus on understanding the embodied nature of identity negotiation.
\end{abstract}




\section{Chapter I: Rationale and Justification}

"To keep the spirit of democracy alive requires a continuous revolution."

Susan Griffin

"Gay brothers and sisters,... You must come out. Come out... to your parents... I know that it is hard and will hurt them but think about how they will hurt you in the voting booth!"

Harvey Milk

Harvey Milk, an openly gay member of the San Francisco Board of Supervisors in 1977 had a very specific idea that catalyzed United States society towards a broader acceptance of gay and lesbian individuals. That idea was for all lesbian and gay-identified individuals to come out to their families and friends in order to destroy "every myth, every lie, every innuendo once and for all." The Gus Van Sant film Milk features a scene in which Harvey Milk delivers a version of that speech and, upon learning that one of his staff members has yet to come out to his father, Harvey hands a phone to that staff member and tells him to call his father immediately. In this scene, someone who was not actively engaged in making a part of their identity salient in a public way is asked to do so because the success of a social movement may depend on it. I often think of this scene when I consider how we manage our (often conflicting) identities in times of possible and ongoing social change.

Identity work goes beyond the struggles in the intersections of social and collective identities; individuals go through a complex process of privileging, silencing, and negotiating a myriad of conflicting identities in ways that are private and public. In my professional life, I think about the pulls between professional and personal identities. During Fall 2015, when a number of students at the University of Missouri, where I was working, were staging sit-ins, 
protests, and demonstrations that brought light to concerns students of color had, I found myself having a hard time managing my responsibilities to students and to the university. I felt that a lack of organizational communication and direction contributed to my sense of confusion, isolation, and burnout. I was not alone in that feeling. Many administrators shared their struggle with managing their personal and professional identities and wanting clear directions for appropriate actions. In my dissertation I wanted to explore that struggle and understand how university workers navigate the tension between professional identities, professional roles, and university directions. This dissertation explored the complex process of identity management in a moment of social change.

Chapter one of this dissertation focuses on social and theoretical problems that I have identified and discusses ways my research project addresses these problems. First, I discuss the social need for this research, then ground that need in theory. Next, I discuss my position as a scholar interested in feminist embodied research in order to explain both the methodological choices I am making and the connection between embodiment and identity. The focus of this dissertation is conflict in identity management that occurs in the times of possible social change. Social changes are typically catalyzed by social movements. In exploring the social and the theoretical problems, I discuss the current literature on social movements and identity and demonstrate how my research can extend the existing thinking.

Thus, this dissertation examines the process of identity management during social movements. I start with an assumption that people who are navigating the process of social change manage multiple identifications and pull from multiple identity resources. Managing identities engages sensemaking around normalcy and troubling the norm. Thus, it engages the 
communicative processes of resistance ${ }^{1}$ and resilience ${ }^{2}$. Using grounded theory, I explore how people engage in resistance and resilience in order to negotiate multiple identities during an ongoing organized social change created by a social movement. I see the process of negotiating identities as embodied, and, consequently, I see the communicative processes of resistance and resilience as embodied. Because I position social movements as the background for navigating identity, I examine the literature that addresses social movements and identity work.

\section{Social Movements}

Social movements are defined as "collective changes, based on common purposes and social solidarities, in sustained interaction with elites, opponents, and authorities" (Tarrow, 1998, p.4). Social movements have played an important role historically and remain significant today. Here, I will briefly discuss the role of social movements historically and later I will discuss the ways identity research has been connected to social movements.

Social movements and calls for social change have been a part of American history "since the pilgrims protested religious intolerance and prosecution by traveling 3,000 miles in leaky ships to start a life of freedom in the new world" (Stewart, Smith, \& Denton, 2012, p.13). Most institutions that Americans appreciate today as key parts of a healthy democracy have their roots in social movements. These institutions include abolition of slavery, environmental protections, and rights for workers, students, queer communities, women, communities of color, and other marginalized populations (Amenta, Caren, Chiarello, \& Sue, 2010; Meyer, 2007; Piven, 2006). Notably, a tension exists where social movements create change, yet the tools used in social

\footnotetext{
${ }^{1}$ I will elaborate on the concept of resistance in later chapters. Here I see resistance as a way employees engaged with power by refusing to comply with it in mundane and overt ways.

${ }^{2}$ I use Richardson's (2002) definition of resilience as "the process of reintegrating from disruptions in life', (p. 309).
} 
movements (protests, walk outs, sit-ins) can be seen as undesirable behaviors by large segments of the population and the organizations that have to face those activities. The tensions between the organizers of the social movements and the organizations that they are a part of have been especially evident on college campuses.

Currently U.S. institutions of higher education are experiencing a series of crises and disruptions centering on race, social class, and creation of new policies that are inclusive of the larger university population (Broadhurst, 2014). Most recently, 400 students occupied the halls of the main administration building in Howard University and led a negotiation that resulted in a resignation of the university's president (Kerr, 2018). However, student involvement in social movements is not a new phenomenon (Rudolph, 1990): “American colleges and universities, in particular, provide environments suited for student activism” (Broadhurst, 2014, p. 3).

Universities serve as a fruitful space for social movements. The social movements happening on college campuses are connected to and in conversation with social movements that happen in the communities, online, and in the streets. On college campuses protesters can generate both the sympathy and ire of outsiders. Angus Johnston (2015), a historian of student activism, speculated that students can hold the reputation of the university in their hands. That, in turn, creates challenges for administrators that are able to respond to students. This relationship is not necessarily adversarial. Often administrators feel compelled to support the students and protect the institutional reputation. These goals are not always compatible, which can create a challenge in the way administrators manage their identities in this process (McElderry \& Hernandez, 2017). My dissertation examines this intersection of university and community agitation as a backdrop on which identity management and negotiation occurs. 


\section{Identity and Social Movements}

With the rise of modernity, identity has emerged as an explicit issue in organizational research (Mongin, 1982). Identity research points to uniqueness ("I am myself distinct from you”) and sameness (“I share identity with you”) of individuals (Cheney, Christensen, \& Dailey, 2014, p. 696). It is important to note that both individuals and organizations have identities. For example, organizations often articulate their values, mission, and hiring practices as a part of the organizational identity. Recent research has discussed that identity functions on multiple levels (societal, organizational, and individual). These levels come together to shape and be shaped by both individual and organizational identities (Watson \& Watson, 2012).

In my project, social movements serve as an important space and place in which identity work occur. Ample research on identity work of those who directly participate in social movements exists (e.g., Friedman \& McAdam, 1992; Taylor, 1996; Taylor \& Raeburn, 1995), but research on identity work of those who respond to social movements or exist on the fringes of the social movements does not. Here I will discuss the existing research and outline the identity work concepts that are useful for this study.

Social movement research contains a strong thread of identity research that is positioned as a "pivotal concept in attempting to understand movement dynamics" (Snow \& McAdam, 2000, p. 41). This research focuses on identity politics (e.g., Taylor \&Raeburn, 1995), contested identities (e.g., Taylor, 1996), and collective identities (e.g., Friedman \& McAdam 1992). In critiquing the current conceptualization of identity in social movements, Stryker (2000), noted that the focus of research on identity in social movements has been on group and category identity distinctions. A key contribution here is that "category-based movements (e.g., most ethnic-based movements) will typically incorporate multiple groups" (p. 30), which can cause 
intra-movement conflict. I want to extend this critique and argue that another important element that is missing is the dynamic nature of identity that happens within movements and groups.

The research on identity in social movements focuses on the process of identity construction. Identity construction is "the process through which personal and collective identities are aligned, such that individuals regard engagement in movement activity as being consistent with their thoughts and actions" (Snow \& McAdam, 2000, p. 49). This process includes identity amplification (strengthening of existing identity), identity consolidation (of previously incompatible identities), identity extension (expansion of a personal identity to fit with a movement), and the ultimate identity transformation where one sees themselves as different than someone they have been before (Snow \& McAdam, 2000). Further, identity work looks different over the course of a movement, and "various highly consequential movement dynamics (e.g., factionalism and decline) may well be related to the succession of these identity work processes” (Snow \& McAdam, 2000, p. 62). Here identity work is only seen from a perspective of identity being tied to a social movement. I argue that the process of identity negotiation around social movement is more complex and includes a consideration of identification, group, and social identities in a way that is communicative and dynamic.

My research aims to expand the current theorizing on identity and social movements in two ways. One, I discuss the process of managing identity and the possible challenges that can that can lead to identity conflicts. Two, I will reframe the focus from how does the movement shape identity to centering research on identity work that occurs as a result of an individual being connected to a movement. In the next section I consider the potential value in connecting the above theorizing on identity and social movements to the study and understanding of resilience. 
Another important thread in this discussion is the question of organizational identification, which is defined as the "perception of oneness with or belongingness to an organization" (Mael \& Ashforth, 1992). The concepts of individual identity and organizational identification have been often treated as one issue in research (Marchand, 1998). Current theorizing untangles those concepts. For example, promising work is being conducted in the work-life area of organizational research.

An area of research that I am specifically interested in with regards to identity is role identification. The shift between personal and professional boundaries is not an easy one. For example, Tracy (2005) found that correctional officers who identify with that professional role have a challenging time with emotional labor at home. Role identification occurs when a person identifies with a professional role ("I am a mechanic, a patent") (Ashforth \& Mael, 1989). My research will consider the challenges of role identifications when an individual sees conflict within different aspects of their professional role ("I am an activist and an upholder of institutional norms").

In my research I ask questions about ways multiple identification functions during periods of organizational resistance. I have discussed that social movements often engage specific dimensions of identity. However, the participants in social movements also possess organizational identifications. Many conflicts are possible here; some could be among the identities and identifications (person of color and an organization that implicitly centers whiteness). Some can be between different identifications (advisor to a marginalized group and a person in a position of institutional authority). The latter is particularly interesting as the research on social movements declares that "people in power do not like to sit down with rogues" 
(Stewart at al., 2012). How does a person manage identity if they identify both as a "person in power" and a "rogue"?

One limitation that I can identify in the current research on identity work is a lack of tying identity work to resilience. The current research discusses resource mobilization of resources such as emotions of anger, fear and positivity in identity work connected to social movements (Britt \& Heise, 2000). This idea of emotional mobilizing of resources is similar to Buzzanell's (2010) work on resilience. Buzzanell theorizes that there are several communicative processes involved in resilience. These include: (a) crafting normalcy, (b) affirming identity anchors, (c) maintaining and using communication networks, (d) putting alternative logics to work, and (e) downplaying negative feelings while foregrounding positive emotions, such as hopefulness and self-efficacy. That last point is theoretically similar to resource management. I want to explore this connection further.

The last area of research that I am going to consider for this project is resistance. Resistance research has traditionally focused on the micro level: the individual acts that show resistance to various forms of organizational control. This research is largely functional in its epistemological orientation in that it typically encompasses employees' ability or lack of ability to stand up to the oppressive organizational norms in form of strikes (Hyman, 1972), theft (Mars \& Gerald, 1982) and sabotage (Dubois, 1979). This view ignores the embodied processes of resistance. Specifically race, gender, social class, social identities that research suggests are embodied (Duff, 2012; Hoel, 2013), are not centered in this research. Embodiment and tying identity to organizational control and resistance are necessary steps in understanding the interconnectivity of identity work. For example, Pullen et al, (2017) made the following argument about the connection between organizational control, embodiment and gender: 
But even though we are constantly targeted by organizational attempts to regulate us, improve us, co-opt us and exploit us, we are capable of leaking our private fluids into public spaces and generating floods that run counter to the main streams of the gendered organization. These leakages tie us together in a joint struggle against gendered oppression in everyday life, work and organizations (p. 117).

These "leakages" are ways that we privilege certain aspects of our identity that run counter to the organizational control. In exploring gender and the body, Pullen et. al. (2017) explain that these "leakages" can be seen when we "break dress codes, speak outside of gendered scripts and step out of stereotypical or 'appropriately' gendered habits" (p. 117). These can be interpreted in terms of resistance to organizational control. An example of this can be seen in ways women refuse to follow the appropriately gendered norms and break the feminine norms of dress code and work. Next, I will discuss my positionality and commitments to feminist and embodied research practice and how those will shape this research project.

\section{Positionality and Primary Focus}

I position myself as a feminist researcher who is deeply interested in intersectionality and embodiment. Here I will discuss my feminist commitments and elaborate on the way these commitments impact my research overall and this project in particular. My positionality as a feminist researcher includes epistemological commitments, the ways I will engage with participants, and methods used to gather and analyze the data. Furthermore, I understand the issues of resistance, resilience, and identity as embodied, capable of affecting the lived experiences, and connected to various aspects of our identities.

Here I want to provide an example of a way my feminist commitment to intersectionality and embodiment creates the perspective I take on the research I am conducting. In the 
subsequent chapters I will elaborate on the ways research on resistance and resilience has been largely positivist. The positivist stance of such research has allowed for the human body to not be readily present in the text, analysis, and findings of the research. While some research has highlighted the specific circumstances class, gender, and racial inequalities produce, the singular focus on one social identity category is not sufficient, as "focusing on one category almost inevitably obscures and oversimplifies other interpenetrating realities" (Acker, 2006, p. 442). In my research I hope to challenge this singular focus and pay specific attention to the issues of embodiment and intersectionality. I elaborate on this in depth in the methods section of this proposal. My choice to actively centering of embodiment is an intentional move to animate the existing research and connect it to an intersectional agenda.

Three principles of feminist research suggested by Donna Haraway (1988) shape my work. Haraway outlined three key concepts that researchers should consider in a feminist project: accountability, positioning and partiality. The first concept, accountability, asks the researcher to explicitly name the contextual relations of power that reproduce knowledge. In doing so the researcher should avoid reinforcing stereotypes about a gender and particular groups of women. The second concept, positioning, refers to micro-politics that occur during research encounters (Hoel, 2013). The researcher and the participants are always connected to specific power dynamics. Haraway (1988) argued that the researcher should take explicit steps to uncover and discuss the power dynamics in the research interaction. Finally, Haraway suggests that the researcher reflects on the possibility of multiple subjectivities and multiple views present in the research encounter. The researcher should attend to these multiplicities and avoid the temptation to generalize and create monolithic representations. I will use these key concepts to pay close 
attention to embodiment, researcher positionality, power, and intersectionality in crafting my research.

The concept of intersectionality is one of the key concepts in understanding ways race, ethnicity, class, and culture are integrated (Dill \& Kolman, 2012). The roots of this concept are found in Black scholarship focused on gender, race, and ethnicity. Patricia Hill Collins (1990) discussed the matrix of domination as structured on many levels: "people experience and resist oppression on three levels: the level of personal biography; the group or community level of cultural context created by race, class, and gender; and the systemic level of social institutions" (p. 227). Seeing the interlocking system of oppression crates the possibilities for new paradigms of resistance and for a conceptual stance "in which all groups possess varying amounts of penalty and privilege in one historically created system" (Collins, 1990, p. 225). Intersectionality as a concept has been used widely in research. A few examples include the research to understand how race, gender, and sexuality of labor organizers affected the social change movement (D'Emilio, 2003); how connections among sexuality, economic inequality, and race affect knowledge production (Ferguson, 1993); and how public policy disproportionately impacts poor women and women of color in United States (Hu-Dehart, 2007). I will use this concept as an analytic tool to consider the complexity of identity work as connected to race, ethnicity, class, social position, bodies, and histories of the participants. Methodologically, scholars working with the concept of intersectionality work to overcome the idea that dimensions of inequality such as race, class, and gender are distinct (Dill \& Kolman, 2012). Deborah King (1988) called for a model of analysis called "multiple jeopardy" that refers to multiple simultaneous ways oppression functions and the multiplicative relationship amongst those ways (p. 47). Qualitative 
approaches can be well-suited to speak to these multiplicities and entanglements. I will further discuss this in the methods chapter.

\section{Project Overview and Conclusion}

In my dissertation I used embodied grounded theory methodology to develop a theory of identity management that incorporates resistance and resilience processes in the face of an ongoing social change. Grounded theory served as ideal methodology for several reasons. First, the use of grounded theory allows the researchers to begin exploring a particular problem or concern that has not been studied in depth before (Charmaz, 2006). Though this exploration, the researchers attempt to make sense of the lived experiences of participants and ultimately construct a theory grounded in the data (Charmaz, 2006; 2014). Second, a grounded theory approach is very effective in developing an understanding of a process, as the construction of a grounded theory focuses specifically on how individual events or experiences link to a larger whole (Charmaz, 2006). That process can be linked to existing theories and knowledge. Finally, grounded theory is congruent with feminist research methodology and embodiment (I elaborate on this point in chapter 3). Because identity management through resistance and resilience is a communicative process, grounded theory is well suited as a methodology.

The remainder of this dissertation project will provide both a review of relevant literature as well as a thorough dissertation of research methods. Specifically, chapter 2 discusses 1) concepts of identity and identification and the difference between these concepts; 2) a theoretical introduction of resistance and resilience literature and the current discussion about these ideas. Chapter 3 provides a detailed overview of constructivist grounded theory to understand the process of identity management during an ongoing social change including: sampling techniques, semi-structured interview guides for individual interviews, and details about data analysis and 
presentation. Chapter 4 provides the data analysis and presents a theory of identity management during time of social change, and chapter 5 presents the implications and a detailed discussion of the process of identity management. 


\section{Chapter 2: Literature Review}

The overarching framework of this project considers the interconnected nature of social change achieved through individual actions. As a scholar, I aim to examine the role of the individual in the social change process and the existing boundaries in which an individual can catalyze change. As a part of that larger agenda, this specific project will examine the communicative process of managing multiple identities (e.g., gender, race, sexuality, professional role) during moments of organized social change. For the purposes of this project, I will consider community organizing and student-led college campus organizing as two sites where social change necessitates complex identity management.

In this project I consider the identity management process that occurs when an individual participates in ongoing social change. This research project focuses on understanding the ways people manage identity when faced with a challenge of upholding potentially conflicting organizational and individual values that may become amplified during an ongoing social change. In chapter one, I suggested that social changes that occur on college campuses mirror those that occur in broader communities. In chapter two, I explicate how existing research suggests that organizational resistance and resilience strategies serve important roles in identity management processes for the actors engaged in the social change processes. IN the beginning of this research project I theorized that people engage in complex processes to craft and manage identities in ways that are resilient when operating in spaces and contexts that call for resistance. Further, I argued that resistance and resilience are usefully understood as one entangled process, specifically when these processes are performed during a time of social change. In this chapter I use different paradigms and disciplines to present the "sensitizing concepts," a place to start this inquiry and create a loose framing of the theory (Charmaz, 2014, p. 30). A more thorough 
discussion of the role of sensitizing concepts and the constructivist turn in the grounded theory methodology I am using will be discussed in chapter three. Here, I will discuss identity management, resistance, and resilience as key sensitizing concepts.

The identity management process that is the focus of this dissertation draws on the following bodies of literature: identity, power and resistance, and resilience. This literature review demonstrates the connection between these bodies of literature in the following way: identity is a complex concept that has ties to social identity and organizational control, which, in turn, is connected to literature on resistance and resilience. In this chapter, I first provide an overview of identity and identification in the field of communication. I discuss the differences between the concepts of identity work, identity regulation, and identification, discuss how those may function during a time of social change, and discuss what tools may be needed to engage in identity management during a period of social change. Next, the theorizing on organizational control of identity leads to a discussion about the ways individuals resist organizational and corporate control. Here I discuss micro and macro levels of resistance in relation to power. Thus, this chapter articulates connections among the research on identity, resistance, and resilience that are useful in understanding identity negotiation during social change. I close this chapter by making the argument for the development of a theory of managing multiple aspects of identity (e.g., gender, race, work hierarchy status) during the moments of organized social change.

\section{Unpacking Identity and Identification}

This section provides an overview of the relevant theorizing of identity and identification as social and organizational constructs. First, I provide an overview of identity and identification, the former being a dynamic construction situated in a communicative practice, and the latter referring to the interactive process organizations and their members use to build loyalty. Later, I 
analyze how organizational control is achieved by promoting identification and discuss the complexity of managing multiple identities that individuals all navigate. My goal here is to illuminate identity research as a contested territory that connects to organizational control, power, and resistance and outline the niche that my research will fill.

\section{Conceptualizing Identity}

To begin, I address two relevant discussions that complicate the understanding of identity in the field of organizational communication. Identity has become a popular frame through which scholars examine organizational phenomena (Alvesson, Ashcraft, \& Thomas, 2008). Broadly, identity is defined as "the conception of the self reflexively and discursively understood by the self" (Kuhn, 2006, p. 1340). This communicative definition is complicated by different epistemologies and ontologies that exist in the field of communication.

These assumptive stances produce numerous contested ideas, the first of which is the durability of identity (Alvesson et al., 2008). Identity theorizing diverges on whether identity is a coherent enduring distinctive concept (Albert \& Whetten, 1985) or a temporary, contextsensitive, and evolving set of constructions (Ashforth, 1998; Gioia et al., 2000). The second contested idea is the question of integration and fragmentation of identities. Scholarly theorizing on this matter varies: "for example, depicting identity as hierarchically integrated into dominant notions of self or, conversely, as fragmented into manifold, simultaneous and shifting notions of self' (Alvesson et al., 2008, p. 6). My view of this stance mirrors Tracy and Trethewey's (2005) stance that identities are at once fragmented and stable (Tracy \& Trethewey, 2005). The theorizing on identity that has occurred in the last 15 years has established "identity as a communicative process and a site of struggle constantly negotiated through interaction with others and retroactive sensemaking about one's self" (Norander, Mazer, \& Bates, 2011, p. 60). 
For the purposes of this research, I see identity as a context-sensitive dynamic construction situated in communicative practice. Kuhn (2006) explained this context sensitivity by discussing that identity construction occurs through practices whose meanings are tied to specific locations. This argument suggests that individuals make sense of who they are in relation to the world around them. Ybema et al. (2009) elaborated on the dynamism and context parts of the definition above by stating that identity is constructed by "the discursive articulation of an ongoing iteration between social and self-definition" (p. 301). Individuals construct identities through active (individual awareness of self-constructions related to identity) and passive (going through a routine) processes (Wieland, 2010) and use a complex decision-making process to analyze the environment in order to communicatively identify with an identity category. The view described in this paragraph is closely related to the constructivist view of identity (Giddens, 1991).

Other views on identity come from social construction theorists. First, our personal identities are in an ongoing state of change (creation, threat, reproduction) through ongoing and embodied interactions (Ashcraft \& Mumby, 2004). In this view identities are fluid and never stagnant. Second, personal identities rely on social structures and discourses for cues about appropriate ways of being and institutionally driven normative identity performance (Thomas \& Davies, 2005). These structures and discourses inform ways in which we manage identity in and out of the organizational setting. Organizations play an important role in identity regulation and identity work and consequently have an impact on how identities are managed and regulated. The following section discusses the impact organizational control has on identity. Later, I will discuss specific social identities that may be relevant for this project. My research specifically focuses on identity work during moments of organized social change. Since our identities are in 
an ongoing state of change and are influenced by institutional norms, moments of organizational crisis provide us with a fruitful space to explore. The institutional norms may be in flux, thus making identity negotiation more challenging.

\section{Identification, Identity and Organizational Control}

While the concept of identity has been an important issue in a wide variety of research fields, the concept of identification has played a uniquely important role in the field of organizational communication. Both concepts play a key role in my research, as I am considering the negotiation process of individual identity and organizational identification. I will elaborate on the differences between the two concepts and connect the concept of identification to the idea of organizational control and, later, to identity work. Identification is often associated with internal organizational rhetoric aimed at organizational members (Hoffman \& Ford, 2010). Identification is defined as the "perception of oneness with or belongingness to an organization" (Mael \& Ashforth, 1992, p. 104). Identification is connected to the idea of social attachment, defined as the state in which an individual perceives him- or herself to be connected to the fate of the group they are identifying with (Ashforth \& Mael, 1989). This connection to the fate of the group may play a key role in tensions individuals experience with navigating identity work and identification, specifically in moments of uncertainty and crisis, which makes identification a helpful concept to use in this study.

Both identity and identification have a history of being once theorized as static (Cheney, Christiansen \& Dailey, 2014). However, current research has focused on the process of becoming as a way to understand identification. Additionally, current research has asked questions about the loss of self that may occur when an individual becomes a part of a group (Cheney, Christiansen \& Dailey, 2014). As conditions of organizational uncertainty further 
increase group identification (Hogg \& Mullin, 1999), this loss of self can increase, which can complicate identity work. Further evidence of the relationship between identity work and identification can be found in experiment-based work of Sani et al., (2007) who developed a concept of perceived collective continuity (defined as group identification that is time and culture bound) as positively correlated to a set of social identity measures. In this research, groups are seen as more cohesive and "somehow tangible" if the group members are seen as the carriers of culture and trans-generational narrative (Sani et al, 2007, p. 1129). Additionally, a group that is unified also increases identification. In summary, identification is connected to our social and group identities, is increased by uncertainty, and is connected to communal and historical norms. This definition uncovers the pull between organizational identification and identification with other groups one could have longstanding trans-generational membership in (which may be closer connected to one's social identity). Another important part of organizational identification literature is that identification can function as a source of organizational control. Team-centered pressure for identification can be seen as a source of concertive control (e.g., Barker, 1993). While management does not have a singular control on the individual, the institutions today provide discursive materials for a worker to connect work to their specific identities (Alvesson \& Willmott, 2002). My research aims to zoom in on this connection to the specific identities and the resulting tension. After all, the effect of managerial attempts to exercise control can be employee resistance (Mumby, 2005).

Alvesson and Willmott (2002) explored the connection between work and identity further by positioning identity work as "a significant medium and outcome of organizational control" (p. 622). The employee as an identity worker is "enjoined to incorporate the new managerial discourses into narratives of self-identity" (Alvesson \& Willmott, 2002, p. 622). Thus, trainings, 
posters, and other forms of workplace socialization can be seen as medium of management's regulatory efforts. In my dissertation I theorize that these managerial efforts can be disrupted during times of social unrest or social change.

There are two useful discussions in organizational research that tie employment to identity work. First, Scott, Corman, and Cheney (1998) explain how individual, group, organizational, and occupational identities may overlap and contradict each other. Scott et al. (1998) claimed that "Activities influence the identities that are reproduced in identification" ( $p$. 323). Meisenbach and Kramer's research (2014) extended this theorizing by demonstrating that in the voluntary based activities (such as choir participation) members differentiate between identification with the organization fostering a specific activity and the activity itself. In turn, I will focus on employment and social change focused activity and consider how employees manage a situation where their definition of an activity differs from that of their employer. For example, one of the locations for my project is a college campus. If the activity in question is keeping the campus safe during a student-led protest, the employees may have conflicting views of what that means in action and in terms of their own identity management.

The second strand of theorizing that is useful here is Ashford and Johnson's (2001) work on ways different levels of identity nest within each other while in organizational setting. These nested identities can be described as higher or lower order. The lower order identities are characterized by restrictive membership, connected to specific behaviors, and able to have a direct impact on an individual. The higher order identities are inclusive, abstract and have an indirect delayed impact. Thus, organizational identities (higher level) may encompass group identities (lower level). Further, social identities may cross-cut the organizationally nested identities. 
The literature on the employee identity regulation as the means of organizational control provides us with an important insight about the tension between the worker and the employer. Deetz (1995, p. 87) describes this tension: "the modern business of management is often managing the "insides" - the hopes, fears, and aspirations - of workers, rather than their behaviors directly." These insides are often connected to the social identities of the employees. The next section introduces a few social identities that I consider relevant in this study. Deetz points out another important aspect of employee-organization interaction - that is organizational control often encounters employee resistance. Later in this chapter I will discuss how resistance is connected to identity and organizing.

In setting the direction for future research on identities and identification Cheney, Christiansen \& Dailey (2014) call for research on the connections between power/control and identity, specifically when it comes to discourses that "may not be classified as propaganda, but function that way" (p. 707). Employees who consider their involvement in social movements certainly have to consider their identification, identities, and the messages about appropriate employee conduct that their organizations are sending. Social movements are specifically important here because they deal with certain renegotiation of larger societal norms and practices. In addition to organizational control, individuals also negotiate social identities. Thus, I explore the process of bringing social identities into the workplace next.

Bringing social identities into our workplace. This research examines how individuals manage identity during an ongoing social change. This approach complicates the existing research that points to the idea individuals will choose or avoid jobs based on the extent to which they support preferred organizational selves (Tracy \& Trethewey, 2005). I argue that the individual construction or management of identity at work can be complicated by an ongoing 
pressure presented by social change or social movement. Ashcraft's (2007) definition of occupational identity is useful in pointing out this pressure of the environment on identity. In this view, occupational identity is defined as "an ongoing persuasive endeavor that traverses time and space, macro and micro messages, institutions and actors, and that serves to (re)organize work by mobilizing discourses of difference in response to lived pressures and material circumstances" (p. 15). First, I outline a few social identities that connect to the discourses brought into the workplace and later I discuss the ways organizations exhibit control in ways we organize around work. I have chosen to review the discourses around gender, race, and sexuality identities in the workplace. Research has demonstrated how the multiple social identities that individuals possess (including race and gender, as well as other identities) shape perceptions of the self and of others (e.g., Cheng et al. 2008; Crisp et al. 2010). I analyze how social identities are represented in social movement and organizational communication research.

Gender. Gender has been a key construct in organizational communication research (e.g., Ashcraft \& Harris, 2014, Ashcraft \& Mumby, 2004; Jorgenson, 2002; Tracy \& Scott, 2006). Gender is connected to identity as "something we think, something we do, and something we make accountable to others," (Gherardi, 1994, p. 595). In and out of the workplace, we enact different gender roles through our discourse. Ashcraft and Mumby (2004) discussed how discourse brings into being the material of organizing and presented four frames that explore the relationship between gender, discourse, and organization. I elaborate on these frames further to help us understand the views existing research takes on gender and organizing. The first frame sees gender as a fixed variable that organizes discourse and is connected to communication differences. In this frame gender is organized around biological sex. For example, the literature that uses this frame focuses on "women's ways" of being and doing (e.g., Gilligan, 1994). This 
frame demonstrates that focus on gender difference can have political consequences. Thus by perpetuation of studies that focus on "feminine" styles the researchers can be in danger of associating gender with women. The second frame takes the opposite view and sees gender as situated or performative and organized by ongoing social discourse. The second frame puts the spotlight on both women and masculinity in organizations. I will discuss the specific contributions of this frame below. The third frame describes how masculinities are inscribed on specific organizational forms and how those forms translate into tangible consequences. For example, Acker and Van Houten (1974) argued that organizations employ gender as a central control mechanism that generates gender variance in organizational behavior. This frame views organizations as socially constructed and gendered. Organizations inject gender into macro discourses. The fourth frame departs from the organization as a site of gendered discourses and takes a broader look into the society. It views discourse as willingly concealing of gendered organizations. Ashcraft and Harris (2014) expanded this theorizing and crated the fifth frame that accounted for materiality. Further it positioned organizations in relation to work, worker and gender as material-discursive formations that become felt and known. The most important contribution of this frame is that it invites materiality to be real-ized in our thinking about gender, discourses and organizations. These five frames have been used to understand existing research (as I will demonstrate below) and can help us shape our thinking and our research questions.

Research situated in all five of the frames can be found in organizational communication. Here I want to focus on the second frame specifically, as it can demonstrate ways social and organizational identities interact. The research here focuses on hegemonic masculinity and workplace norms. Research on gender and work in the United States has found that the 
workplace privileges unachievable hegemonic masculinity (e.g., Trujillo, 1991) and masculine norms of organizing (e.g., Acker, 1990; Forbes, 2002). Men and women actively participate in the reproduction of masculinity in the workplace both discursively and by engaging in a specific set of behavioral practices (Forbes, 2002). Shifting work norms do not change this dynamic, but may change the discourses connected to work. For example, with changes in the airline industry, men felt emasculated and reframed their new role from "empowering manager" (which was seen as weak) to "benevolent father" (which retained their power and connection to masculinity) (Ashcraft, 2005). In this cultural landscape, professional women are considered to be a paradoxical construct: "there is a basic contradiction between abstract social definitions of "woman" and normative behavioral expectations of "professional”(Wood \& Conrad, 1983, p. 308). Women actively seek ways to negotiate the tensions around this paradox and their responses can perpetuate, reframe, or transcend it (Putnam \& Bochantin, 2009). Additionally, women seem to engage in "gendered code-switching that functions as a productive response to the professional paradox" (Pfafman \& Bochantin, 2012, p. 574). This notion of codeswitching seems to be conceptually close to the idea of identity negotiation. Here women are operating under a specific organizational framework and this codeswitching seems to be closely connected to the concepts of identity management and may be an example of a resilience strategy. The overlaps in these concepts need to be further examined, and I hope that my dissertation will accomplish this.

Race. Organizational communication as a field has begun to focus diligently on organizing and organization theory as gendered, yet it has not adequately attended to race as a factor in how we organize (Ashcraft \& Allen, 2003). For the purposes of this research race can be understood as "a largely social—yet powerful—construction of human difference that has been 
used to classify human beings into separate value-based categories" (Orbe \& Harris, 2001, p. 6). Race is socially constructed amid the intricate interplay of chance (e.g., "accidents" of birth), context (e.g., the local meaning of physical features), and choice (e.g., ever negotiated decisions to highlight certain aspects of identity) (Haney Lopez, 1996). Race can be seen as both a hegemonic process and an outcome with individual, interactional, and systemic consequences (West \& Fenstermaker, 1995). In similar way that gender was disused in terms of hegemony where masculinity and male bodies are presented as universal norm, race can be seen in those terms as well. Ashcraft and Allen (2003) argue that white (collar) workplaces and workers constitute "universal" work settings, identities, and practices.

Notably, race has played a significant role in developments around education, social movements, and in organizational life (Remedios \& Snyder, 2015). Organizational communication research demonstrates that race-based stereotypes and expectations shape interaction across a variety of contexts (e.g., Allen, 1998; Orbe \& Harris, 2001; Van Dijk, 1993). Organizational scholars claim that race is "manifested in everyday life experiences and social interactions" and that race remains one of the "major bases of domination in our society and a major means through which the division of labor occurs in organizations" (Nkomo, 1992, p. 488). Historically numerous social movements focused on the inequalities surrounding the lived experiences of non-white populations (Rickford, 2016). Additionally, race has played an important role in social movements on college campuses and in the community. African American women played a key role in de-segregating education on American college campuses (Synnott, 2008). However Black female scholars note that mere acceptance into the predominantly white academy does not translate into belonging. For example, Brenda Allen (1998) summarizes her experiences as a Black academic as a "twofer" who is treated as a token 
and a symbol not as an individual. Organizational research scholars demonstrate that individuals who are nonwhite have additional challenges in the workplace with acceptance, belonging and the perception of their ability (ex. Acker, 2006; Forbes, 2009; Remedios \& Snyder, 2015).

It is important to consider the identities discussed above (race, gender), not only as solitary concepts, but in relation to each other. In fact, Acker (2006) offered the following critique of organizational communication scholarship: "Most studies of the production of class, gender, and racial inequalities in organizations have focused on one or another of these categories, rarely attempting to study them as complex, mutually reinforcing or contradicting processes" (p. 443). An intersectional approach is needed in order to best understand identity management. Further, Ashcraft (2013) added that it not tenable to theorize work and diversity separately, since we judge the nature of work by the gender and race of the workers. Below I will place intersectionality into the larger conversation about how different epistemological approaches can influence the way researchers unrested identity and draw a conclusion that intersectionality is the appropriate approach to take with the specific ser of questions I am asking. I argue that the intersectional approach is the key to understanding the process of managing identity.

Approaches to Understanding Identity. To help contextualize the value of an intersectional approach to identities, I first consider how different approaches to understanding identity can influence research. In a functionalist approach understanding identity "it remains common to demarcate objects of analysis as personal or social identities" (Alvesson et al., 2008, p. 10). Personal identity refers to personal attributes and social refers to shared group identities (Watson, 2008). This view offers limited possibilities to understand identity as a complex, dynamic, embodied communicative entity, therefore, it is not used to guide this research. 
Critical scholars resist the divisions that the functionalist approach offers and see the personal-social as one cohesive lens in identity research (Alvesson et al., 2008; Tracy \& Trethewey, 2005). When we define ourselves by our position (managers, administrators, faculty, etc.) this act of defining "does not entail simply stepping into pre-packaged selves," but involves a process of negotiation with our simultaneously held identities (e.g., Black female faculty) and meaning making connected to systems around us (e.g. class, social status, etc.) (Alvesson et al., 2008, p. 10). There is a lot of value that critical scholarship can bring to this research, specifically its focus on power, negotiation, and meaning making.

Poststructuralist theorists see identity as a site of disunity and conflict that is influenced by power relations (Jackson \& Mazzei, 2012). A key contribution here is that identity is conceptualized as an ongoing state of becoming, rather than a fixed state of being in the world (Weedon, 1997). Deleuze and Guattari discussed the concept of becoming as a line that passes between two points, a state of in between, the "continual production of difference immanent within events" (1997, p. 293). We can see identity negotiation through the theoretical concept of becoming. When an individual who is managing multiple identities encounters something that challenges one of the identities he or she is managing, a process of change occurs. This is a "process of becoming or double deterritorialization: one force acts on another by lending it a fragment of its "code" offering some of its conventions or habits" (Goodchild, 1996, p. 38).

The last approach to studying identity that I want to consider is that of intersectionality. Intersectionality as a term has risen to prominence thanks to the work of Black scholars including Patricia Hill Collins (1991) and Kimberle Crenshaw $(1989,1991)$ and has been used both as a paradigm and a methodology (McCall, 2005). In chapter three I will discuss the methodological implications of this framework, and here I will discuss how intersectionality fits 
this research paradigmatically. I want to take up Mirza's (2013) call to researchers to study "embodied intersectionality", which seeks to make sense of the gendered and raced experiences and their material implications in organizational settings. An example of such embodied intersectionality can be seen in the words of Felly Nweko Simmonds, a black woman academic who writes: "The world I inhabit as an academic is a white world ... in this white world I am a fresh water fish that swims in sea water. I feel the weight of the water on my body" (1997, p. 227). It is impossible to escape the body and its constructions and reconstructions one engaged in identity negotiation in our embodied social situations. Intersectionality was originally defined by Crenshaw (1989) in a way analogous to an accident in a four-way intersection. If a Black woman is harmed at such a conceptual intersection, "her injury could result from sex discrimination or race discrimination" (p. 149). Recent feminist scholarship has taken this idea and applied the idea of intersectionality broadly and globally to women in the Carribean (Freeman, 2000), immigrant domestic workers (Hondagneu-Sotelo, 1994); affirmative action (Kahlenberg, 1996), women living with HIV/AIDs (Lather \& Smithies, 1997) and many others.

I believe that intersectionality fits my research paradigmatically since it will allows me to consider multiple identities, organizational environment, and embodied realities. In chapter three I discuss my positioning as a feminist scholar and a "theoretical fence sitter" (Charmaz, 2014). In building the sensitizing concepts I am drawing from, I consider what new ideas these approaches bring to understanding identity. Identity management is a complex process that engages elements of resistance and resilience when performed in an organizational setting while there is an ongoing social change. The following section will discuss what contributions theorizing on resistance and resilience makes to understanding the process of identity management. 


\section{Resistance and Power}

I have discussed identity, identification and outlined the role of organization in identity work. Here, I outline how resistance serves as an important element in understanding identity management in context of organizational control. Critical scholars have approached identity as a powerful way to understand contemporary relations of control and resistance (Alvesson et al., 2008). I discuss the existing research on resistance, connect it to theorizing on power and discuss how identity work fits within this theoretical framework.

Individual Resistance. Resistance research has been largely conceptualized in traditional terms, namely as open, overt, and organized acts of rebellion (Fleming \& Sewell, 2002). Primarily the focus has been on the individual acts that workers can take to show resistance to various forms of organizational control (e.g., Hochschild, 1983). In this conceptualization, resistance focuses on employees' ability or lack of ability to stand up to oppressive organizational norms. In demonstrating resistance, employees may engage in a wide range of behaviors: "from failure to work very hard or conscientiously, through not working at all, (to) deliberate output restriction, practical joking, pilferage, sabotage and sexual misconduct" (Ackroyd and Thompson, 1999, pp. 1-2). It is possible that employees may not coherently articulate to themselves, "we are now resisting" (Fleming \& Spicer, 2007). The workers can avoid the identification of being resistant yet participate in organizational subversion (Edwards, Collinson, \& Della Rocca, 1995). An additional dimension of resistance in this scope of research focuses on the hierarchy between the workers. Many work places contain workers of different ranks. Larson and Thompkins (2005) found that managers often subvert institutional change efforts by communicating ambivalence about the changes and supporting lower ranked workers in resisting those changes. These research studies focusing on the individual resilience allow us 
to understand what mechanisms employees have to resist the organizational control. Identity management could provide the available options for resistance opportunities.

A notable limitation to this line of research is that this research ignores the embodied processes of resistance. Specifically, race, gender, and social class are not centered in this research as constructs or dimensions of one's identity. As an illustration of expanding the focus of resistance research, Fleming (2005) built an argument that resistance and processes that produce resistance are always contextually bound by class, capitalism, nation, gender. Another limitation to viewing resistance as focused on the individual is that by only focusing on everyday acts, there is a danger of reducing resistance to the most banal actions. This focus on the everyday "strips the concept of its most striking connotations" (Fleming \& Spicer, 2008, p. 303). Next, I will discuss the ways resistance research has been expanded to allow for a more complex view of the individual acts and the way power animates the social and cultural landscape in which resistance occurs.

Poststructuralist, feminist, and critical theorizing extend the theorizing on resistance from the level of individual acts of rebellion into more complex territory. In this view resistance is not seen as mere acts done by an oppressed worker, but as a part of a larger web of power (Dougherty, 2011). In this web of power, resistance is conceptualized as a process of struggle. Identity and identity management cannot be untangled from this process of struggle.

Poststructuralist and feminist research extends resistance from being viewed as individual acts to a broader social context. Feminist researcher Penny Dick (2008) used Bourdieu's (1990, 1991) concept of field to theorize resistance as "an automatic product of field dynamics, generated as individuals and groups jockey for position" and "a refusal or challenge to dominant ideas that exist to enable people to make sense of the dominant order" (p. 341). This theorizing is 
particularly useful as it accomplishes two things - it connects resistance to social contexts and power ("the dominant order"), and helps us understand the conditions of "possibility for the reproduction or transformation of the social order" (Dick, 2008, p. 342). As noted in the beginning of this chapter, my research path will focus on social order and transformation of the existing social order. This research helps us understand resistance as something that exists as a product of field dynamics.

In these conceptualizations resistance is deeply tied to the concept of power. This view expands the focus of resistance research from the individual acts of rebellion (where power is seen as hierarchical) to broader changes that can have a more pronounced impact on transforming the existing power structures. For example, resistance can be seen as manifesting in the proletariat's refusal to accept or perpetuate their own subordination in the capitalist system. Further, resistance can be seen as a way to block or gain access to power in order to express voice via the legitimate "organs of domination"(Fleming \& Spicer, 2007, p. 20). For example, labor organizations such as trade unions and, at the broader level, the International Labor Organization (Aronowitz \& Gautley, 2003) use the power of numbers to voice change to the power structures that affect such material conditions as hours of work and reasonable pay. While some scholars argue that resistance comes first and then invites further acts of power in response (Ackroyd \& Thompson, 1999), others argue that power and resistance are in a codependent relationship that makes it impossible to tease them apart. In fact, Mumby (2005) argued that the study of resistance should focus on how covert acts of resistance to power and acts of obedience "intersect in the moment to produce complex and often contradictory dynamics of control and resistance" (p. 21). I theorize that moments of social change produce a number of these acts of resistance and obedience and that identity management is entangled in this struggle. 
Fleming and Spicer $(2007,2008)$ developed the argument of conceptualizing resistance as an ongoing and unending struggle, which positions power and resistance as an interconnected dynamic. The term struggle has the following defining features: struggle lies at the heart of political change; struggle constitutes the self-consciousness of the actors involved; struggle produces self-esteem; produces new identities, institutions and social arrangements; struggle occurs through communicative action; struggle involves a process of categorization (Fleming \& Spicer, 2008). Conceptually, struggle is a two-way process that involves a dynamic of give and take. This dynamic produces a cycle that features an infinite process of mutual reinforcement where an initial action on the part of one actor will provoke a certain response on the part of another, which will then be responded to in a particular way and so on (Fleming \& Spicer, 2007). The two subjects are "mutually dependent on their opponent in the struggle for their own sense of being" (p. 52). While Fleming and Spicer do not approach the topic of resilience in this cycle, I wonder if resilience plays any role in this cycle. I intend to explore the ways resilience and resistance are interconnected. I theorize that identity management is a process that involves a struggle and that resistance plays an important role in that struggle. Foucault (1979) argued that workplaces are steeped in power struggles focused on who controls the means of identity production. Organizations are deeply interested in controlling identity, as employees may be interested in resisting that control. In order to resist this control during moments of uncertainty brought forth by an ongoing process of social change, institutional actors may tap into resilience processes. I argue that resilience literature allows us to understand how discourses play a role in reestablishing shared norms. 


\section{Resilience}

The last theoretical area that I explore is resilience. The communicative process of resilience has strong ties to identity management in times of instability and change. I will discuss the complexity of understanding resilience, provide a few key themes in the current resilience research, and discuss how I can use the communicative approach to resilience in understanding identity.

Resilience is challenging to study as a concept because it draws from many disciplines and encompasses many definitions. Below I will offer a few broad definitions of resilience. While no universally adhered to definition of resilience in the empirical literature has been published in this century (Aburn et al., 2016), there are some mutually agreed upon key elements of resilience. These elements are: 1) rising above to overcome adversity, 2) adaptation and adjustment, 3) 'ordinary magic', 4) good mental health as a proxy for resilience, and 5) the ability to bounce back (Aburn et al., 2016).

Resilience can take many forms in individuals, communities, and organizations. Resilience can focus on individual capacity to persevere in crisis and construct one's identity in transformative ways (Agarwal \& Buzzanell, 2015). In organizations, resilience can be defined as "the ability to repair old practices and develop new practices when the old ones are no longer possible" (Mark, Al-Ani, \& Semaan, 2009, p. 690). Additionally resilience could be viewed as a "whole-system" response to change, where individuals, groups, organizations, and systems as a whole respond "productively to significant change that disrupts the expected pattern of events without engaging in an extended period of regressive behavior" (Horne \& Orr, 1998, p. 31). Here the focus is not on individual agency, but on an organization as a unit to be theorized. Communal resilience research focuses both on the tools communities use to become resilient and the models 
of community resiliency. For example, Ch'ng (2016) demonstrates how Twitter users organize for resilience online. This research suggests that online communities play an important role in social and strategic support. Facebook groups appear to strengthen and widen the options for employee resilience in an age of continuing trade union retreat (Cohen \& Richards, 2015). Online organizing and monitoring of online organizing processes has been a key feature in the research on social movements.

Communicative scholarship offers an important understanding of the concept of resilience. Communicatively, resilience is studied in a variety of contexts including job loss (Buzzanell \& Turner, 2003; Lucas and Buzzanell, 2011), a response to family and relational stress (Afifi \& Harrison, 2018), environmental disaster (Carter, 2018; Curtis \& Cicchetti, 2003), environmental resilience (Mitra, 2018), and dirty or extreme work (Agarwal \& Buzzanell, 2015; Ford, 2018; Granter, McCann, \& Boyle, 2015).

In my research I draw from the communicative definition of resilience because it clearly connects to identity work as being key in the resilience process. Buzzanell (2010) outlined the following aspects of the communicative aspect of resilience "These include: (a) crafting normalcy, (b) affirming identity anchors, (c) maintaining and using communication networks, (d) putting alternative logics to work, and (e) downplaying negative feelings while foregrounding positive emotions, such as hopefulness and self-efficacy" (p. 1).

I discuss the process of affirming identity anchors, as it most closely relates to the issues of multiple identity management during a social change. Buzzanell (2010) defined an identity anchor as "relatively enduring cluster of identity discourses upon which individuals and their familial, collegial, and/or community members rely when explaining who they are for themselves and in relation to each other" (p. 4). These identity discourses can be interpreted as 
different social and work identities that an individual must manage in a time that requires resilience. Buzzanell's definition is discourse-based and does not directly address the role embodiment plays in identity management. A key piece of theorizing here is that, in times of crisis or change, people go back to the socially upheld discourses. For example, in the study of families managing job loss, the participants fought hard to maintain heteronormative patriarchal identity anchors of male bread winners, whereas female spenders were viewed as equipped with play money. This talk occurred even when the female partner made the larger financial contribution to the family budget (Buzzanell \& Turner, 2003). Meanwhile, other families relied on the religion-based discourses of God as the ultimate provider and discursively disregarded material realities. Buzzanell (2010) concluded that identity construction based on the reinforcement of identity anchors grounded in these specific discourses may not serve the participant's best interests. For example, women talked about having to put aside the feelings about their own contributions for the greater good of the families. These larger discourses seem to be based on traditional norms of femininity and masculinity and social good. At times of social change, traditional norms and values that organizations rely on may be threatened. Conversely, employees may feel the pull of different identities that they are managing. When the process of resilience is based on affirming identity anchors, and that process is reliant on conflicting discourses, individuals may experience conflict around managing their identity. I want to understand this conflict further.

Another aspect of the communicative definition of resilience is putting alternative logics to work. The process of putting alternative logics to work is similar to the process of enactment discussed in the organizational change literature. As an example of enactment, Karl Weick (1979) explains that "managers construct, rearrange, single out, and demolish many objective 
features of their surroundings" (p. 164). Both the ideas of enactment and that of putting alternative logics to work rely on one's ability to "construct" their environment though a communicative process of sensemaking. When managers share these visions of "what is going on" they "purposefully or incidentally influence the process of enactment of others" (Lewis, 2011, p. 24). In this way, alternative logics or enactments can serve in a role of suppressing triggers for change. I find it important to consider these ideas simultaneously as they demonstrate that resilience strategies may serve to both promote and dampen change. In other words, if a strategy can be used for resilience building and suppressing organizational change, employees and organizations should be aware of the impacts that such a strategy may have. This analysis suggests that the researchers should consider the unintended or negative consequences of resilience during challenging or unstable times.

In the discussion of identity management, I have outlined the ways individuals feel a tension between identity (social identities) and identification with an organization. Since organizations privilege hegemonic masculinity (Trujillo, 1991), masculine norms of organizing (Acker, 1990; Forbes, 2002) and whiteness (Allen, 1998) employees whose identities do not reflect those dominant identities may struggle with identity management specifically at times of ongoing social change. Throughout, I have argued that this research has to be embodied, as identity management is not only a discursive process. The contribution of the resistance literature is that power plays a role in an ongoing struggle process that individuals, organizations and larges societal discourses are involved in. My questions point to the center of this complex process. Here I use Buzzanell's language of identity anchors and discourses: how do people craft and manage identities in the moments of social change when the identity anchors may be in conflict. In the introduction of this prospectus I have discussed how little research there is on 
people managing identities when they have ties to both the institutions they operate in and the social movements they wish to support. We can see the social movements and the institutional identifications as tied to specific identity anchors.

\section{Towards Identity Management during a Social Change}

In this chapter of my prospectus I have argued that the concepts of identity and identity management during a time of social change need to be further developed. I theorize that actors who operate in social movements may struggle with negotiating personal identities and institutional identifications. This process engages sensemaking around normalcy and troubling the norm, and engages the communicative processes of resistance and resilience. Using grounded theory, I explore how people negotiate multiple identities during an ongoing organized social change. Additionally, I ask about the roles resistance and resilience play in this process. The process that I describe is embodied. Because of that, I will consider how the communicative processes of resistance and resilience are embodied. I will examine the ways is identity work is as an embodied communicative process.

Thus, I ask the following research questions:

RQ 1: How do individuals craft identities in resilient ways in moments of social change?

RQ 2: How, if at all, do people manage identity conflicts in moments of social change?

RQ 3: What role does embodiment play in the process of identity creation and maintenance during social change?

In the next chapter I discuss the methodology by which I constructed a theory of identity management. During the process of data collection and analysis it became apparent that my original research questions did not fully encapsulate the process of identity management. Qualitative research in general and grounded theory in particular allows for this flexible and fluid 
analytic approach (Charmaz, 2014). Working with the data itself led me to a larger question that encompassed the identity negotiation process more fully. Thus, my overarching research question became:

RQ 4: How do administrators, faculty, and staff manage identity during student-led protests on a university campus? 


\section{Chapter 3: Methodology}

In this chapter I introduce the methodology of grounded theory (e.g., Glaser \& Strauss, 1967; Charmaz, 2006; 2014) that I used to understand how individuals manage identity amidst a period of strong social change. In this project I am taking a feminist approach focused on embodiment. In order to explore a complex process from a feminist paradigm, I used a constructivist approach to grounded theory (Charmaz, 2014). This approach attends to the ways participants construct meanings in specific contexts (Charmaz, 2006). Constructivist grounded theory does not simply report what participants believe and present it as objective reality; rather grounded theory theorizes the interpretive work that participants do to construct contextual meanings. Constructivist grounded theory advocates for a social constructivist perspective that includes emphasizing diverse local worlds, multiple realities, and the complexities of particular worlds, views, and actions. (Charmaz, 2014). In this chapter, I first discuss how those commitments shape my research. Next, I describe the specific data collection techniques I used in this dissertation. Finally, I discuss how I analyzed the data collected and the validation techniques I used.

\section{Philosophical Commitments}

Choosing data collection methods that will provide the richest and deepest insight into the questions being posed by the researcher is key in conducting quality research. Researchers have a variety of methods to choose from when designing their study and these methods are connected to one's epistemological stances. In chapter one I positioned myself as a feminist scholar, and in this chapter I elaborate on the ways grounded theory connects to feminist research methods in its pragmatist epistemology and ontology. I discuss my epistemological and ontological stances, as those stances drove my choice of methods. I have previously mentioned 
my feminist commitments. I see feminist research not as a method or methodology, but as a set of ontological and epistemological assumptions that are influencing my choice of both methodology and method. Specifically, I discuss how my commitment to embodiment in research is a part of a feminist research practice and how it connects to grounded theory.

Before discussing specific details of this project, I would like to discuss a guiding principle that informs this project: "Researchers begin with the body" and embodiment plays a key role in the research process (Ellingson, 2017, p. 1). Below, I elucidate key ideas that embodiment provides and discuss the ways embodiment and grounded theory complement each other. Embodiment refers to:

the experiential body [that is] both a representation of self (a "text") as well as a mode of creation in progress (a "tool"). [...] Embodiment is a state that is contingent upon the environment and the context of the body (Perry \& Medina, 2011, p. 63).

I assume that human embodiment is constitutive of the world and societal discourses. Thus, thinking with embodiment can inform the research process. Notably, Ellingson (2017) has asserted that research is always already an embodied communicative process for two key reasons. First, research can be understood as already embodied because the human body interacts performatively in the research process. "One is not simply a body, but, in some key sense, one does one's body" (Butler, 1997, p. 404) and one does so (performs) in specific historical circumstances and societal discourses. This performativity and interactivity are conducted in our bodies; consequently the research is a part of this embodiment. Second, knowledge production is an embodied process. That is, "a holistic understanding of embodied knowledge centers on being in the world through our bodies" (Ellingson, 2017, p. 17). All knowing is woven through our bodies. Ellingson (2017) provides an example of the participants in a study on the use of 
prosthetic limbs, who discuss how the use of prosthetics generated specific embodied knowledge. I am interested in pursuing the idea of embodied knowledge in my research. In the current project I speculate that bodily knowing is produced by mentoring, marching, and occupying a work space. Third, bodies exist in a "sticky web" of cultural norms, ideas, discourses, and practices (Rogers, 2003, p. 2) or what Dougherty (2011) called a "web of power" (p. 107). An example of this web can be seen in Scott's (2013) study of African American women navigating a predominantly white institution. The participants discussed modifying their postures, gestures, and clothing to navigate discourses and practices that center whiteness. I am interested in exploring how this sticky web of power is animated when employees manage identity when specific cultural norms, ideas, discourses, and practices are present.

In order to attend to embodiment and these power dynamics, I embrace Ellingson's (2017) call for researchers to consider intersubjectivity when considering embodiment. Our experiences are never fully subjective or objective, but reciprocal and entangled. The aspects of intersubjectivity include attending: to the lived space that shapes how we interact; to our bodies and their interaction with the bodies of others; and to the lived experience of time and our relation to others.

In this project I attended to the embodied and intersubjective experiences of the researcher and the participants as I considered how identity management and resilience are embodied processes. For example, I considered how issues of specific body markers communicate multiple identities for myself and my participants. For example, I thought about my whiteness and accent and what they would produce in the interview. I considered how embodied markers of gender, race, and ethnic backgrounds would impact data collection. Furthermore, as part of my belief in the intersubjective nature of identity negotiation, I remained 
attuned to how my own embodied practices contributed to the data collection process. Even though this attending to my own embodiment was the original plan, I remained surprised that my body was present with this dissertation. I experienced feelings of anxiety and sadness after many interviews. I felt drained and physically ill through much of the data analysis process. Part of my project addresses how grounded theory allows for such exploration. I will outline the connections between grounded theory and embodiment below.

I argue that embodiment fits well with the constructivist approach to grounded theory. Ellingson (2017) echoed Charmaz (2006) in stating that: "grounded theory can be situated within social constructionist theory, reflecting the relational nature of knowledge claims; that is, meaning resides not in the people or texts, but among them.” (p. 43). As those people have bodies, this stance suggests the importance of attending to embodiment. Furthermore, constructivist "grounded theory leads us to attend to what we hear, see, and sense while gathering data" (Charmaz, 2014, p. 3). Therefore, I believe it is appropriate and even necessary to engage in and attend to the embodied practices in relation to my research question.

In terms of methods, Ellingson and Chamaz agree on boundary transgressing methodology Ellington (2017) advocated that "we embrace embodied analysis" in a way where "there is no need to choose between coding and becoming; data analysis assemblages can accommodate a wide tangle of process, concepts, and body-selves, including holding space for philosophical contradictions without resolving them" (p. 152). Chamaz (2014) echoed that call for boundary transgressing methodology: "an emerging grounded theory can indicate needing more than one type of data and can incorporate more than one type of analysis" (p.323). In positioning herself as a researcher, Ellingson (2017) advocated for "theoretical fence sitting” (p. 3). Charmaz' constructivist theory approach allows for such methodological wanderlust in that it 
does not tie the researcher to a specific set of theories at the start of a project. Both scholars advocate for a similar set of openness and curiosity driven practices in the beginning of a project. Ellingson suggested starting the research process with a reflection on the researcher's body, identity, knowledge and positionality. Charmaz (2014) advocates for starting a research project with "sensitizing concepts [that] give researchers initial but tentative ideas to pursue" (p. 31). Both reflections of the embodied knowledge and the theoretically-based sensitizing concepts allow the researchers to begin the research process without being tied to specific theories or expectations of findings.

Here I want to take Ellingson's invitation to start with my embodied experiences and positionality. I saw a need for this project because I found myself lost in a moment of organizational uncertainty at the University of Missouri. In the fall of 2015, a group of students of color organized to claim space on a campus that they saw as not safe. This was not the first time students of color have not felt safe here or organized here, but this time the administration felt particularly silent. As the students organized in more visible ways, I found myself lost in what to do as a person who existed on campus and as an administrator responsible for a first year program that interacted with one third of all incoming students. While I was taking classes as a doctoral student as well, the pressures I felt around identity and role management centered on my administrative and student mentoring roles. I wanted to show support and solidarity with the students who were organizing, yet my supervisors were silent at times and directed us to not get involved. I saw a lot of the students I mentored at protests and sit-ins, and knew that my absence and presence were also seen. I spent a lot of time thinking about the role of universities as being not only places for training for a specific work, but also as spaces where students learn to be engaged citizens. As we know "to keep the spirit of democracy alive requires a continual 
revolution" (Griffin, 2009). I start this project thinking about my identities as a feminist scholar who has spent a lot of time working on mentorship and leadership. I hold identities that are culturally privileged and not privileged and know that my body has an impact on spaces I occupy and will impact my participants. For me, feminist research is deeply tied to values of seeing multiple realities, diverse worlds, and complexities in the topic and the participants who share their stories and experiences with me. I reflected on what feminist embodied research could look like in practice and I share those in the next section.

\section{Methodology}

I have reflected on my values as a feminist scholar who is interested in embodiment and have selected to construct a grounded theory that focuses on how individuals negotiate multiple identities, build resilience, and resist others' and organizations' interests amidst a period of strong social change. The intent of grounded theory as a methodology is to move beyond description and to generate a theory or unified theoretical explanation for a process or action. The development of the theory does not come "off the shelf" but rather is generated or "grounded" in data from participants who have experienced the process (Charmaz, 20014, p. 1). As a methodology, grounded theory has a rich history of being used and respected in communication scholarship (Bryant \& Charmaz, 2007; Oktay 2012, Tracy, 2013).

Grounded theory fits this project for two key reasons: it focuses on exploring complex processes, and it is deeply aligned with my feminist research philosophy. First, in using grounded theory, the researcher focuses on a process or an action that has distinct steps or phases that occur over time. Grounded theory studies have "movement" or some action that the researcher is attempting to explain (Creswell, 2013). For example, Dougherty et al. (2009) used grounded theory methodology to explain the process of language convergence and meaning 
divergence by examining language around sexual harassment. In this study I focused on the process of identity management during an ongoing social change. Using grounded theory, I explored what practices people follow to determine how to engage in the process of managing multiple identity during an ongoing organized social change.

Second, grounded theory is consistent with feminist research practices. The feminist ethos I am evoking seeks to understand and uncover the dynamics of sexism, racism, classism, and queer-phobia as well as their complex interrelations that are often theorized as intersectionality (e.g., Collins, 2004; Crenshaw, 1991). I have discussed my feminist commitments in depth in chapter one. Here I will elaborate on the ways grounded theory has always been "already implicitly feminist" (Clarke, 2012). Grounded theory potentially aligns with a feminist commitment in the following ways: (1) it emphasizes actual lived experiences and practices of social life; (2) it uses Mead's (1962) concept of perspective that emphasizes partiality, situatedness, and multiplicity; (3) it assumes a social construction grounded in materialism; (4) it foregrounds multiple simultaneous readings to produce multiple codes and create space for interpretations of these codes by others; (5) and it aims to "help us understand the incredibly variegated panorama of human living" (Strauss, 1993, p. 49). I will elaborate on a few of the points above to further explain the feminist possibilities in using grounded theory.

First, Mead's (1962) concept of perspective allows the researcher to represent a fuller multiplicity of perspectives in order to disrupt the "representational hegemony that usually privileges some and erases others" (Clarke, 2012). This multiplicity of perspective is consistent with the feminist assumptions about the need of many voices to be present in research. Next, grounded theory is aligned with the feminist research practices in accounting for the construction not only of the symbolic, but also the material world. While many people understand social 
construction to only be ideological or symbolic (Clarke, 2012), it is important to note that the material world is also constructed by both us the researchers and the participants that we study. This material world includes both nonhuman bodies and our own embodiment (McCarthy, 1984). The material world is always present and needs to be accounted for in our interpretations and analysis. This presence of human and non-human connection to knowledge production mirrors Ellingson's (2017) theorizing about how our bodies and knowledge are deeply tied to the material world. Finally, grounded theory and feminist research practices both encourage multiple possible readings of data. In grounded theory multiple readings are not seen as correct or incorrect, but as "consciousness rising" in a way that allows one to develop an understanding of multiple experiences and interpretations (Clarke, 2012). This multiplicity and multimodality can create grounded theory that is committed to feminist research goals.

While grounded theory can be understood as "implicitly feminist," it has not always been used in research that is unambiguously feminist. However, there are examples of researchers combining a feminist research focus and grounded theory. These examples include research on emotion work in an abortion clinic (Wolkomir \& Powers, 2007), batterer intervention programs (Schrock \& Padavic, 2007), and exploration of meanings of race, class, and disease (Shim, 2005).

In this dissertation I used grounded theory as a feminist researcher with an understanding that: the work of grounded theorists will be enhanced with ... [greater] recognition, so deeply rooted in the symbolic interactionist bones of grounded theory, that researcher and participant are mutually imbedded in the social context of the research and that data are co-created (Olesen, 2007, p. 427). 
I position this as an explicitly feminist project that aims at social justice ends (Chamaz, 2005, 2011). Throughout this research project I name my feminist goals explicitly and animate the possibilities that grounded theory presents with those goals in mind.

\section{Data Collection Methods}

For this project, I followed a constructivist approach to grounded theory (Charmaz, 2014) since it is in line with my own philosophical assumptions. In this dissertation, I positioned my approach to scholarship as a feminist scholar who is interested in issues of embodiment. As a methodology, grounded theory provides both well-developed yet adaptable data collection and analysis techniques. Data collection and data analysis are merged in using grounded theory, however, I followed the model that Charmaz (2014) has set in her Constructing Grounded Theory book and discuss them in separate sections below.

Initial sampling, theoretical sampling, and participants. Initial sampling of the participants in grounded theory provides a researcher with "a point of departure," as the researchers cannot anticipate their theoretical categories in advance of starting the project (Charmaz, 2014, p. 197). For initial sampling the researcher will establish a criteria before entering the field. I was interested in understanding the process of identity management in the face of an ongoing social change utilizing resistance and resilience. This focus directed who can participate in this study. In the introduction and the literature chapters I have articulated the tension of personal identity and organizational identification. Identity management, proximity to a social movement, and location in the organization are all factors that I considered in the initial sampling criteria. I focused my participant selection on individuals (administrators, faculty, and staff) who self-reported connections to social movements and protests and self-reported having to negotiate identity as the social movements unfolded. I was interested in understanding how 
these administrators, faculty and staff communicatively negotiated their embodied identities (e.g., race, class, gender) and roles (e.g., student mentor, advocate, and administrator) during a campus-based social movement that received national media attention. The participants were asked to self-identify their level of participation or interaction with the movement and discuss the identities salient to them. Because I am building a theory of identity management that is interested in resistance and resilience strategies at times of social change, I asked the participants to discuss their perceptions and understanding of these processes with me.

Next, I address the relevant demographics. To ensure that this project met the institutional review board's (IRB) regulations regarding protected classes, I only recruited individuals over the age of 18 . I did not limit the recruitment based on race, class, national origin or gender. I am specifically interested in how gender and race function as one of the identities and how people navigate these identities.

I used multiple approaches to advertise my study and recruit my participants. I utilized my current personal networks to recruit an initial group of participants and used snowball sampling techniques to deepen my participant pool (Tracy, 2013). Snowball sampling involves identifying individuals who meet the criteria for participation, interviewing them, and then asking these individuals to suggest someone who also meets those criteria to participate in the study (Tracy, 2013). I posted a call for participants on a university-wide mail list-serv. Finally, I used social media and various list-serves to solicit participants (I include my recruitment script in Appendix A).

The phase of the initial sampling is coupled with comparing data, selecting codes and writing memos on them. I wrote memos after the interviews and as I was transcribing. I embraced the embodied process by handwriting all of my memos and then typing them out. 
Overall, I had 42 pages of handwritten memos that were retyped into 34 single-spaced pages. In composing the memos, I reflected on the interviews and on poststructuralist theory that I was reading. I saw many initial categories emerge through these memos. Some of the early memos were: body as always present, silencing done by the institution, reliance on familiar scripts and roles. Early in the process, I wrote to my advisor: "the participants really talk a lot about being mothers." Eventually the theme of mothering became a script in the data. I felt pulled in many directions and found myself making sense of what I was seeing by reflecting on the concept of a rhizome. I also typed out my feelings in thinking about these memos. I reflected on how challenging it was for me to make sense of the data and physically be present with the data.

Once a few categories emerged repeatedly through the initial sampling, I conducted theoretical sampling, which "involves starting with the data, constructing tentative ideas about the data, and then examining these ideas through further empirical inquiry" (Charmaz, 2014, p. 199). I asked participants about the messages participants received from the organization, resources or discourses they relied on in managing identity, and their embodied experiences. Theoretical sampling, which was spurred by memo writing, occurred once I identified categories (Charmaz, 2014). I sought out the participants who were likely to contribute to the development of theoretical depth in the established categories. Sampling and data collection ended when I reached saturation, meaning when all theoretical categories were well developed and additional data did not provide new theoretical categories or insights (Charmaz, 2014).

Interviews. I conducted intensive interviews (Charmaz, 2014) to gather data for this project. I conducted 26 interviews, resulting in 442 pages of single spaced transcripts. The shortest interview lasted 42 minutes and the longest 2 hours and 37 minutes. I concluded recruiting participants when I felt that I have reached saturation. Charmaz advised the researcher 
to enter the interview fresh (without reading theoretical literature on the topic), but current on the situation they are studying. Because this project is a dissertation that has specific university determined process requirements, I was unable to follow the principle of entering the field fresh. Intensive interviews, defined as “gently guided, one-sided conversation that explores a person's substantial experience with the research topic" are semi-structured in nature and focus on a predetermined list of questions (Charmaz, 2014, p. 56). This interviewing allows the researcher to ask questions, probe, and follow up on insights elicited in the interview process. Constructing an interview guide allows the researcher to be prepared to take these dynamic steps in an interview. The interview protocol for this study focused on management of multiple identities, understanding of one's role in social movements, and conflicts that the participants experienced in negotiating multiple identities (see Appendix B).

Following the interview I asked my participants to fill out an open-ended questionnaire that asked their age, gender identity, sexuality, race, geographical location, class, occupation, and job title (see Appendix C). I have included an abridged version of the demographic information in this dissertation as many participants expressed concern about being identified through certain clues. Many participants shared that they are the only person of that race, gender identity, or sexuality in that particular role or field. Therefore, I made strategic decisions about what to omit from the demographic appendix. For example, I did not put the participant ages (the average age was 46) to minimize the opportunities for the participants to be identified. This decision invited a conversation about what demographic characteristics are important to reveal both for the purposes of a rich contextual explanation and for the purpose of creating new knowledge.

There are additional important considerations beyond the interview procedure. First, embodiment matters in the interview (Charmaz, 2014; Ellingson, 2017), as the interview process 
is interactive and collaborative (DeVault \& Gross, 2012). Ellingson advised that researchers should pay attention to location, bodies in the room, and the knowledge that is produced. The feminist research perspective emphasizes listening in the interview process. This listening is focused on allowing the "experiences that have been disavowed, overlooked and forgotten" to resurface (DeVault \& Gross, 2012). Additionally this listening should allow the uncomfortable to be heard. For example, Audre Lorde (1984) has written on the consequences of white women not hearing about the consequences of racism in interviewing Black participants. This point is particularly important for me, as my identity as a white woman may affect what participants share and what I hear.

One of the ways that I want to consider embodiment is through engaging in object elicitation in my interview process. Ellingson (2017) described this as a democratic method that can expand who can express themselves as a research participant. Participants are not limited to their verbal answers, but can express their experiences, views and identities in different ways. I encouraged the participants to bring three objects to the interview: things that are symbolic of their identities or the state of being before, after, and during the protests. This process also engages kinetic senses and may bring specific bodily knowing into the research process. One of the most important benefits of using this process for me is that it helped me think through the complex concepts like identity and resilience with my participants. The participants used these objects to start the interview - they were able to talk about identity through abstract and embodied ways by having this physical prompt. This process allowed participants to become engaged in the research process in unique ways by discussing the interplay between discourse and materiality. While the objects themselves did not make it in the results section, their presence animated interviews and allowed for deeper exploration of the concept of identity. 


\section{Data Analysis}

In discussing data analysis, Charmaz (2014) emphasized the flexible guidelines of qualitative research, rather than inflexible methodological rules. In grounded theory "method ... is not the servant of theory: method actually grounds the theory" (Jenks, 1995, p. 12). Charmaz (2014) provided the following logics for the analysis and coding of grounded theory data. I started analyzing the data as the data collection was occurring, directing the subsequent datagathering towards the analytic issues that occurred.

I first conducted the initial coding, during which I studied the "fragments of data - words, lines, segments, and incidents - closely for their analytic import” (Charmaz, 2014, p. 109). These initial codes are simple and descriptive of what is happening in the data. They give direction and an initial set of ideas. During initial coding I studied fragments of data (words, lines, segments, incidents) with a goal to attend closely to the data, coding it as actions and avoiding labeling the participants or using extant concepts. Some of the early codes were: "professional calling," “community/family relations," "imposter," "impact of students." Charmaz (2014) nudges researchers to see coding not only as work, but also as play. Through this play we are able to "make discoveries and gain a deeper understanding of the empirical world" (p. 137). I engaged in the process of play by memoing extensively (as noted above) during the data analysis process. I also wrote out short stories about the data to animate it and think with it in playful ways.

The initial codes provided me paths to analysis. I pursued these paths and conducted focused coding that allowed me to test out the most useful initial codes against extensive data. While the participants described different experiences, the structure of initial codes revealed a process or a "theoretical story" (Charmaz, 2006) that allowed me to expand my focused codes into a larger analysis. Focused coding synthesizes the initial codes and provides for analytic 
theory development. Some of the initial codes that I identified were: ("body knowledge," "prior knowledge (cultural)," prior knowledge (professional)," “organization as limiting”). In the analysis process I studied and compared initial codes, chose initial codes, and devised a code that subsumes numerous initial codes. While the participants described different experiences, the structure of initial codes revealed a process or a "theoretical story" (Charmaz, 2006) that allowed me to expand my focused codes into a larger analysis. This process is iterative. I went back and forth between theory and data the whole time. Throughout the interview and coding process I engaged in memoing to focus, define, and brainstorm connections between codes (Charmaz, 2014). These memos formed the core of the grounded theory I was developing. Charmaz (2014) discussed the importance of processing theoretical sensitivity in this part of the process: the researcher should be able to understand and define theoretical concepts and understand the relationships between phenomena. I wrote and rewrote detailed outlines to help me understand how identity management was a process. Concurrently I continued to read poststructuralist theorizing.

There are questions about what makes qualitative research valid. Here I will discuss ways we can evaluate research conducted via grounded theory. Grounded theory can be evaluated with the following criteria: credibility, originality, resonance, and usefulness (Charmaz, 2014). Credibility refers to strong links between a wide range of observations. Originality refers to freshness of ideas. Resonance focuses on the fullness of the phenomenon studied. Finally, usefulness refers to applicability of the applications to people in everyday lives. In this study I achieved these benchmarks by conducting a careful study of relevant literatures to position a newly developed grounded theory within and outside the discipline; gathering rich 
data; considering multiple possible readings of data; and attending to the historical and social contexts in which the data is produced.

In summary, this research used grounded theory to understand the complex process of identity management through resilience and resistance strategies. I examined the conflicting identities and engaged the participants in the photo elicitation process to gain a deeper understanding of their identity management process. The next chapter will address my findings. 


\section{Chapter 4: Findings}

Tamara, a staff member at the University of Missouri, waves me into her office where we get comfortable on one of the many low to the ground couches for the interview. Tamara hands me a sculpture that captures what she felt like while the student protests were happening. I run my fingers over the rough and scratchy surface. Tamara tells me that this clay sculpture makes her think about the protests every time she sees it. The sculpture is a cantaloupe-sized egg that has just hatched and depicts a delicate light human figure emerging from the egg. "A gift from a former student," Tamara says. She rubs her hands together and looks at me directly. She then tells me about a moment she experienced while sitting in her car on campus during the student protest in fall of 2015. Her cheeks flush. That day Tamara needed to decide if she would join her students in protesting or leave the campus for the day. Tamara takes a deep breath and tells me:

In that particular instant, when I was in the car, I did feel, like I totally recall my heart, like racing. I don't know if it was racing because I saw the students and it was the students I knew, or because I saw the police, or if it was racing because I knew I had to make a decision in the moment. What am I going to do? And feeling like either one was like a bad decision. Right? So I remember that. I remember the nervousness, like I remember because I was driving, I remember the steering wheel and like I had to like actually rub my hands because (rubs hands) I remember like, ah, you know, um, “And then what?" I made that decision and I turned off the street and took a detour or another way to loop around and pretended in my mind I was going to run errands that were really important and so thats why I couldnt be there [where students were protesting]. Like I had a reason. Trying to convince myself. (...) I recall like the physical sensation of like, 
of heat, and I dont know if that was like embarrassment or like letting someone down.

Like, I recall that part of it as I was driving away.

I start this chapter with this story as it demonstrates the visceral embodied experience of managing ${ }^{3}$ identity that faculty, staff, and administrators engage in in the midst of a student protest. Tamara discusses her intense embodied experience navigating multiple discourses and material conditions: the obligations as a mentor to students, the experience of seeing police, the embarrassment and confusion associated with her decision to leave the situation. This quote points at the complexity of the identity management process. In this dissertation I discuss identity management as a complex communicative and embodied process that is created in and continuously affected by material, social, and political forces. Tamara's story highlights the themes that will be further explicated in this chapter: lack of clarity; identity building through embracing, rejecting, and interweaving various (often competing) scripts; and the role embodiment and materiality play within those discourses. This research process has been guided by a question: How do administrators, faculty, and staff manage identity in the midst of a student protest? Tamara's exemplar illuminates the ambiguity that is present in the identity management process. My analysis reveals that this ambiguity partially exists in response to organizational enactment of a script of silence. Individual identity management is closely bound to organizational scripts and organizationally constructed material boundaries. In order to understand individual identity management during a period of protest, I will discuss the organizational context and the organizational script.

\footnotetext{
${ }^{3}$ I use the words "management" and "creation" to point to identity work that individuals are doing. I see identity as a process of construction that is at times intentional and visible and at other times invisible and reactionary. I choose the word management as it captures the uncertainty that often needs to be managed, a desire to reconstruct normalcy, and an attempt to find purpose in a chaotic environment.
} 
This chapter will briefly discuss a few historical and geographical nuances that help situate the organizational script of silence within a broader set of material and discursive constructs. The script of silence was enacted in implicit and explicit ways. The implicit expression of the script of silence relied on denial that anything noteworthy was happening and the organization's perceived lack of providing direction to the employees. The explicit expression of this script was enacted in reliance on legal discourses and unambiguous directions to employees about not engaging with the student protests. The participants saw and interacted with the organizational script of silence and also engaged with other familiar scripts to build identity and make sense of their roles and responses. This process of identity management was enacted in ways that accounted for materiality, historical context, and overarching discourses.

\section{Organizational History and Context}

Despite the fact that student protests are a part of American history (Hensmans, 2003), campuses do not often have set policies and action plans to navigate student protests. Historically, protests agitate the systems that are in place and create new openings and possibilities for change (Foust, 2010). Employees who work on college campuses often engage with student organizing when they see that the protest is philosophically in line with the institutional mission (Broadhurst \& Martin, 2014). However, employees still look to the institution for clues about acceptable responses to protests (Gaston-Gayles, Wolf-Wendel, Tuttle, Twombly, \& Ward , 2005). These responses are (a) connected to the university employees' identity management and creation processes and (b) are constructed within the discursive and material constraints that the organization is creating.

Fall of 2015 was a semester full of student protests across the United States (e.g., Princeton University, Occidental College, Georgetown University, Yale University). The 
University of Missouri, a land grant AAU institution located in a historically politically

conservative area in the middle of the state of Missouri, experienced multiple protests during this semester. The cultural realities and social expectations in this geographic region are rooted in a long history of racism, which Christopher, a faculty and administrator who identifies as Black, mentioned as soon as we started the interview:

Christopher: As uncomfortable as I find Columbia and Missouri [pause], you know what the name of this area is?

Anna: No.

Christopher: Its known as Little Dixie. (...). Well, here we are in Little Dixie. Nobody here actually ever said anything like that (referring to students being called by racial epithets) to me but I know when somebody looks at me a certain way what that look is intended to convey.

The university's geography and history are connected to student protests that occurred in 2015. Christopher's quote reveals the overt and subtle cultures and behaviors that are present in this space and place ${ }^{4}$. I will point to a few key historical events for the university and connect those to the climate in which the student protest occurred. This move allows for the identity management to not be seen as happening in vacuum, but as connected to, informed by, and located within specific cultural and historical parameters. Located in a historically conservative state, surrounded by farmland and two major cities, Mizzou draws a varied group of students 5 .

${ }^{4}$ Little Dixie is a historic region of mid-to-upper-mid Missouri settled by the migrants from the south. The southern migrants brought many of their practices including slavery. After the Civil War this area saw many incidents of lynching and mb violence against Africa American population (Crisler, 1948)

${ }^{5}$ Fall 2015 Enrollment data for the University of Missouri (categories reflect the language used in the enrollment report):

Total Undergraduate students: 27, 812; Total Professional \& Graduate students: 7636 
As a predominantly white institution, the University of Missouri has a history of racial exclusion. In fact, the University of Missouri has a well-documented deep history of racist, sexist, and homophobic occurrences on campus (e.g., Goldstein-Hode \& Meisenbach, 2014). In 1936, Lloyd Gaines, an African American student was denied admittance to the University of Missouri on the basis of his race. Gaines successfully challenged the university's decision and won in the Supreme Court, yet disappeared before he ever stepped foot on campus. The University did not admit any black students until $1950^{6}$ (University of Missouri Notable Firsts). Sophia, a university staff member who identifies as Chicana, explains the racial climate on campus: "Something has happened for the past 10,12 years, every single year around Black History Month or around certain months, but specifically around black history month. The school has a history of having incidents, particularly at that time" In recent years these incidents included cotton balls being placed in front of the Black culture center in February, 2010, and two instances of graffiti (racist and anti-Semitic) being sprayed in and around residence halls in February, 2011.

The history of repeated racist incidents contributes to organizational culture and storytelling that, in turn, shape student and employee expectations and behavior. Jillian, a white faculty member who had administrative responsibilities during Fall 2015 shares, "The issues that were raised by the students in 2015 were issues that have been going on more than decades, you

$44 \%)$

Gender by classification: Undergraduate (Female 52\%, Male 48\%); Graduate (Female 56\%, Male Ethnicity/Race Enrollment (categories reflect the language used in the enrollment report):

White 75.5\%; International 7.1\%; Non-Specifies 1.3\%; American Indian/Alaska Native .2\%; Asian 2.2\%; African-American 7.2\%; Hispanic 3.4\%; Native Hawaiian 0.0\%; Multi-Race 2.7\%

${ }^{6}$ The name of the student protest, CS 1950 gets its name from this fact. 
know." Jillian makes it clear that student protests were created in response to the history of racist occurrences. Dakota, a white faculty member, discusses the cumulative effect of this racist history on organizational culture and suggests that the only way that the students (those who she views as disproportionately affected by racism) could create a shift in this culture is through protest:

Theres a lot of trauma. Theres racism in this university. The only way theyre [the marginalized students are] going to really be heard is by massive protest. Then the protest happened. In my belief, they had to. Thats the only way of the students were ever going to be heard, is to protest.

Dakota's words point to a view that many participants have shared: for students to be heard in the organization students had to take disruptive actions. Dakota's quote presents a view of the organization that has a specific racist past and culture that supports racism where the students are positioned as responsible for agitation for a change to occur. In sum, the University's organizational history is full of incidents of racism. The student protest (that gives a nod to this history with their name) is influenced by both this history and the current response that the organization continues to provide. Additional complexity exists because many organizational members disagree about whether racism exists and how it functions on campus. Not everyone I interviewed agreed that the students were acting as agents of positive change. Peter, a faculty member, described students as having "mob mentality" as the protests disrupted a campus and created unwelcome conditions.

I was curious to explore what the organizational responses to the protests were both in context of the history and geography of the organization. In my analysis I saw that the 
organization did have a specific script that employees understood and often found insufficient.

Below I will outline this primary script and the ways employees engaged with it.

\section{Organizational script related to student protests}

My analysis of the data suggests a presence of a specific organizational script with which the participants interacted. The organizational script serves as set of discursive practice that connected to the material phenomena and were embedded within the historical and geographical realities. This intra-action ${ }^{7}$ animated the process of identity management for staff, faculty, and administrators. Organizational scripts are narratives, directions, and directives that organizations share with employees. Poole, Gray, and Gioia (1990) define an organizational script as a "specialized cognitive structure that retains expectations of how to behave in specific situations and contexts" (p. 212). I argue that protests disrupt the sense of normalcy and that this organization struggled to have a comprehensive script. The participants have discussed a sense of being disoriented without having a clear direction from the organization about what to do around the protests. During a time of organizational uncertainty, employees turn to institutions to understand professional and personal identity ${ }^{8}$. Previous literature suggests that organizations

${ }^{7}$ When describing organizational members' interaction with the scripts I think about the concept of agential intra-action (Barad, 2003). Barad develops this concept based on Bohr's theorizing. Barad explains:

This account refuses the representationalist fixation on "words" and "things" and the problematic of their relationality, advocating instead a causal relationship between specific exclusionary practices embodied as specific material configurations of the world (i.e., discursive practices/(con)figurations rather than "words") and specific material phenomena (i.e., relations rather than "things"). This causal relationship between the apparatuses of bodily production and the phenomena produced is one of "agential intra-action." (2003, p. 815)

${ }^{8}$ Cynthia Stohl (1986) discusses a concept theoretically similar to organizational scripts when she says that employees rely on organizational messages to achieve two goals: "One, they enabled understanding of situations and thus provided sense-making structures. Two, they provided a guide to behavior appropriate to the organizational setting" (p. 247). 
have vested interest in controlling identity and day to day sensemaking of organizational members (e.g., Alvesson \& Willmott, 2002). The process of controlling identity can take place through clearly developed and communicated organizational scripts. During moments of organizational uncertainty, employees look for organizational scripts to rebuild a sense of certainty. Organizations control identity and day to day sensemaking of organizational members through structures and discourses. Perceptions that the dominant organizational script was insufficient led organizational members to pull on other existing scripts to manage their identity.

Here I map out the script I call the script of silence that the organization had, and discuss how the organization reinforced this script in explicit and implicit ways. The script was implicitly upheld through overt directions by supervisors and through reliance on legal discourses. Additionally, the organization explicitly upheld this script by avoiding any conversations about the protests. In a move I call "nothing to see here," the organization simply refused to acknowledge that any conflict was occurring. Both explicit and implicit enactments of this script left the participants with limited options with which they could manage their identity. Later in the chapter I discuss this challenge and lay out other scripts the participants used to manage their identities.

\section{Script of Silence.}

"These are not natural silences - what Keats called agonie ennuyeuse (the tedious agony) - that necessary time for renewal, lying fallow, gestation, in the natural cycle of creation. The silences I speak of here are unnatural: the unnatural thwarting of what struggles to come into being, but cannot. In the old, the obvious parallels: when the seed strikes stone; the soil will not sustain; the spring is false; the time is drought or blight or infestation; the frost comes 
The key organizational script that I was able to clearly identify in my data was the script of silence. The participants felt that they were silenced by the organization. Before I go further, I discuss some distinctions among the participants in relation to the script and the way it is enacted. All of the participants I interviewed were able to speak to this script and the ways they managed their identity in response to it. It is important to note that not all the participants in this study supported the student protests, and even fewer were directly involved with them in any capacity. My recruitment protocol focused on identity management during a social movement, which, in turn, attracted participants who were in one way or another engaged in an identity management process that directly related to the student led social movement. This an important point of clarification, as it is vital to know that the organizational script impacted identity management whether the participants supported the student movement or not, or what level of engagement they had with the students in the movement.

The script of silence centered mostly on employees feeling explicitly prohibited or discouraged from engaging with the students, the movement, or each other around the issue of the student movement. Specifically, in this script, participants received organizational directions to be silent and to not engage with the protests. The following exemplars demonstrate the script and the manner in which it was enacted.

Alia, a staff member, specifically names the organizational script of silence directions as something that impacted her understanding of her identity during the protests and her sensemaking after the protests. She discusses a reflection session that she attended a year after the protests that was led by an outside speaker. The speaker asked what happened during fall of 2015. Alia recalls what happened next: "Everybody just kind of looked at each other like, I dont know, do we say what happened? Wed not been given that narrative even, other than it didnt 
happen. Like, basically dont talk about it." In the first part of this quote, Alia shares that the organization did not provide her and her coworkers with a narrative of what happened except to pretend nothing happened. This is a script of silence in action - an employee must be silent and pretend that there is nothing that is happening on campus.

This caused a sense of confusion and frustration for the employees. The employees desired a clear script that could help them manage identity. Selma, a staff member, expressed her frustration with the silence in these terms:

It was very frustrating to be on campus and not have that communication from the higherups as to what were going to be doing. There was no strategic planning on their part either. They didnt know how to respond to this.

Selma sees having scripts as a fundamental responsibility of an organization in crisis. This absence of script produces anger that communicates that Selma and other participants expected to have organizational scripts. The script of silence can be interpreted as an action that is rooted in organizational history, geography, and current social contexts. By engaging in this script, the university can be seen as enacting values that refuse to trouble the racist incidents of the past. In fact, many participants shared that the organizational script was steeped in refusal to discuss race and whiteness. Next, I discuss how the script of silence was enacted in explicit and implicit ways. I will close the section about organizational scripts by analyzing the scripts as rooted in (un)troubled whiteness.

\section{Explicit enactment: Voice of the authority.}

The script of silence was enacted through the voice of authority. The participants who interacted with this script shared that they learned about this script through their supervisors and discussions with colleagues. Many participants talked directly about being told by their 
supervisors to not visit the quad where the student protestors gathered and set up camp. For example, Cathy, a staff member, talks about her supervisor, a senior level administrator: There had been not so veiled comments by [my supervisor] as to whether I was going outside to join the protest or what I was doing during my lunch hours or why was I leaving the office and things like that. And he actually told me, you better not be doing the protests or you will not have a job.

Cathy felt threatened with a possibility of job loss and felt silenced by her supervisor. Her supervisor participated in disseminating the organizational script of silence. Cathy discussed her position where she has to engage in managing her professional role with the script of silencing. Cathy shared that she sees herself as someone who wants to support the students. The silencing script created a conflict that Cathy had to manage. The participants most likely to discuss the silencing fell within the staff and nontenured instructor roles.

Katrina, a staff member summarizes the messages that she received from the university. I asked her about what she and her friends and colleagues talked about:

Oh, we talked about, I think we really talked about how did we fit in the picture. Like how do we offer the support to students and experienced that with them but then still have my job and while in my job Im being told A) stay out of it, B) if you choose to, you have to use your own time or, or, or take time off or C), Um, its not in your busines s. Like we had so many different messages from so many different people. This quote demonstrates that the institutional script was confusing ("so many messages"), yet ultimately silencing ("stay out of it"). Katrina's quote also shows that the organizational script of silence plays a role in individual identity management. Here Katrina asks how she and her colleagues "fit in the picture." This fit is a larger question about employees negating personal 
values (what many referred to as their humanity) and professional responsibilities (that seem to construct that humanity). This is the question of not only professional roles, but individual identity management.

Another way this script was disseminated was through colleague interactions. Stevie, a staff member in an entry level role, shared that she became aware of the script of silence by listening to her coworkers: "There were always rumors to that about people losing their jobs or being threatened." This script may have been originally produced by top key members of the organization (e.g., Cathy's supervisor, who is a senior administrator), but it was reproduced by the organizational members. Stevie and Katrina both identify this dynamic. Thus, the script of silence becomes a part of the organizational narrative that is omnipresent and shapes identity.

The first few exemplars in this section highlight voices and experiences of staff, who overall felt dismissed and marginalized at this time (this will be discussed later in greater detail). Faculty and higher-level administrators articulated the script of silence as a lack of direction. Nina, an administrator, shares the following: "So its really, [a] really good way to describe it is that there was no consensus at the time because everybody has different opinions about how we should respond." Nina's quote suggests that there was a larger confusion throughout different levels of the organization about the appropriate response to the movement and the role that the organizational employees should play.

A few participants discussed the different ways they navigated the script of silence. These individuals acknowledged that the script existed and that there may be material consequences (such as job loss) for disobeying such a script, but they found ways of navigating around it. For example, Forrest, an administrator, discussed the script of silence and his efforts to navigate around it: 
And, you know, I was prohibited from emailing my staff about any of these issues. But no one said I couldnt send an email to all the students, and so I did. Knowing that many of the staff would want to be able to read that as well. (...) And so, in that sense, I felt the great deal of pressure because I understood the interest and the demand or the expectation from our student staff or other staff that the institution responds to this.

Forrest sends the email about the movement and the role of the university in supporting the students to students, knowing that his staff will be able to access the email. Forrest does not question or challenge the script directly to his supervisors. He sees the script as something he cannot change, yet this script is not aligned with his personal and professional values. So he finds a workaround and in doing so finds a way to manage both his personal identity and his organizational role in relation to the organizational script of silence. I want to point out that the professional role and personal identity (throughout the interview Forrest discussed his personal identity as his values) are seen as deeply connected.

Cathy provided another example of challenging the script though embodied action. Cathy shared that her supervisor, who told her to not go to the protests if she wanted to keep her job, also discouraged cellphone use in the office and discouraged discussing the protests with student employees. This was a challenge for Cathy, as Dana, one of the students she supervised at work, was African American and felt a lot of identification with the student movement. Cathy shared that she "made sure that [Dana], even though it was against our policy, she had my cell phone. I was available to help because if something happened, her family was not close." On the day the 
campus experienced YikYak threats ${ }^{9}$, Dana told Cathy that she was afraid to come in to work on campus. Below is the conversation we had about the event:

Cathy: I was a little worried about her, so I was covertly texting her throughout the day. She didnt feel like she was, she didnt feel comfortable going to, you know class, so she didnt g o. I was texting her, I said: "Dana, where you at?" "Back in my apartment." I said: “Okay." "Did you email your professor to let her know?" "Yes, I did." "Whens your next class?" (...) Well [my supervisor was] walking around. So, the phone is under the desk, but I want to have it on me, because I want to keep my communication open with Dana. Bathroom break: "How are you doing?" Lunch: "Did you make it to campus?" Anna: So you literally had to hide your phone? Cathy: Yes. Anna: And what was that like? Cathy: I thought it was really stupid. She is one of our.... Shes not just a student. Shes our employee. I was just like, fine. Im going to be a rebel. Im going to use my cell phone, whatever. If worse comes to worse, Ill blame my moms freaking out in [hometown] because she saw that MU made to the news. What are you going to do? Cathy identifies that a part of the organizational script of silence is an explicit ban on contacting students regarding the protests. Cathy balances two compelling pulls: to care for her student by checking in on her and to obey the organizational script. Balancing of these pulls is an identity management question as well as a compliance question. Cathy, like Forrest, does not tell the

${ }^{9}$ The University of Missouri campus community saw the following anonymous message on the YikYak app: "I am going to stand my ground tomorrow and shoot every black person I see." This post created widespread fear on campus ("Man who made threats on Yik Yak switches plea to guilty," 2016) 
supervisor that the script is unreasonable. She finds a way to challenge it by hiding her phone in the bathroom and coming up with explanations if she is caught. Both Cathy and Forrest subvert the organizational script thought their embodied actions. These actions suggest that Cathy and Forrest are aware of the script and the consequences, but are not willing to show complete obedience. Indeed, they see the need to act and do so, even as they think that there could be negative consequences. As such, Forrest and others manage their identity in similar ways - they see the organization scripts as non-negotiable, and they manage their identity to work around that. Finally, it is notable that they challenge the script through embodied action, and not through talk. Consider Cathy's decisions to not only hide the phone, but also remove herself from the sight of her supervisor, these are embodied moves. Having now established the manner in which the organization script of silence was enacted, I discuss the role legal discourses played in this enactment.

\section{Explicit enactment: Silence of the law.}

Several participants mentioned how the organization's reliance on legal scripts and legal speech contributed to the script of silence. Furthermore, a few participants shared that they saw the organization using the scripts that were rooted in legal discourse and legal practices.

Christopher explained that the cultural change that CS 1950 protesters were talking about was not possible because of the legal limits of what the university was able to do:

Here are these dominating concerns, we want to change how people speak, we want to change the demographics of a campus. We have no legal ability to do that. If we tried it, we would be sued, we would lose, and it would be wrong to try in the first place because its illegal. 
Christopher discusses that the university is bound by their legal ability to perform certain actions in their response to the protestors. Christopher continues:

We cannot as an institution state that we are recruiting, admitting, and retaining students to a racial quota. Apparently in complete ignorance of the series of a Supreme Court cases on this very issue. One of which was ripening at that time, Fisher versus Texas. Legal scripts appear to be neutral, objective, rational. Their objectivity and rationality lend the sense of neutrality to the institutional script of silence. The objectivity of the legal scripts supersedes the "dominating concerns." When an organization provides a legally fueled script of silence, the employees have to manage their identities precisely in this framework.

Dakota, a faculty member, discusses how organizational reliance on legal discourses impacted her work and her identity. She discusses a statement she helped craft as a departmental response to a protest related incident on campus. She shares what happened after she crafted this message:

Then they send it up to the university level; they liked it, send it to the lawyers. They [the lawyers] stripped everything out of it that was content. (...) I mean its stripped everything out of this message. I had to work to get it put back in. It was, what a mess, and when it finally came out at five oclock that night, it was too fucking late.

Thus, some participants perceived the legal script as hindering their ability to do their work and communicate effectively. Moreover, since the employees integrated their professional capabilities into their overall construction of identity, silencing and cutting off communication made the participants feel like they were no longer a part of the organization. The use of an expletive here illuminates the anger and frustration that Dakota experiences about the script of silence and legal bounds within which it was rooted. Dakota is not showing anger about the 
protests here. Her anger is connected to the fact that she sees herself as unable to perform her professional duties because of the institutional enactment of the script of silence. In sum, the organization enforced the explicit enactment of the scripts of silence by relying on the organizational scripts. In addition to these explicit enactments of the scripts, the following section outlines how the organization implicitly enacted the organizational script of silence.

\section{Implicit enactment: Nothing to see here.}

A second way that the organization upheld the script of silence was implicit. Participants perceived that the institution did not provide employees with directions on what to do in this anomalous situation that was marked by ambiguity and conflict. All participants, regardless of their place or role at the university, either expected or desired an institutionally-provided script for how to deal with the protest. In the previous section, I have demonstrated how the participants did not receive any information, and both perceived institutional silence as well as replicating and enacting it themselves. Here I describe the lack of organizational direction that implicitly enacted the script of silence.

Many participants discussed that they expected to have a clear set of directions related to their professional roles specifically in the context of the institutional uncertainty that was created by the protests. The participants shared that their roles did not have a clear set of tasks related to what their response could be. Andrew, a staff member, describes his confusion and frustration. He was working in one of many offices that received an onslaught of phone calls in response to many events on campus. He recalls that there was minimal input from the organization on what to do:

Even though there, were professionals in that office, not being prepared for that moment that needed someone to say "this, dont say this, feel free to hang the phone up." But 
because it felt like we were under the microscope - It, I feel silly saying this, it doesnt seem like we would have the freedom to hang up on people. ... I, and my co-worker who were both there on that day, felt really alone, like on an island, trying to - and what Ive been told, is that other people in parts of the campus were experiencing those same types of phone calls. But I think because of the nature of the [unit] we represented, it just felt very isolating.

Andrew expresses his feelings of isolation and confusion related to the organization's implicit enactment of the script of silence. I was curious about what feelings or responses that script produced and Andrew shared "feeling kind of pissed because it had taken them all day to get to this place and we were just out there, on the front lines so to speak." Andrew is upset that he did not have guidance from the organization to make sense of the protest, and how he should manage his personal and professional identities in the face of it. Andrew continues:

Youre paying me talk to like shock jocks who are calling i n, trying to get sound bites on the air and saying horrible things, and people calling from all over the country saying horrible things. I mean it was just - it was kooky to me.

Andrew sees his professional role as capable of doing more than "talk(ing) to like shop jocks." He equates institutional silence with lack of respect for his role and his identity as a professional. This professional identity ("We're professionals in that office") is valuable to him, but is not necessarily valued by the organization, as they fail to provide him with the tools to do his job well. Organizational silence on the appropriate conduct by professional staff is deemed 'kooky,' a sign of deep confusion and disidentification. As a part of the professional identity, Andrew has certain scripts and expectations. 
Andrew's quote also illustrates identity management as an embodied process that connects to discourses of hyper visibility (described as being "under the microscope") and invisibility (described as being "alone" "on an island"). Andrew is visible under the gaze of the institution, yet he feels not valued and alone. Identity management engages existing scripts, embodied conditions, and relationships with the coworkers and the organization. Like Andrew, most employees expected that the organization would provide a functional script around the protests. What they found, however, is a script of silence.

The script of silence led to a sense of confusion in identity management and a sense of loss that Andrew alluded to. Ade, a faculty member, develops this point further. She describes a sense of loss and confusion that she experienced:

You are in the middle of scattered pieces and, and really sort of not knowing how to do your job or how to do it right or what to do. I mean, we had no emails, um, well there were no at the time, no emails, I wont say no, but very few emails coming from central administration sort of telling us, you know, how the..... and there is no right or wrong way ever to do anything but some direction on, okay, this is whats happening in here. Heres how you can support your students or support your program as a department chair or here are the things that we want you to do sort of as a professional in the society; in this organization that, none of that was happening. And so, we felt like we were just guessing at.

The specific organizational script that Ade desired and did not receive were directions on how to do her job during turmoil. This lack of directions (implicit enactment of the script of silence), created a tension between what Ade perceives as her professional and personal identity (“can support your students or support your program" as a "professional in the society") and her 
ability to enact that role. All the employees interviewed, regardless of their support or disapproval of the student movement and the university response, expected to have a script that allowed them to follow clear guidelines, make sense of their environment, and their roles in that environment. In the absence of a meaningful organizational script, employees relied on other resources to construct and manage their identity in the midst of a student protest. The employees were left without substantial guidance even though they knew that protests were not a unique occurrence limited to this university.

In my analysis I interviewed participants who discussed that they were a part of creating a script, but that such a script was not ultimately used by the university. Dakota discussed that her role was creating a script that the university leaders used briefly in their response when commenting on the protests. The script was:

University of Missouri is always proud to be at the center of the national conversation about race in the United States. Universities are designed to be the hub of knowledge production, and social development. As a country, we need to be talking about race relations. As such, this is precisely where we need to be in this conversation This script is clear and precise. It acknowledges the university history, geography, and the role of the institutions of higher education. A question may arise why the analysis I provide here claims that the university used the script of silence when an alternative was available. I make the claim that the university used the script of silence precisely because the participants identified the script of silence as the guiding one. Dakota explains what may have caused this when she discusses a conversation with a communication professional from the university:

I had some messaging created for that and I sent it to the communication people at the time. Then I went over to have a conversation with her at her invitation some weeks later 
and I asked her two things. Had she utilized that messaging at all for forward motion work and she said no, shes hoping she didnt have to use it. She put it in a file just in case. The point of that was so you dont have just in case. Thats not a "just in case." Were having a crisis message thats a pre -crisis message and thats not going to work if you have a crisis, so youre not going to use it, just tear it up.

Two important things are happening here. First, Dakota discusses that the script she created was not ultimately used. Second, she feels a sense of professional disappointment. By shelving this script, Dakota's expertise is willfully disregarded by the organization.

The organizational decision to not use the scripts developed by this organizational member and instead lean into the script of silence in implicit and explicit ways produces a sense of neglect for organizational members. Noelle, a faculty member, discusses this lack of script in terms of the overall organizational impact:

Um, and we tend to ignore our internal population a lot and we dont communicate to it. Like the protests, right? Um, but it felt like we were being silenced by not being asked and we were being silenced by not being, you know, like there were people who were reaching out to the students. There was no official reach out to the faculty and staff who were involved. And there never has been. And like to this day. and now, just to speed up, um, so it felt like we were ignored and neglected, but there was kind of an excuse, which is were too busy doing this thing over here.

Noelle describes how the organization silenced the employees by not having scripts. She refers to the complex processes that the organization needed to coordinate by sharing that focus on these processes feels like neglect to her.

\section{Silence that Corroborates Whiteness.}


In developing this theme, I wondered what the script of silence was producing. In my analysis the script of silence seems to erase (by not naming) the history of racist events that occurred on campus. It erases individual time limited events (cotton ball incident, MU for Mike Brown events, etc., as discussed in the Organizational Context section) and fails to grapple with how those events form numerous "histories" of MU and how those histories ignore the larger history of marginalized people. Silencing and reliance on legal discourses produce an ahistorical effect where the protests happen and folks on campus are aware of them, but they are not integrated into the larger publically discussed historical narrative of the university. By not integrating the history or the current events the institution is privileging whiteness in its script. While I will not go so far as to say that language is the only thing capable of producing meaning, ${ }^{10}$ I see scripts as capable of marking important cultural and historic touchstones. This marking highlights what is important and valuable to the organization. Thus, absence of a script still holds discursive power.

The script of silence is animated by whiteness, often through reliance on the construct of professionalism. The idea of professionalism is embodied, gendered, raced and classed (e.g., Tye-Williams \& Krone, 2016; Mumby \& Putnam, 1992). The participants engage with the organizational script of silence and privilege whiteness by simultaneously foregrounding professionalism and disregarding embodiment, gender, race, class, and the histories they carry. The following exemplar demonstrates how the ideas around professionalism replaced a very important conversation about race. Here privileging whiteness is embedded in the organizational

${ }^{10}$ I agree with Barad (2003) and Cloud (1994) that language has been granted too much power and that the discursive and material intra-actions are important to consider. Here I am speaking to what absence of language produces. 
script of silence and the concept of professionalism is the tool by which this embeddings is enacted. Noelle discusses how the organization's focus on whiteness was reaffirmed both by what she did and did not do in her job. Noelle shares this example from her work:

The Faculty council couldnt talk about the race thing at all. I mean it was so much easier for us to talk about the chancellor should get a letter or we should draft this... Theres some resolution. We stayed late to craft it and it was basically a: "the faculty council would like to register that it is rather disturbed by what appears to be the leadership falling apart." Like thats basically what the statement said. It was like a memorandum of concern. Right? It was... So... it was so faculty. It was so faculty council. It was so committee, but that was so much easier than the council talking about race. Um, and professionalism is easier to talk about than whiteness.

Noelle here reveals that the organizational script of silence also limits her and other employees from discussing the raced nature of the student organizing. The organizational script of silence here functions to provide a bait and switch - the talk about race evaporates and the talk about professionalism takes its place. The faculty group discuss various actions, misdeeds, and steps, but they do not address that most student protesters are Black or that their demands specifically address the racial inequalities present in of the institution. When Noelle says that "professionalism is easier to talk about than whiteness" she reveals that the organizational script of silence affirms whiteness by never questioning or problematizing it. Further, if the organizational script around professionalism is so tightly connected to whiteness that it cannot allow for the employees to discuss the racial issue at hand, then this script only has the power of affirming whiteness as the norm and accepted practice. 
The script of silence creates a very specific set of material and discursive realities for organizational members. The script of silence also produces inconsistencies and tensions that are challenging to navigate, and the social movements create a turmoil that exacerbates the challenging process of identity creation. Notably, I see these scripts as not fixed. They are tools out of toolboxes that are used in creating identity. There is fluidity and play in the use of these tools that create some opportunities for resistance and resilience building. The organizational members engage with the following scripts in discursive and embodied ways in their identity creation. The rest of the chapter lays out these scripts.

\section{"We have discovered the performance by making it" $" 11$ Navigating identity building}

\section{through familiar scripts}

I have established ways in which employees look to the organization to provide scripts during a time of student protest and are met with silence, legal scripts, and limiting structural and discursive realities. The organizational members engage with these scripts to gain a better understanding about how to create and manage their identities during uncertainty that is likely to occur during student protests. The protests themselves function as a disruption of the script of what university students do. In this case, organizational scripts were full of omissions, silences, and limits, making it so the organizational members had to look elsewhere to make sense of the complexities and their identities within this process. Sociologist Donileen Loseke posits that identity can be understood as pulling together narratives: cultural, institutional, organizational,

11 "We have discovered the performance by making it" is a title of a Goal Island exhibit in the Chicago Cultural Center. The description of the event reads: "Freed from prescribed narrative and dialog, the work of Goat Island is built slowly in a creative process informed by repetition, chance, and individual perception." I have selected this as a name of this theme because of the similarities I see in the identity management process: the sense of discovery by repetition, change and perception that forms the performance of identity. This invites the play, uncertainty and interactivity that marked this process. 
and personal narratives of identity (2007). Below, I will discuss the various scripts participants rely on to understand their role, responsibilities, and identity in relation to the organization and the students.

The structure of this chapter may suggest these scripts are singular, clear, and disconnected from each other. That is not the case. These scripts are rhizomatic ${ }^{12}$ in that they start from the middle, are entangled, and connect to each other in ways that are discursive and material. I see this as an entanglement of "and, and, and, and," rather than clearly delineated parts of identity. Additionally, I take guidance from Butler (1996) who positions identity as a performative repetition, a copy of a copy without an original. Later in the chapter I will discuss how the participants put these scripts together. For now, I discuss scripts that reached thematic saturation in the analysis process.

In my analysis I found that participants engaged with four distinct scripts. First, I discuss the scripts rooted in organizational hierarchy. The participants relied on organizational structures (tenure and staff roles) to build scripts about what to do in this time of organizational uncertainty. Second, I discuss the scripts based on occupational roles. The participants looked to their occupations/professions for the knowledge, skills, and discourses used to construct their identities during a student protest. Third, I discuss the script that many female employees used, which is maternal roles and mothering. Lastly, I discuss how scripts rooted in participants' background, family history, and current community played an important role in helping

${ }^{12}$ Defined as a-centered multiplicity. To think about identity as a rhizome helps us think about how everything is multiple and interrelated. The everything here includes space and place, embodiments, scripts, and others. Another allure of the rhizome as a way of understanding identity is that rhizomes do not have a starting point - neither does identity management. It is always entangled with various scripts, materialities, embodiments. The student protest and the organizational response that it creates produces an impact on identity management, but does not define or limit one's identity (Deleuze \& Guattari, 1987) 
employees manage their identity. I close this discussion of scripts by illustrating how employees use these scripts in entangled and interconnected ways.

\section{Scripts rooted in organizational hierarchy.}

Participants discussed that organizational hierarchy and structure were infused with scripts. The main structural element that the participants discussed as particularity conducive to meaning making around the protests was the set of discourses and practices around tenure. Specifically, the script was that tenure was the only structural element that offered tangible material protection that all other employment statuses (staff, nontenure) lacked. Participants in this study referred to structural components of the university, particularly the organizational hierarchy, as a way of understanding their position and subsequently constructing their identities within the context of the organization. These structural scripts can be conceptualized as discursive-material intraactions. Organizational structures provide material and discursive constraints to the participants. Below I discuss ways the scripts around tenure and staff roles played a role in discursive and embodied ways participants made sense of their role in understanding the student protests.

\section{Tenure as the ultimate protection.}

Most participants conceptualized tenure as a discursive-material intra-action capable of producing scripts. Participants interacted with these tenure scripts to manage their identities. Participants described tenure as the ultimate form of protection any employee could have against what they saw as a precarious position that they were in. This was specifically true for faculty who identified as people of color, who saw tenure as not only important for their protection, but also in terms of representation. I provide an example from a tenure track faculty (Acadia) and a teaching faculty (an exemplar by Jillian) to illustrate this script. Acadia, who identifies as Afro 
Latina, explains all the maneuvering she has to do to align her values with the structural limits the tenure process provides:

I kind of isolated myself (...) I have to get tenure and thats really like in order to survive in this place. You have to get tenure, you have to get these kinds of things in order to move forward. And if I dont get tenure and Im doing so much service on campus, then I wont, you know, we wont win with representation if I dont do that.

Tenure was perceived by Acadia as a way to provide both job security and freedom to behave or communicate in genuine ways with some semblance of protection. Acadia discusses tenure in relation to working with students and representation ("we wont win with representation if I dont do that"). She is doing identity work in that she is balancing her goals as a scholar, someone who understands and values representation, and navigates specific material and discursive constraints that lead to tenure.

Acadia talks about how tenure grants specific material consequences when she discusses her choice to not be visibly involved on campus in general and with the CS_1950 movement specifically: "I would not risk my materiality to that point because I know that I have to remain present in this place. Get tenure and beyond in order to have a broader impact in the long term. I can't risk my body now, I cant." Acad ia positions tenure as something that enables and constrains her in both discursive and material ways.

She discusses her body as the precise site of struggle in her identity management. She does not separate identity management from her body ("I can't risk my body now," a body that contributed to representation, a body that wrote "like a 100 recommendation letters"). She does not separate identity work from body work. There is an element of fear in not receiving tenure and the protection she perceives tenure could grant. However, receiving tenure is also positioned 
as a way of getting out of the bind. Acadia sees herself as being able to contribute to a greater good (representation and scholarship) through navigating this structure. In reviewing this chapter as part of my member checking process, Acadia mentioned that while she did not actually write 100 recommendation letters, the amount of emotional and mentorship labor she was engaged in felt overwhelming and was greater than what she would do during a more typical academic year. Acadia, as many academics do, was already participating in the "get tenure" script before the student movement happened. But the questions that the student movement brought into existence animate the identity management process in a new way. It is not surprising that a tenure track faculty would pull on the tenure script for guidance. Since Acadia has not yet reached tenure, this script does not offer her ways of integrating all her values. Specifically, she positions tenure as a time when she could have enough protection to contribute to representation, engage in writing, and support students. This discussion of tenure illuminated identity management as discursive, embodied and connected to the organizational structures.

Jillian describes how lack of tenure is a precarious position that animates identity management for faculty on tenure track specifically related to the protests:

One thing that really stands out for me during this time was, um, [top administrator] was contacting faculty in my department a lot during this time, asking them to provide their perspectives, help him get a handle on how best to respond to things. Um, two faculty in particular in my department were called on a lot, both of whom were early career, not with tenure. Both of them were African American. And I also felt like I needed to say to them that I think what hes asking of you is inappropriate. I think he should be taking into account, you know, you, I want you to do what you think is best for you to do and you can decide whatever you want to do and Im going to support that. But I think its 
inappropriate that hes asking this of you. He should know better than to single out people of color who always gets singled out to be the spokespeople for all these other people and frankly putting you in a position as someone without tenure.

Jillian draws a clear connection between discursive and material structures and embodiment. Tenure here is seen as a script that provides ultimate protection. The script of tenure animates the employees' positionality, power dynamics within their roles, and their own values. This quote also demonstrates that this script, like many others, cannot be separated from the embodied experiences of the participants. Another script was discussed as particularily precarious and hard to navigate - that of being a staff member.

\section{Fragile position of staff.}

The participants who were familiar with staff roles discussed that the script and material reality of being a staff member left them feeling unsupported and overextended, particularly during the student-led protests and the semester that followed.. Staff members discuss that the structure of their roles is uniquely different in that they provide logistical support to keep many of the processes of the university running, but that this work was not reflected in the compensation they receive nor the status they hold, which ultimately informed the way they manage identity during this time. Kartina, a staff member and a biracial woman, who has been with the university for over 10 years specifically positions the staff role as being less secure, seen, and stable than the faculty role:

Its either faculty, its tenured faculty, its nontenured faculty. Students and adminis tration.

Staff are left out, like were hidden. We, we run the university from everything from getting them (students) here to getting them graduated and we are behind the scenes. Nobody acknowledges the work that we do. Everything comes out about faculty and staff 
or faculty and students just like, no, no, no. Youre missing the biggest employee of everything at the university - staff.

In this quote Katrina establishes staff role as "hidden" despite all of the work that people in this role accomplish. For Katrina this is a question of identity management, she sees herself as valuable and capable of doing important and quality work that contributes to "running" of the university. Yet, "nobody (meaning the organization) acknowledges the work that (staff) do." During the protests she felt even more marginalized and the staff role did not leave her with helpful scripts for identity management. Katrina shares that "it was frustrating because no communication was being given to us." She must pull on other resources to manage her identity This is a discursive and embodied process. I could see a lot of emotion in Katrina's frustration and tears during the interview. It is this staff script that was limited by the organizational hierarchy that left her feeling marginalized.

In addition to discursive construction of identity, the structure of a staff role has material consequences as well. Andrew, a white staff member, explains the material barriers present: "non-exempt staff are usually lower wage earning, not always. Theyre subject to progressive discipline. They can be given verbal warnings, written warnings, suspension and termination. Theyre usually in their non -exempt positions more dependent on that revenue stream." This structure where staff are both seen as replaceable and are very dependent on the revenue stream puts staff in a bind where they must navigate their identity in a way that may cause internal conflict.

Sema, a white staff member, discussed an example of such conflict that occurred during the protests. Sema was asked to come in to work on the day the campus experienced threats of 
violence. She discusses her own fears of coming in to work, and her conversations with her son (a student at the university), who also feared for her safety:

I had a very awful conversation with [my son] the night that the social media threats came out against black students on campus, and he was begging me not to go to work that day (..) I was like, "I have to." They told the faculty and the students they dont have to show up, but they dont care about the staff.

Sema expressed deep sadness about the position that she found herself in - her son wanted her to not be in danger, but her organizational responsibilities were to go to work. Sema sees the organization as doing two things: one, structuring the job responsibilities and roles, and two, producing scripts about what people in those roles can and cannot do. The structure of the staff role is creating specific fractures and barriers for identity work. Here Sema engaged in identity management process where the scripts of motherhood and script of professional role (staff) were in conflict. The larger point that I made earlier remains - individuals pull on many available scripts to manage their identity. The participants considered their specific organizational hierarchy script and did not find clarity in that script. Their place in the organizational hierarchy left the participants feeling unsafe.

I want to further elaborate on this staff and tenure script as an embodied process. I have mentioned throughout the examples I provided that participants expressed a lot of strong emotion (typically associated with sadness, frustration and fear ${ }^{13}$ ). Navigating the scripts to manage identity was not only a discursive process, but an embodied one. This process also connected to

${ }^{13}$ Furthermore, I found myself experiencing embodied effects of the interviews. After particularly grueling interviews (like the ones that I pulled exemplars from in this section) I experienced headaches and nausea. While I cannot prove direct correlation, I can say that the silencing that the participants experienced had an effect on me as an interviewer. 
the material reality of job loss and wage discrepancies that Andrew mentioned. The identity management process encompassed discursive, material and embodied elements. Next, I continue discussion of scripts, highlighting occupational scripts that the participants were able to utilize to greater extent in identity management.

\section{Occupational scripts.}

Many participants shared that they relied on the knowledge, skills, and discourses of their chosen professions to construct their identities in the midst of a student protest. Participants had limited success with building identity through organizational and professional scripts, and organizational scripts offered a set of discourses and practices that allowed the participants to build identity and practice resilience. The student protest movements put in sharp focus the fact that individuals do not rely exclusively on their job title to build identity. This is important as the job title can be seen as generating a kind of a script that the organization provides (though I am not referring to the script of silence here). Going outside of this script again signals that the script itself is not sufficient and the participants use what they know to supplement it. For example, Allana discusses that it is her training as an archaeologist that helped her make sense of how to best relate to students. In this exemplar she shares a story about going to the site where students were starting to build a camp and putting her knowledge to use to help students:

And so my job was to be sure that they were okay. In my mind. Nobody asked me for anything. I didnt explain it that way. I just went. Look, Im, Im an archeologist. I spend most of my life on the field. I know how to put up tents. If nothing else, I know how to do that. They did not. So, when I was there, the first thought it was like uhh. I didnt say anything. And one of them struggled and I just kept looking.... Didnt say anything because I didnt come to them: "Let me just h elp you." Because thats not [my] place. So, 
one of them looked at me and goes, "Do you know how to do this?" And I go, "Yeah, you need help?" He was, "Yeah," and that was Alex [a student organizer]. And they were very organized. And Alex was in charge of campsite. And so I finally told him and I said, "Listen, do you need to design the city and you need to have all your tents facing inside." Here Allana expresses that she knows that she wants students to be safe, but she does not have an organizational direction or script to ensure that safety. This phrasing "if nothing else, I know how to [put up tents]" points the fact that she must rely on her own training to make sense of what to do in this situation. Allana relies on her own knowledge as an archaeologist to make sure that students are take specific steps to be safe from the weather elements. She does so in a way that allows for the students to make their own decisions. She goes to the site and is physically present. Building tents is a physical activity and Allana's identity management here is an embodied process. The recollection of this event has embodied elements as well. Allana does not say "I helped build the tents," she reenacts the scene for me, using the dialogue and tone she used at the campsite. Identity management is an embodied process, and it is evident in these quotes.

Other participants echo Allana's comments when they say that they relied on their occupational knowledge and training (as advisors, lawyers, archaeologists, scientists) to make sense of their roles and their identities. In another example, Acadia discusses how she thought of herself as someone who had a very specific knowledge, which she labels as capital, to share. She discusses her role as a faculty member who talked to students in CS 1950:

And so when I met them all, I basically said like, hey, you know, what can I do to support you? Like, what can I do? Like seriously? [...] I also know that theres certain things youre going to need from faculty that you may not get from fac ulty depending on who your faculty are. You know, are you applying to Grad school? Again, Im in a [a 
particular field]. So, Im always thinking about that. Like, are you applying to Grad school? What are you doing for Grad School? What are the things that you need in order to be successful moving forward that I can help with? And so, so yeah, I remember [a student] was applying to Grad School and was like "Can you write a recommendation letter?” I was like: “Absolutely.” [...] So I wrote like 100 recommendation letters for everybody. And again, (..) this is what you do. Um, when you have power, you had the power of recommendation letters you give, you give, you know, you use that power to, you know, to bring others up.

Acadia is speaking to the occupational script when she says that she has the power of the recommendation letter. She refers to a specific knowledge gained through her organizational discourse to inform her identity management. She, like many participants, uses her role to contribute to managing her professional identity. These scripts become anchors that help the participants build a sense of normalcy in an environment that is desperately in need of stability. When asked about what identity became most salient, Ade says that it was one of "faculty member and a chair." She understands that a chair is responsible for certain administrative and logistics tasks and was able to accomplish those. She sees this as a reliable agenda: "Like, okay, this is crazy, but guess what, heres what you know, Ive got a class to teach today, Ive got research to do today. Ive got grad students to mentor today. [ ..] Were going to communicate to people that guess what, thats what were doing every day, the same thing we were doing yesterday." The notion of using familiar identity anchors to establish normalcy can be understood as one component of resilience (Buzzanell, 2010).

Participants also sought spaces for resistance through occupational scripts. Employees pull on occupational scripts to create spaces within which they can enact acts of micro-resistance 
to the overarching script of silence. While evidence of that is present in a lot of exemplars already analyzed, I wanted to provide a few explicit examples of how occupational scripts provided spaces of resistance to the organizational script of silence. Staff, faculty, and administrators create small moments of organizational clarity by operating both within their roles and in opposition to the institutional silencing. Alia provides an example of that when she discusses her work with writing a speech for her supervisor. She crafts sentences so that a close critical reading of them can reveal her own dissatisfaction and critique of the institution, yet are not overtly critical. I am omitting the actual language of the speech to protect Alia's privacy, but I am including Alia's explanation of how that speech functioned, to demonstrate how it was a direct response to the organizational scripts. She explains "like that little sentence that was resistance and nobody else would (see it), but I get a real kick out of that." The humor in her comment points to lessening the tension of resistance. Here I want to go back to a quote by a participant named Forrest that I have discussed earlier on page 77. He discusses a move similar to Alia's when he talks about the limits that were placed on him. He was not allowed to communicate via email to his staff, but he found a loophole as an act that he described as resistance when he talked about emailing the students instead. Forrest juxtaposes his professional title and the restrictions of that role with his professional values to craft spaces that he calls resistance. This resistance functions as a way for him to manage his identity in relation to his professional identity. He knows that the organizational script prohibits him from contacting the staff, even if it is via the students, yet he places his own values over the organizational script. Resistance to the organizational script does not imply support of student protests or the students involved. It is an act that questions and challenges organizational dominance and creates space for individual identity work. 
The participants were effective in finding identity management resources that stemmed from the occupational scripts. The primary resource for that were the informal networks, as they helped the participants navigate the institutional uncertainty. When occupational scripts did not provide sufficient resources for managing uncertainty, participants sought out other members of the same occupation (HR professional, communications specialist, administrative assistant, etc.) to build resilience and manage identity. I see these occupational scripts as identity building. Identity is a "communicative process and a site of struggle constantly negotiated through interaction with others and retroactive sensemaking about one's self' (Norander, Mazer, \& Bates, 2011 , p. 60). The scripts rely on shared meaning-making where the employees in shared roles cocreate the script and enact it.

\section{Professional networks and relational organizing.}

Occupational scripts were catalyzed by shared personal networks. These networks served certain discursive functions in that they allowed for sensemaking and were embodied representations of what the participants needed but were not getting from the organization: directions, support, and material resources. The process of forming networks was especially prevalent and seen as valuable on the staff level. While many staff members expressed that sentiment, Katrina offered the most descriptive comment:

Anna: So when you say that we didnt know whats happening, do you mean you and like other staff around you?

Katrina: Absolutely. So theres an underground staff support network, you know, um, especially being here over 10 years, I know a lot of the staff. So it was like: What did you hear? You're sending an email, or youre calling, you're text messaging somebody in another department going: 'Whats going on over there?' And um, know. So I guess. Im 
very, I felt very fortunate that I had that ability to engage with other staff people to kind of just [say] 'what the hell.'

Katrina uses these professional networks to respond to the organizational script of silence in two ways: one, to find out information to navigate uncertainty ("What did you hear?") and two, to express frustration ("ability to engage with other staff people to kind of just [say] "what the hell."'). Katrina is privileging and relying upon a co-constructed subgroup's communicative information sharing norms (that do not obey the script of silence). Just because the organization developed the script of silence, does not mean that the employees supported it. They navigated around that script by forming occupation-based networks. This example demonstrates the importance of professional networks based on a shared staff role. The occupation-based networks serve as ways of gaining direction and information in a situation where the institution only provided a script of silence. This interpersonal talk fills the gap that the script of silence leaves behind. This talk allows for administration, faculty, and staff to create normalizing scripts about their roles.

Employees sought out and created informal groups because they did not feel like the script of silence was adequate. Alia, a staff member, demonstrates this point. Alia shared that she kept asking her supervisor, an executive administrator, for directions and was not receiving any clear action steps:

I figured that out, like that moment, that conversation with her is when I realized, okay, Im on my own. Ive just got to do what I think I need to do. And then from there I did it and I pulled together a group of people, just informal group. We were meeting daily every morning to kind of touch base on whats where and what do we need to manage and who 
needs to do what. And everybodys working outside the job descriptions at that point, you know, triaging, emails, voicemails.

Alia here articulates that she gathered informal group because she did not receive directions from her supervisor. The idea of "working outside the job descriptions" hints at shared sensemaking that occurs in these groups. This quote also suggests that professional identities are not the same as job titles.

The participants discussed that one of the reasons that the strategy of organizing in these networks was beneficial was that the script of silence created a lot of fears. These informal networks allowed the participants to sensemake together and create space to think about identity with a group of peers. Jim discussed an informal network that was built among staff members in a similar role and noted why that network needed to be invisible:

And um, and there was one meeting where we actually sat down and we said, you know, "I dont know whats going to happen. You could get fired. I just want you to know that." And this was like one person was talking to the whole group of my peers. And um, we, were saying we dont know whats going to happen, but you know, this is what needs to happen for our students and if we get fired, we get fired. But, so if youre in, youre in, if youre out, youre out, um, but please dont share that with your supervisors, that kind of thing.

Jim here discusses that he was a part of an informal network of people in similar roles (entry level professionals), which demonstrates an important concept - participants privileged an action-oriented script promoted by other coworkers over the organizational script of silence. The group discusses "this is what needs to happen for our students" and I see that as a way of negotiating identity. The group discusses who they are in relation to the protest (people who 
know "what needs to happen for our students"), who they are professionally, who they are in relating to each other. They are engaged in sensemaking around their identities.

Jim points to the fact that this network organized and then discussed a material fear of being fired that was catalyzed by the script of silence. However, this fear is outweighed by the need for an action plan (a script to engage with). Professional networks are tied to occupational scripts, as this exemplar demonstrates. Jim points to a very specific call or obligation "what needs to happen for our students" that he received through his education into his chosen profession (student support staff). The professional networks fuel the scripts generated by occupational roles. Occupational scripts allow the individuals opportunities for resistance to the larger script of silence. We see evidence of that throughout the exemplars in this chapter (e.g., Allana's occupation allows gives her skills to build tents). In the following section I broaden my overview from occupational scripts to the broader understanding of professionalism.

The participants also used scripts that seemingly did not have any connections to their organizational roles to build identity during student protests. The next script I discuss is the script of mothering. Female participants specifically discussed this script.

\section{Mothering script.}

Most female participants who I interviewed discussed the ways they engaged with scripts around motherhood to make sense of their identity in the movement, find motivation to be involved in the movement, and construct their identity in an uncertain time. Allana talks about motherhood as helping her construct an identity that distances herself from her university role. When she thinks about the role she played when she attended the campsite, she shares that: "Oh, Im just a mom, was never part of the university faculty. I was never anything because I was there as a mom, as a human, as a person." Allana's quote suggests that "mothering" does not fully 
replace one's role as a faculty, but it does provide a more productive way of engaging with identity than what the script of silence can offer.

\section{Mothering script as embodied care.}

Participants interpreted the mothering script differently when they described their involvement in the movement. Some considered their own children as a motivating force and asked themselves what they would like for someone to do for their children. Allana, who was present at the campsite and had a child who was often present at the site too, talks about her relationship with the students and her verbal responses as a literal script that she kept reciting:

So they call me mom and many of them still do. And so, my first order of question is:

"One, Where the hell is your blanket, because its cold. Have you eaten; what do you eat?

Wheres your blanket? And have you done homework? Because one thing is one thing, but you have to meet to finish your semester."

The phrase "one thing is one thing" serves to help students align their priorities and take care of their bodies and wellness with their goals in the social movement. Participants who identified as staff discussed how this mothering script overlapped with their professional roles. Katrina, a member of academic support staff, who has more complex feelings about the movement, shares that faculty often required her to do this mothering when they shared with her that students were not coming to class due to their involvement in the protests. Katrina was asked to provide care to students, by the concerned faculty: "So it was a, let me find you, let me text you, let me, lets have a real conversation about is it in your best academic interest to make posters or is it to engage in the academic process?" Again, mothering here is interpreted as helping students a make choice that are consistent with their (and arguable institutional) academic goals, while taking care of the student's embodied needs. Katrina continues: 
Im like, look, this isnt my job, but I n eed to make sure youre safe. Um, yeah. I mean, I donated blankets. I got blankets from my, you know, or supplies for those students. Um, thats not part of my job, but its, you know, you are staff and you are mom, whatever. The mothering script often was activated by the fact that these participants were themselves mothers. As Sema put it, her motivation was "this feeling of what would I want other responsible adults to do if my children were in this situation and needed assistance." Sema and other participants who pull on the mothering script to make sense of their identities see this script as a logical response to seeing students in what they perceive as a need of help. They are inviting mothering into their professional roles, to fill the void created by the organizational script of silence..

\section{Mothering script as paternalistic overinvolvement.}

The second interpretation of the mothering script was that of paternalistic overinvolvement. Nina, who serves an administrative executive and works primarily with faculty discussed her explicit pushing back on the narrative about taking care of students and what motivated her pushback:

You hear that "please take care of students." I always feel that its not about taking care, because thats demeaning the fact tha they are intelligent bright adults. What we need is to help guide them to be able to take care of themselves, it is not our role to take care of them. Thats really very tricky space that people often say, as administrators, we should "take care", but its not the right thing to do. (..) And people are very glib about that and "take care" because I think thats a bit... Condescending.

Nina's comment points to a tension between those who she sees as subscribing to the mothering script and those who do not. Here mothering label is assigned to taking care of 
student's immediate wellbeing needs. This way of "taking care" of students is labeled as condescending and demeaning to the intelligence and capabilities of the students. These two responses (mothering as embodied care and mothering as paternalistic overinvolvement) exist in such stark contrast partially because the organizational script of silence was largely seen as not productive. Participants who agreed with Nina discussed that this way of protecting the students by the individual employees is negative and paternalistic. Tamara explains "Theres like the protection of, of university and reputation and the work that we do and yes, we should be concerned about our students and their safety and their wellbeing. Um, but not in a paternalistic way." This last exemplar suggests that there is something curious and gendered happening here. The university (a seemingly disembodied entity) is seen as in danger of being paternalistic, yet individual actions of the female participants are seen as acts of mothering (which had more positive connotations). I will discuss the gendered nature of mothering script and ways it connects to the material constraints below.

\section{Mothering and gender.}

The script of mothering was tied to material and embodied pieces of identity management and was performed by women who identified as mothers (had embodied experiences with raising children) in ways that entangled the material and discursive. The act of mothering is traditionally connected with female gender roles and the script is concerned with care giving and providing for basic needs. The participants who described this script identified as female, there was no parallel "fathering" or "brothering" script that male participants identified. Some participants in my study put this in conversation with their embodied roles as mothers to young and collegeaged children (their kids who did and did not participate in the movement). Allana discusses that she pulled on her role as a mother in part because her daughter was frequently at the CS 1950 
campsite. As a part of her own parenting/mothering role, she sent her daughter away to protect her on the night Allana stayed back to help take down the campsite: "That was brutal. In that moment. I told [my daughter and her friend] to go [to a location downtown]. and I would stand on the ground." Here Allana engaged in the mothering script while her daughter was present. She explains the danger she felt:

The police was worried. If the police is worried, you worry. I just remember there we were just taking down tents and taking stuff and there was so much stuff. ...And eventually it became very evident that [MSA - student government came to the campsite] and linked arms to protect the black students and they walked them to the BCC.

Allana manages the sense of fear, her responsibilities as a mother, and the mothering discourse. She pulls all those together to make a decision about identity management at a time that feels very dangerous for herself ("If the police is worried, you worry"), her daughter, and the students she is seeing.

Malina, a white staff member, who shows me a photo of her white daughter surrounded by her friends (who look white and Black in the photo), all jubilant and with their hands wrapped around each other on the day the chancellor resigned, discusses the fears she had as a mother of a MU student:

At the same time, it can be scary because you go, "I put myself out there. I get slapped with the label and all of a sudden... Im not trying to lose my job." Your kids get hit with something because your parent now has a label on them, so its not just me. Im just trying to live my life. I want to help people, but how?

Malina indicates that her role as a mother connected to her responsibilities to her children and her role as a main provider (which she mentioned earlier in the interview). She also discusses the 
dangers of being a troublemaker (when she is referring to being slapped with the troublemaker label) in the organizational context. Tamara underscrores this material constraint with her desire to be supportive of the students: "Could I put myself on the line at this time to be arrested, given my responsibilities as parent?" Both of these participants discuss how they engage with their identity and scripts associated with motherhood in relation to protests.

Yet, the participants share that they also use these embodied mothering roles and scripts that flow from them to create spaces for resistance. For example, Tamara talks about her focus on the material restraints of being a working parent who relies on her paycheck. This discursive bind was challenged by her students who joked: "like, well right now youre the one with the paycheck." She continues: "So my student staff, they knew my children, they respected my role as mother, which was really like, thank you all, you know, like, um, so it was through them that I came to terms with. (...) I certainly can be the person who gets the call at the end saying I need bail funds." Tamara is leveraging the discursive, embodied and material to successfully construct her identity that is bound by the organizational script of silence and the material consequences of job loss. With the help of her students she reimagines the material bind of her paycheck as an opportunity to offer support.

Participants have discussed how their roles as mothers informed both their actions and the construction of their identity in relation to the student protests. Some have positioned this mothering script as paternalistic overinvolvement, others as the key script in helping them make build identity in turmoil. The last set of scripts I discuss describe how cultural and communal influences played a role in individual identity building. After that I clarify how the scripts were interconnected and embodied. While we see traces of this throughout the chapter, I wanted to explicitly point to those embodied connections. 


\section{Roles of culture and community in developing scripts.}

Background, family history, and current community played an important role in helping participants manage their identity. Similarly to the mothering and professional scripts, the cultural and communal scripts allowed the participants to engage with the experiences and discourses that have proved reliable in the past to make sense of uncertainty and build identity.

\section{Pulling from the cultural backgrounds.}

Cultural backgrounds played an important role in creating scripts that helped participants make decisions around protests. The reliance on scripts born out of cultural backgrounds suggests that identity management is a historically situated process ${ }^{14}$. A few participants pulled from their culturally-based narratives about seeking justice to make sense of their roles in identities in response to the organizational script of silence. Allana discusses her upbringing in a different country and her education abroad informed her thinking about her current university role:

I mean we used to have encounters with authorities where there was like a few students, and if youre not protesting som ething, what in the hell are you doing? So it was like, oh, finally something is up in here. Right. So it came back a second nature. The student needed something, you just need to go see what they need. Theyre protesting something that they feel they need to protest and the only deal that I needed to have as the adult in the group was to go there and say, "Hey, what do you need?" It went automatic because thats what we got when we were young and when we were protesting for this or that. In

\footnotetext{
${ }^{14}$ Here I mean individual and societal history.
} 
[the country she attended a university], students are very politically active. And I never ceased to understand the United State why people were so quiet.

Allana compares her experience as a student with what she is experiencing as a faculty member in the United States. She clearly refers to a well-developed culturally bound discourse that informs both student roles ("if youre not protesting something, what in the hell are you doing?") and her current "adult" role (that of unquestioning support). The cultural script helps Allana manage her identity as a faculty member who is rejecting the organizational script of silence.

However, moving from a different country that has a history of political instability and protest result in this specific cultural script. For example, Peter, a faculty member, discussed his move from a country that had history of violence and terrorism. He shared that he saw the behavior of the student protesters as irresponsible. Specifically, he described them as having "mob mentality." Peter found the organizational script of silence as sufficient for his identity management. Similar cultural backgrounds did not unquestionably predetermine the script that the participants used.

Some participants discussed their educational backgrounds as generative of the cultural scripts. For example, Terry and Jim discussed their own college experience with protests. Terry discusses his support of the protests of the Vietnam war and ways that this student protest "harkens back a little bit, to you know, my, my youth." Jim discussed his experience with Occupy and Iraq was protests:

I got to be like, on the ground floor of like, heres how a protest, like officially its organized. Um, and so I came back like just.. just fired up, like ready and like I tried to organize a protest or like a group of people at school. 
Both Terry and Jim connected their experiences of their college organizing to what they saw on campus in the fall of 2015. They pull on these familiar responses and scripts to make sense of their identities and have an alternative to the organizational script of silence.

Finally, a few participants point to their political background to manage their identity in the midst of a student process. Acadia, who identifies as an Afro-Latina and an immigrant, shares that her background allowed her to continue doing identity work in when the only organizational script was that of silence:

Because I feel like I had to navigate racial and ethnic, um, you know, racial ethnic forms of oppression, right? And so those things like that was part of what I talk about, like that was resistance capital. That was cultural capital.

Acadia discusses capital to mean an accumulation of knowledge, behaviors, and skills she has gathered as a part of her cultural identity as an immigrant Afro-Latina. She specifically positions cultural capital as her resistance capital. Acadia later connects her intellectual and scholarly work to the cultural capital as a part of her identity. As I mentioned earlier in the chapter, identity management is a constant pulling of all available scripts and resources. The word resistance here is important as it signals that this particular faculty member had specifics forces she felt she has to work against.

The exemplars above show the cultural backgrounds, and the related scripts give participants a better way of navigating their identities. Cultural scripts are connected to geography in ways that impacted identity management. At times participants experiences tension with managing their identities specifically because they had to navigate spaces that had different cultural expectations. The next section discusses this in detail. 


\section{Community as always present.}

In part to the University of Missouri's geographical location, many participants discussed identity management as not only occurring at work, but also taking place in relation to their communities (neighbors, spouses, families). This identity management involved many processes and raised many questions about organizational identification, embracing or rejecting communal and family values, and asserting one's own values. Many participants discussed the challenging nature of their daily drives from the university and into their communities, being stopped in grocery stores with questions about the organization they were a part of, and receiving numerous calls from their friends and family. This positioned the participants in place where they had to engage in particular kind of emotional labor within their identity management. Ade discusses these concepts here:

Well, I had to be a representative and a beacon for - beacon is not the right word, but essentially represent, um, the university in the community I lived in. So I lived in a very rural community south of here and um, you know, people read things and hear things and of course, you know, take very passionate stances on things that they have very little knowledge of. Um, and then just having this onslaught of people who knew me in the community who would just come up to me and just say these horrible, you know, and, and once we engage in a conversation, you know, in the grocery store and they want to engage in a conversation about this and ask me questions and so feeling sort of always on and not knowing how to speak about that in ways that are productive and helpful and respectful and you know, all of those kinds of things. So that one probably did go beyond the scope of the job in a lot of ways. 
This quote illustrates an important concept related to identity management. Ade discusses being a beacon or university representative in her community. This role is not something she selects as part of her identity management process, but something that is thrust upon her by the community she is in. She is performing identity management specific to both her role in the university and her role in the community. This positions identity management as geographically situated. Additionally, this quote alludes to a lack of a script that Ade is grappling with as a part of her identity work. She refers to pressure she feels to speak (or have a script that is) "productive and helpful and respectful and you know, all of those kinds of things."

Community impacts are also felt in family relationships. It is not uncommon for the university to employ multiple partners and multiple members of the same family. Throughout out the interviews I kept hearing examples about the ways the events that were happening on campus leaked into family lives. Many partnered couples discussed that the events on campus seeped into familial discourses. Dianne, whose partner also worked on campus at the time, mentioned that as a family they "didnt really talk about anything else at home other than what was happening on campus." This perception she shares about her home life at the time demonstrates that identity management is an ongoing process and that certain events can have lasting impacts.

\section{The cultural impact of whiteness.}

One theme that emerged in my analysis was the importance of whiteness that I could not quite analytically capture. Whiteness, specifically proximity to whiteness, was something that participants reflected on regardless of their racial backgrounds. They discussed roles the discourse of whiteness and the embodiment of whiteness played in their identity management. It is not a surprise that the participants engaged with the construct of whiteness as the protests specifically problematized race relations on campus. James Baldwin (1998) speaks to this 
construct of whiteness and what it produces when he discusses the historical origins of whiteness:

America became white — the people who, as they claim, "settled" the country became white - because of the necessity of denying the Black presence, and justifying the Black subjugation. No community can be based on such a principle — or, in other words, no community can be established on so genocidal a lie. (pp.178-179)

Baldwin called whiteness a lie, a construct created with a single focus of capturing and holding power. The participants in my study understood this power. They engaged with this power and grappled with how to use it.

A few participants who identified as white discussed their role in responding to protests. Whiteness was seen as a tool that could be used to either create resistance or afford safety. Participants who identified as white relied on a script that can be understood as "if I am white, I should use this power for good." Lane explains:

I think actually my racial identity was pretty important to me during that time. Um, I, I really felt that like as someone who was a professional on this campus and Im a white person who has an understanding of my own privilege and power in the world that I, I needed that to be supportive of our students and really do my best to listen to them and learn from them and support their requests and their, um, their identities during that time, you know, like whatever that meant.

Lane, a white female staff member discusses that she sees herself as a professional and as a white person. She seems to prioritize the professional role, but mentions her identity as a white person and is someone who understands that her whiteness carries privilege. This white identity seems to have a script: "listen and support our students." The students here are the students who are 
protesting. Further, the words "whatever that meant" seem to portray that the script here is shaky and uncertain. Lane understands that she needs to listen to the students who are protesting, but does not quite articulate the power in whiteness or how it impacts her identity management.

Jillian discusses a similar struggle around her understanding of her white identity. She is commenting both on the intersection of her identities (which I will discuss in greater depth in the next section) and what her white identity is producing.

Im white, that matters, that matters in that, in what happened in 2015 . Um, because I have privilege and I have power and I want to recognize my privilege. And I also need not to be, you know, like white fragility thing, you know, its, so its working through that as well. I think, you know, and I probably came to terms more with that at that time that I had previously just because the topic was at hand. I mean it was there and I had to face it and I didnt have to face it. I had to face in other circumstances but not nearly to the same extent. Um, and so I would say thats part of the identity, part of my identity that really mattered as well.

Jillian discusses how the whiteness and white fragility was something that she specifically had to manage because of the protests. It appears that Jillian recognizes that whiteness was part of her identity that mattered specifically because of the proximity to the protests and the events on campus.

Jim, a white male, discusses how the events on campus informed his role and his understanding of what his white identity meant to him: "Like I feel like thats kind of where my responsibilities lie as a white male, especially in Missouri where its unsafe for some people." Here he talks about his obligations to "speak to folks who wouldnt, normal ly speak to someone who is different from them or looks different than them, knowing what I know. Im about hearing 
about experiences from people who have a more minority identities and things like that." These participants discuss that their own script around whiteness functioned to inform them about action steps white people should take during protests. This script of whiteness (when enacted by participants who identify as white) still holds the protests at a distance from the participants. Participants who are not white have to navigate an organizational script that only sees whiteness as a norm. Alia talks about her "non whiteness." She discusses her presence at the campsite. The exemplar below evokes how scripts around whiteness are discursive and embodied and can produce very specific effects on identity construction. Here her identity is positioned in direct relation to whiteness:

I did take things to the campsite. That was definitely outside of my job description. I took my daughter down there and my husband, hes white and he works [with a prestigious employer] downtown and it was really eye opening for him. I didnt actually want to take him, like I didnt want to go with this white guy that because he and I have had disagreements and we, theres def initely been some discussions that in terms of identity, it made me realize how not white I am.

Alia understands that there is power in this construct of whiteness. She sees her position in relation to that power specifically when she is at a campsite with her white husband. Writer Zora Neale Hurston means this interaction of space and race in identity production when she says "I feel most colored when I am thrown against a sharp white background.” Alia discusses her proximity to whiteness as seen by white people:

Obviously I present an Asian American, I walk into a room and I looked different. The interesting thing though, and I dont know theres a term for it, but I feel like a lot of folks look at Asians, and they see whiteness or some form of whiteness, not whiteness because 
theres still otherness there as well, but its an assumption that I think like a white person. Before November I had more than one white man tell me: "I just dont see it" Because Like, well why would you see it? Again, Alia is speaking to this embodied and discursive concept of whiteness. The white man discursively pulls Alia under the umbrella of whiteness. He makes an assumption that Alia is "white enough" so she should "think like a white person" (which I read as think without seeing discrimination). The white man in this quote refuse to "see" Alia's racial/ethnic identity. Whiteness as a social construct seems to co-opt all Alia's Asian American identity. She is told that she must identify and "see" things similar to what the white script calls for. This call to "see" events in a specific way evokes the organizational script that privileges whiteness that I discussed earlier. Participants who identify as white may struggle with articulating and managing their whiteness within this larger organizational script. Alia does not discuss her Asian American identity - she only discusses herself as "not white" - positioned in stark contrast to this organizational white background.

These exemplars serve to illustrate how whiteness is both a discourse that engages institutional and cultural contexts and an embodied power laden construct that has the ability to animate organizational scripts. Participants who identify as Black, Asian, African American and Latino are aware of the scripts that are placed on their bodies. Most participants pull on the scripts created from this discursive-material entanglement to make sense of their role within the organization and manage their identity.

\section{Pulling scripts together.}

In this chapter I have discussed how organizational scripts provided administrators, faculty and staff with limited options of sensemaking around the protests. I have also traced the 
scripts participants use to manage their identities during protests. My data analysis showed that specific discursive and embodied tensions emerge as the participant are integrating various scripts to manage their identity. This process creates a liminal identity. The notion of liminality, meaning "betwixt and between," has been developed in social anthropology (Turner, 1967) and has been adopted by some organizational researchers (Tempest and Starkey, 2004; Sturdy et. al., 2006). I start with a discussion about how the participants blurred boundaries in identity management scripts. Then I discuss the ways participants navigated invisibility and visibility as a discursive embodied intra-action.

\section{Blurred boundaries.}

Participants discussed a challenge of drawing clear distinctions and boundaries in various responsibilities, values, and scripts that they engaged to manage identity. These challenges occurred in ways that were discursive and embodied. The participants navigated different organizational, professional, and personal roles and the corresponding scripts. They saw multiple scripts as distinct while acknowledging that a clear separation is not truly possible as the scripts informed and leaked into one another. Dakota articulated this tension around boundaries and identity work.

Theres so many pieces of this, like being a [field] expert, whos actually g ood at communication, how can I use that not only to help the university get past this, but to help us move into a better place for both diversity and equity issues for students to just be a better place? How can I use my professional identity, my scholarly identity, my persona out there? Thats a different identity, how people see me. (..) How can I bring all of those to bear to do what we need to do, all those identities into one place at one time? I feel like there is a conflict: like this idea is not going to work for me here because I got this thing. 
It was more like how can I take all these pieces and put them together to really support the university at this moment in time and the department at this moment in time? Identity management here is articulated as pulling on different scripts (professional, scholarly, "persona" - which I interpret as cultural background) to answer questions such as who Dakota is and what identities Dakota holds in relation to the organization, to her students, to the "better place" she is trying to create.

The questions of identity management blur boundaries because identity management is always material, discursive and embodied. Many participants had roles and responsibilities that physically put them in spaces and in conversations that made identity management challenging. Dianne talks about her professional role and identity:

I felt and continued to feel very strongly that my role on campus for [... years was to be an advocate for students, you know. And that is a layered thing. ... I think that there is a misconception [about giving in to students' demands] but really its more, student development, very focused. And understanding, stages of growth and development and where folks are positioned and my training as a social worker, Im also considering personal environment. And all these contexts that bring the person to our doors at the university and then all of their experiences once theyve gotten here. And that I think was part of what made those experiences so - I mean, they were professional but they were personal too. Those lines were blurred very quickly. And youre sitting with someone in their pain and trauma and injustice and, you know, a feeling that within as well and for them and then also, understanding that this a movement if you will.

Again, identity management here is discussed as pulling on different scripts: occupational (“social worker"), personal ("sitting with someone in their pain"), and professional ("advocate 
for students")) that causes blurring of lines. Dianne also positions identity management as happening in relation to another - a human who is sharing space and trauma with her. This image is evocative and embodied - sitting with another to negotiate identity, connection. Both the interpersonal connection and the identity work are influenced by roles of the institution ("all these contexts that bring the person to our doors at the university") and the larger social forces (“their pain and trauma and injustice').

Organizational events created blurred lines between the professional and familial relationships. Alia, who is non-White woman married to someone who does not share her racial/ethnic identity, discussed how her identity was impacted during that time. During the week of the campus protests and the time the student government president was called an N-word on campus, Alia attended a dinner with her family, who were dismissive of the students who were protesting and rejected the idea that racist incidents happened on campus. Here she had to navigate among multiple competing scripts where family played an important role. The one I focus on in this exemplar is connected to her script as a family member. Alia shares the following:

What do you, what do you say to that? ...I mean I havent spoken to [the family members featured in this exemplar] since homecoming and that was Friday. That was even before the parade. Um, because I showed up to dinner. Oh man, that was exhausting. We had had that Monday or Sunday night, Monday morning, the LBC candidates have been called the n word, personally knew the LBC king. Um, well he would be voted King. So Im thinking all this is a, [whispers] - shitstorm, this is going well [said with sarcastic tone], and then I show up to dinner and Im exhausted and [a family member] wants to pick a fight about this. "Well, I dont know what the chancellor is doing, blah, blah, blah and 
theres no racism." And I was like, "well, I disagree" but I really dont want to [say anything]. I was trying not to. I didnt want to have the conversation, you know? And [the family member]kept pushing it and [another family member] said, "Well they just dont need to talk about it." And I was so upset.... I said, "our students are devastated. Im devastated for them," and then I ran out of the restaurant crying. That was awesome. Alia's story demonstrated that community, family relationships, work, race, and ethnicity are all interconnected in the way individuals manage identity. These entanglements cause familial and identity conflict. When I shared a draft of this chapter with Alia, she mentioned that in this incident the thing that was the most impactful was the statement that "they" (the students) do not need to talk about the racist incidents. It is this "they" that cut and made Alia feel othered and alone. This experience viscerally brought her back to the childhood experiences of being mocked about her race. This example demonstrates that the identity work process is embodied and connects professional, familial, and childhood events into one entangled process.

Another element of pulling multiple identities together has to do with the gaze of others in the institution. Many participants, specifically those in administrative roles higher in the institutional hierarchy, described their existence in the institutional gaze as a process of perishing of their individual identity in favor of being viewed as a part of an organization. Forrest, a senior administrator, described the following:

You know, we cant always separate Forrest the administrator from Forrest the person and I started to realize that anything that I might do might be viewed as an institutional response. And the fact that we were getting - not only getting no direction but a lot of discouragement for that just made that even more confusing and challenging. 
Forrest struggles with the fact that his identity management process is so sharply tied to his role in the institution. He does not get to enact his identity without that enactment being interpreted as a part of the organizational script. Forrest suggests that his identity is deeply connected to his position in the organization.

At times, this identity work and its visibility created a tension that the participants also tried to resolve in discursive and embodied ways. Specially, the participants discussed their desire to occasionally be invisible. The next section explores what this work of invisibility and visibility means in embodied identity management.

\section{Managing identity as managing visibility/invisibility.}

The identity management process sometimes caused tensions that the participants attempted to resolve by attending to the roles discourses and embodiment played. This identity management often meant navigating embodied issues of (in)visible presence in spaces where visibility could cause specific material harm. In these spaces the individuals discussed moves they made to remain invisible. The possibility of harm was particularly true for participants who identified as Latinx, Asian, and Black, or identified as staff lower in the organizational hierarchy. Conversely, people who identified as having identities that are historically privileged described themselves as not having the ability to support the cause, as they were seen as the representatives of the university (See Forrest's quite about visibility on the previous page) Acadia first mentions this idea early in our interview when she talks about being a woman of African descent "You know, my work is to typically on display, Im usually typically on display." She elaborates what that being on display means for her in her everyday identity management and visibility for her and her colleague (another woman of color): 
We were being unseen as far as university campus type stuff. Unseen to the point of like: We will be involved, Ill be present. Students will know where Im present and Im here for them individually and collectively to do this thing. But as far as like media, right? So, first of all, [my friend] was like, these fucking assholes, will fucking tear us down, like dont fuck with the media. So I was already like super scared of the media. So like I wouldnt, I didnt like grant interviews. Like I had gotten requested to tons of interviews and I was like, oh no, no. I was like, nope, not doing shit. Im. Beca use I was just like, I cant, like Im not tenured, not protected.

Acadia discusses the fact that she needed the protection of tenure to afford to be seen as supporting of students. She also mentions that it is her colleague, another woman of color, who advises her on ways of invisible to the media. This is a very specific kind of identity work that is being performed where one wants to remain visible only to those that share specific goals and values.

Katrina, a staff member who identifies as biracial, also shares this identity management strategy: "Um, I, I made sure I was, I did my best not to be seen in those [spaces around the protest cites]. I made my, I made sure I was seen by students, but I was making sure I wasnt seen by others." Earlier in the interview Katrina shared that while she may not have supported all of the strategies and tactics of the student movement, she wanted to show support for the students. Cathy, a white staff member, also shares this strategy: “There were times where I wanted...I desperately wanted to be more visible, but I knew it couldnt be more visible." Katrina, Cat hy, and other participants who discussed visibility explicitly discussed that they wanted to remain invisible because of the fear of negative consequences of being seen. This fear included job loss, change in professional reputation, or being seen on national media. Invisibility and visibility as 
an identity management strategy seems to be in conversation with the organizational script of silence. The employees who engage in this work acknowledge the script of silence (by voicing the need to be invisible). Yet, they rebuke this script by taking steps to be visible in limited and strategic ways. Here identity management is positioned as a part of public-facing performance, where the participants who are engaged with thinking about the protests navigate the physical spaces in very intentional ways. Allana mentions this embodied public movement that engages organizational discourses when she talks about her supervisor questioning her lunch time trips to the student campsite:

I took my lunchtimes and I just went [to the campsite]. And the person that was my supervisors said: "How come you never see you on TV?” I said "I dont know... because I wasnt next to the chancello r?” meaning Im not hiding when Im doing, but its my lunchtime, right?

Here Allana adheres to the organizational expectations (that she should remain silent) by positioning her body away from the chancellor so she remains invisible and off camera. At the same time she maneuvers around the organizational script of silence in a way that allows her to still be present at the campsite (supporting the students). The visibility and invisibility provide a palpable embodied tension - after all, one cannot remain materially invisible. This tension informs how participants navigate their identities.

Allana's supervisor assumes that all those attending the campsite will eventually be on camera, and thus seen by the institution and the larger publics. This script is a curious inversion of the panopticon. Foucault wrote:

He who is subjected to a field of visibility, and who knows it, assumes responsibility for the constraints of power; he makes them play spontaneously upon himself; he inscribes in 
himself the power relation in which he simultaneously plays both roles; he becomes the principle of his own subjection(1995, p. 203).

The supervisor seems to be speaking to this panopticon - if one disobeys the organizational script of silence, they will be seen by omnipresent cameras. Yet, the participants seem to briefly escape the panopticon by being strategically invisible (staying off cameras and not granting interviews), coaching each other of the dangers of the destructive gaze ("these fucking assholes, will fucking tear us down, like dont fuck with the media”), and prioritizing being visible in spaces that will not cause them harm.

My analysis revealed that the participants managed their identity in discursive and embodied ways so they could navigate the script of silence (which at times meant showing support to students). This chapter positioned identity management as a process where participants are engaged in constant pulling together of scripts (in ways that are embodied and discursive) and testing them in conversation with material realities of organizational controls. These scripts are found in organizational hierarchy, occupational backgrounds, mothering and cultural backgrounds. I discussed identity management as a complex communicative and embodied process that is created in and continuously affected by material, social, and political forces. Next I discuss my theoretical mad practical contributions and provide concluding words. 


\section{Chapter 5: Discussion}

The primary question that guided my dissertation project was: How do administrators, faculty, and staff manage identity during student-led protests on a university campus? I focused on the university as an important catalyst for individual identity negotiation, creation, and maintenance, and I examined how administrators, staff, and faculty negotiate multiple conflicting identities during a student-led social movement. However, the organization only provided one script - a script of silence, that employees did not find sufficient in providing proactive directions for managing their identities during a turbulent time. The organizational script of silence was enforced explicitly through supervisors and reliance on legal discourses and implicitly through what I call a "nothing to see" sub-script. The organizational script silenced employee communication and directed employees to not engage with the protest. The employees built on other available scripts to supplement, engage with, and, at times, resist the organizational script as a means of managing identity during a student social movement. These additional scripts were located within the discursive and material constructions of organizational hierarchies, occupation, mothering, and cultural backgrounds. Employees managed identity by engaging with these scripts in discursive and embodied ways.

This chapter starts with answers to the research question. Next, I discuss the contributions of these results to the practical and theoretical problems I have explored in my dissertation. I started this dissertation with three research questions, which I will answer below. In the process of my data analysis, as is often the case with qualitative research, another question emerged ${ }^{15}$.

${ }^{15}$ Grounded theory studies what emerges from the analytic process over time, rather than being designated a priori (Clarke, 2012). A theory is "grounded" in data from participants who have 
This question was: How do administrators, faculty, and staff manage identity during student-led protests on a university campus? In my answer to this question, I am offering a grounded theory of identity management during a social movement. I discuss the theoretical, methodological, and practical implications of my project. I conclude the chapter with a discussion of the project's strengths, weaknesses, and possible future directions.

\section{Original Research Questions}

Here I discuss the three original research questions. These questions focus on identity, resilience, and embodiment as important parts of the identity management process. I explore both identity management and identity conflict. Later I will discuss the research question that emerged in the data analysis process.

\section{Research question 1: How do individuals craft identities in resilient ways in}

\section{moments of social change?}

My research demonstrated that individuals rely on multiple strategies to craft resilience in the process of identity management in moments of social change. Here I take Richardson's (2002) definition of resilience as "the process of reintegrating from disruptions in life"(p. 309). First, administrators, faculty, and staff rely on what Buzzanell (2010) theorized as existing identity anchors to create resilient responses during moments of uncertainty. Individuals affirmed their identity anchors, defined as "a relatively enduring cluster of identity discourses" to make sense of student protests and create identity (Buzzanell, 2010, p. 4). In analyzing the data, he resilience strategy I saw most frequently used was affirming identity anchors (through

experienced the process, thus, guiding questions may shift to better reflect the emerging theory (Charmaz, 20014, p. 1). 
connecting to the occupation, and establishing and using personal networks). Individuals built resilience by relying on "a relatively enduring cluster of identity discourses upon which individuals and their familial, collegial, and/or community members rely (Buzzanell, 2010, p. 4). This identity work was done as a means of individuals explaining who they are for themselves, in relation to each other, and in relation to the organization that they were in. Individuals discussed relying on identity anchors created through affirming discourses found in their chosen occupations. For example, Danielle discussed her values developed as a part of her training as a social worker to construct resilience and manage her identity during student protests. Another participant discussed her training as an architect to inform her role in physically guiding the construction of the campsite. Participants relied on previously developed clusters of identity discourses to explain to themselves (and to me in the interview process) their role in relation to the process in a situation that was tenuous and confusing. Notably, most participants, regardless of their level of support of the student protests, utilized identity anchors to manage identity in resilient ways.

Second, participants communicatively developed their identities and built resilience through maintaining and using communication networks. These informal networks existed outside of the main bureaucratic, officially-prescribed communication networks. The participants relied on their intraorganizational social capital to maintain networks across the organization in order to survive a shifting, fear-laden, and uncertain organizational environment. While a lot of participants relied on the communication networks, this process seemed to be especially important to employees in lower ranks of organizational hierarchy who perceived to have less access to information and decision-making power. In the interviews I conducted, the employees that held similar titles to each other, such as administrative assistant or entry level non-supervisor 
staff, most readily discussed their reliance on informal networks to share information and create resilience.

A final thought that I offer here is the notable lack of resilience that my findings revealed. Literature discussed in chapter 2 outlines strategies individuals and communities use to go back to normal, but not the conditions that make it possible for those strategies to be implemented. In other words, we know how resilience is possible but not when it is unattainable or undesirable. My findings reveal that some participants used resilience strategies some of the time. However, largely participants seemed baffled when I asked them about resilience. Once I encountered that I modified my interview protocol by including probing questions, different language around the concept of resilience, and deeper follow-up questions. This change did not produce different results. Future research may explore the concept of resilience and when individual resilience is not a possibility in more depth. Two ideas converge here: first, resilience is conceptualized as an active agentic process; second, the University of Missouri is arguably back to normal (here I am using retention and lack of national scandals as a measure of normalcy). These two ideas raise a question about how, why, and if the University of Missouri is back to normal, considering that the employees interviewed in this project did not identify as actively being resilient. Is resilience possible without us choosing to be resilient (what is the connection between resilience and agency)? How can we determine that an organization is "back to normal")? Perhaps we cannot use retention and lack of national scandals as our primary metrics for determining resilience. Future research will examine how organizational resilience and individual employee resilience intersect and coexist. 


\section{Research question 2: How, if at all, do people manage identity conflicts in moments}

\section{of social change?}

My data revealed that one of the main sources of identity conflict that participants experienced was the lack of a proactive organizational script that provided a way for employees to build identity that fit with their other social identities. Employees were only able to identify the script of silence, which they described as insufficient in helping them build identity and create a clear narrative of the events happening on campus. Participants discussed their fears of possible job loss and other negative consequences if the organizational script of silence was not followed. For example, Jim and Stevie discussed how rumors about possible job loss created instability and uncertainty. Cathy discussed explicit threats of termination her supervisor made in discussing what would happen if she went to the quad that was the site of the protests. Participants discussed a sense of trauma and loss that emerged as employees were navigating their space in relation to the organizational roles and other aspects of their identities, while struggling to create a sense of normalcy.

\section{Research question 3: What role does embodiment play in the process of identity creation and maintenance during social change?}

My research also sought to understand how embodiment played a role in the process of identity creation and maintenance during a period of social change. Ellingson (2017) theorized that embodiment is not simply thinking with the body. Embodied research refers to complex and active engagement with reflexivity and methods around the following key concepts: doing bodies, sticky web of culture, sensorium, actants, intersubjectivity, embodied knowledge and flux. Perry and Medina's (2011) definition captures these elements. They define embodiment as: 
Bodies as whole experiential beings in motion, both inscribed and inscribing subjectivities. That is, the experiential body is both a representation of self (a "text") as well as a mode of creation in progress (a "tool"). In addition, embodiment is a state that is contingent upon the environment and the context of the body. (p. 63)

Employees discussed ways they managed identity through negotiating invisibility and visibility in the relation to the organizational script of silence. (In)visibility is a particularly interesting and important concept, as it is impossible to be invisible. However, participants discussed ways and spaces in which they chose to not be seen. Some discussed their decisions and efforts to not appear on camera, grant interviews, or walk in spaces where student organizing took place as a way of managing their professional identities. This decision can be understood as complying with the organizational script of silence, which in an embodied sense expected their absence from protest spaces and actions. Others discussed subverting the script by being "visible" to students who needed support. The embodied tension of visibility/invisibility revealed how participants navigated embodied-discursive intra-actions to create and maintain their identities.

Participants also discussed the embodied experiences of trauma and tension connected to identity management processes. Participants discussed having surgery, miscarriages, insomnia, anxiety, and weight changes that occurred during the student protests. Remarkably, many participants discursively separated these personal embodied happenings from what was happening at work on campus. The participants conceptualized these traumatic bodily experiences as somehow separated from ways they managed their identity at work. The employees discursively prioritized the organization and its needs by de-prioritizing their own body and the trauma it carried. For example, Christopher discussed his weight loss of 10 pounds, which he attributed to prioritizing the organization and his work over his own body and trauma. 
Participants discursively backgrounded the body and foregrounded organizational instability as the primary focus of the identity management work. However, the participants did refer to the semester as producing trauma; many expressed sadness, cried during the interviews, and discussed the anxiety that the semester produced. Moreover, the participants discussed the ongoing nature of trauma that managing identity during a student movement produced. Many started the interview process by expressing that they may tear up at some point. Participants' embodied experience of tension was connected to the identity management process.

In the process of analyzing my data, I realized that while my original research questions produced interesting and important findings, they did not fully capture the process of identity management. Charmaz (2014) explained that grounded theory research is not linear: "quite often we discover that our work suggests pursuing more than one analytic direction” (p. 18). In this case, my initial questions led to a larger question that encompassed the identity negotiation process more fully than the original questions did. I still shared the answers to the original research questions above to maintain methodological transparency. In this next section, I present and discuss the overarching research question and results that developed out of the grounded theory process.

\section{Primary Research Question: How do administrators, faculty, and staff manage identity during student led protests on a university campus?}

Analysis of my data shows that the geographic and historic material realities of the University of Missouri provided a fruitful setting to study identity management during a social movement. While the site of my research is a college campus, social movements are a common occurrence nationwide, making this question relevant beyond this one campus. The discursive and material conditions that were in place at the University of Missouri animated both the 
organizational discourses and individual identity management. The university produced the organizational script of silence that employees engaged with. When employees did not find the script sufficient, they generated their own in order to manage identity. Next, I elaborate on the identity management process that my analysis revealed.

My analysis suggests that, faced with student protests, the university provided the employees with a script of silence that directed employees to be silent about the protests and the institutional response. The participants shared their perceptions that any overt discussion of the events surrounding the protests and the university response was strongly discouraged. The organization enforced this script in ways that were explicit and implicit. Explicitly, the organization enforced the script of silence through communication by supervisors and reliance on legal discourses. Implicitly, this script was enforced through lack of any directions from the university on how to handle the day to day occurrences and atypical crisis related events.

I theorize that the organizational script of silence can produce meaning and impact identity work for the participants. Administrators, faculty, and staff turned to the institution during the protest to help understand their personal and professional identities. This organizational script impacted all of the participants. Some participants agreed with the university stance of not engaging with the students, yet felt that the script of silence impacted their professional identity negatively. They felt confusion, saw lack of direction, and experienced uncertainty. The participants who were supportive of students felt conflict between their professional, organizationally provided scripts, and the pull of other scripts connected to their identity. I elaborate on that process below.

Many participants found the organizational script insufficient and, therefore, turned to other familiar scripts to manage their identities during the student-led protests. The participants 
pulled on and interweaved other familiar scripts to manage their identities. As noted in the discussion of RQ2, the other scripts that I identified in analyzing this data were: organization roles, occupational knowledge, motherhood, and cultural background. First, organizational roles: many participants discussed that the structural elements of their work were infused with scripts. Specifically, the tenure script was that tenure was the only structural element that offered tangible material protection that all other employment statuses (staff, nontenure) lacked. Participants used this script to manage their safety around engagement with the protests. Second, occupational knowledge: many participants relied on training they received related to their chosen fields and occupations (e.g., social worker, anthropologist, lawyer) to make sense of their identity and determine what actions they should take during this time of upheaval. Third, roles as mothers: some relied on a script I call "mothering" to provide care through checking in with the students protesting. They asked questions like: "What would I want for my child to experience as care in this situation?" to guide their actions and make sense of their identities. Finally, the participants engaged with the experience of marginalization found in their own cultural backgrounds. For example, Tamara discussed her cultural upbringing, which was marked by obedience to authority. This upbringing informed the way she managed identity and impacted her decision related to her involvement with the student protest. Another participant discussed her LGBTQ identity and experiences of marginalization as she made decisions to support the student movement. Not all participants supported the student protests and their goals. However, all participants responded to the organizational script (centering silence) by pulling on and supplementing with additional scripts in order to construct their identity during the campus protests. 
Participants discussed embodied practices in terms of managing visibility and invisibility. These practices were especially important for those participants who had to negotiate where they could be seen regardless of their involvement or support of the protest. Many were aware of and wanted to avoid the institutional gaze (connected to the script of silence). As such, employees, particularly women of color and individuals with other marginalized identities, discussed discursive and material spaces in which they had to remain invisible. They distanced themselves from spaces and discourses marked as dangerous by "becoming invisible" (making sure they were not seen by cameras, physically avoiding spaces) yet aimed to remain visible in spaces they saw their skills and identities as being able to produce what they saw as social good.

In sum, the process of identity management for administrators, faculty, and staff during student-led protests on a university campus was a discursive and embodied process of interweaving familiar scripts in response to limited and limiting organizational scripts. This process engaged and was informed by specific cultural, historic, and geographic realities.

\section{Theoretical Implications}

In this section, I highlight the primary theoretical contributions of my project. I begin by discussing the contributions to identity literature, then I discuss a contribution to the resilience literature, and finish with a discussion of the methodological contribution. In discussing identity, I make a contribution to identity as constructed though reliance on multiple scripts. Then I discuss identification and identity as connected to social movements. I end the section with two main arguments: identity can be understood as rhizomatic, and the identity management process is an embodied process. 


\section{Identity Literature}

This project extends theorizing on identity in a few ways. First, I discuss a contribution to a narrative-based construction of identity that comes from sociology. I offer a contribution by demonstrating how in the absence of a satisfactory functional organizational script, the participants pull on other cultural, institutional and personal scripts to manage identity. Second, I contribute to literature on identity management in social movements. Here I theorize that individuals use occupational identity scripts as one of the ways of managing identities. Finally, I overlay the theory of identity management developed in this project to the concept of the rhizome and theorize identity as a rhizomatic process.

\section{Contributions to identity literature.}

My dissertation makes a contribution to identity management literature. First, I discuss the existing theorizing I will build on, and then discuss my contribution. Sociologist Donileen Loseke connected identity to social change and theorized that "effective social change must be cultural and institutional and organizational and personal" (p. 678). I agree that these four threads are needed for social change and are key identity narratives that animate identity work. First, cultural identity narratives rely on story themes around families, gender, age, religion, citizenship, and race/ethnicity. Institutional identity narratives are consequential narratives around public policy and law. Organizational narratives of identity "are created by the organizers and workers in ongoing organizations, programs, and groups designed for people who evaluate themselves, or who have been evaluated by others, as having troubled identities in need of repair" (Loseke, 2007, p. 670). Personal identity narratives build coherence by "linking diverse life events into unified and meaningful wholes" (Polkinghorne, 1991, p. 136). Loseke suggested that the cultural identity takes primacy in the identity construction and management process. 
Loseke also asked "where, how, and under what circumstances organizational narratives of identity continue to be embraced by workers; where, how, and under what circumstances personal narratives told by individual clients challenge and modify organizational narratives" ( $\mathrm{p}$. 663). While Loseke positioned these narratives as distinct and discussed previous calls for their bracketing in research, she concluded by noting that "exploring relationships among narratives of identity is the examination of theoretical and empirical links among cultural and personal meaning, power, and social structure" (p. 681).

I see the idea of scripts that I discuss in my findings as similar to Loseke's narratives. Loseke explained that narratives are "a recognizable story" that is "conducted, told, heard, and evaluated within particular historical, institutional, and interactional contexts" (2007, p. 663). Similarily, scripts aminate how we "behave in specific situations and contexts" (Poole, Gray, \& Gioia, 1990, p. 212). Narratives and scripts provide opportunities for meaning making in specific contexts. However, I find the language of scripts more meaningful in this research project. A script allows the participants an opportunity to follow it or reject it, to read their lines or improvise. Narrative language focuses on a story that is told or retold.

My research offers a contribution to Loseke's call to explore relationships among narratives of identity. In this research I develop a theory of identity management at a time of social turbulence and theorize that while all four of the narratives Loseke discussed are important, the participants were able to fill the gap of the organizational narrative by engaging with the existing narratives or scripts. A specific contribution that I am making is that I expand Loseke's work to theorize what happens when only three scripts (out of four that Loseke lays out) are reliably available. In my research I see that the organizational script was perceived as not sufficient by many participants, thus, they relied on cultural, institutional, and personal 
scripts to manage identity. In other words, the gap created by the organizational script was filled by the cultural, institutional, and personal scripts. The organizational script relied on the existing hierarchical power structures. Its absence made hierarchical power structures hyper-visible to the participants. Participants pulled on the other existing scripts to engage in meaning making around the protests while being aware of the material and discursive effects of these power structures.

\section{Identity in a social movement: Personal and professional divide.}

The second contribution this dissertation makes is contributing to understanding identity management in a social movement. This project extends the research on identity in social movements as previous research has asked about identity politics (e.g., Taylor \&Raeburn, 1995), contested identities (e.g., Taylor, 1996), and collective identities (e.g., Friedman \& McAdam 1992). I theorize that an element that is missing from understanding identity as it relates to social movements is the dynamic nature of identity that happens within movements and groups.

I position identity management as occurring between two important pulls that can produce identification: social movements and organizations. Identification here is the "perception of oneness with or belongingness to an organization" (Mael \& Ashforth, 1992, p. 104 ). In part because of the previously established organizational identification, employees expected to use scripts related to their professional roles (e.g., job titles and responsibilities) and the organization in order to manage uncertainty and build identity. When that expectation was not satisfied, employees pulled on personal scripts (occupational, culture, motherhood) to supplement what the organization was not providing them. The social movement here acts as a catalyst for this identity management process and provides a space for identification development. Because the organization provided such limited scripts, the employees feel the pull of personal scripts that 
have the capacity to connect them to the social movement, that is, to feel a sense of identification with the social movement.

A related finding that extends identity and identification literature is role identification. Role identification refers to a person identifying with a professional role ("I am a mechanic, a patent”) (Ashforth \& Mael, 1989). Tracy (2004) found that the shift between personal and professional boundaries can be challenging; for example, in her study, correctional officers with strong occupational identification struggled with managing emotions at home. Russo (1998) studied journalists' professional and organizational identification and found that her participants identified with the profession of journalism more strongly than with the journalists employing newspaper. My study extends the theorizing here and demonstrates that when the organizational script is not sufficient (e.g., organizational script of silence) the employees manage identity by pulling on occupational scripts. The occupational script fills the gap that organizational and role scripts are not capable of filling.

Finally, this study calls into question the work on nested identities. Ashforth and Johnson's (2001) work on nested identities suggests that identities nest within each other in an organizational setting. Ashforth and Johnson described identities as higher and lower order, where organizational identities (higher level) may encompass group identities (lower level). Social identities may cross-cut the organizationally nested identities. In this theorizing, an employee is as an identity worker who is positioned to readily "incorporate the new managerial discourses into narratives of self-identity" (Alvesson \& Willmott, 2002, p. 622). My research demonstrates that in times of conflict the identities are not nested within each other like Russian dolls. They are fluid and rhizomatic (this theme is further explored below). The participants did 
not talk about identity in an abstract theoretical way, but did talk about pulling on multiple identities. For example, Lane says:

I do believe my identity as a woman matters. I believe all of my identities matter. I'm white. That matters, that matters in that, in what happened in 2015. Because I have privilege, and I have power, and I want to recognize my privilege.

In times of organizational uncertainty, employees can discern which organizational discourses are not adequate and build self-identity outside of, and at times in resistance to managerial discourses. The employees reject the organizational managerial discourses by reflecting and animating their personal scripts. One of the key contributions of this project is understanding how this script work happened in the body. I discuss the embodied and material aspects of identity work next.

\section{Materiality and Embodiment.}

Bodies in fight do not leave the world behind ... they take the world with them into the future

(Massumi, 1992, p. 105)

Another clear contribution that this dissertation makes is situating identity management as an embodied process. Here I draw distinctions between materiality and embodiment and invite future research to bring embodiment into theorizing in identity work. "Materialism maintains that whatever exists is or depends solely upon, matter", where material also precedes knowing. (Jackson \& Mazzei, 2012, p.105). Feminist new materialism (FNM), a theory that emerged from Donna Haraway, relies on the premise that humans and non-humans are not separate from everything else in the word. Harris, McFarlane, and Wieskamp (2019) used FNM 
to make a case that organizations are agentic in making sexual harassment easier or harder to occur.

Materialism, and specifically new materialism, and its ontology "involves not simply the abstract study of the nature of being but also the underlying beliefs about existence that shape our everyday relationships to ourselves, to others, and to the world" (Coole \& Frost, 2010, p.5). Butler takes up identity as a process of impersonation and approximation for which an original does not exist (1997). She wrote: "For the "I" is a site of repetition, that is, if the "I" only achieves the semblance of identity through a certain repetition of itself, then I is always displaced by the very repetition that sustains it" (p. 304). Materiality acknowledges the body, but does not hold it as a cite of a complex and messy knowledge production. Embodiment, on the other hand considers somatics, our inability to distinguish the self (emotions, actions, beliefs, interactions, perceptions, ethics, morals, and the drive for dignity) from the body (Strean, 2011). Identity management is deeply connected to all of those and the body should be considered as a site of knowledge production, performance, and replication.

Previous research has focused on materiality in identity management. For example, Ashcraft (2005) analyzed materiality and discourses in studying how pilots manage their identities during change. Trethewey (1999) applied the material lens to the body when she argued that "professional and gendered discourses are literally written upon members' bodies" (p. 423). Women learn to dress, move, and position their bodies when they are young, and that process of docile movement into workspace discourses continues throughout their lives. This work connects to the professional identity management. Trethewey's research positions the female body as something that is purposefully molded to fit the masculine gendered discourses. 
In my dissertation I saw additional nuances that are best examined by considering embodiment. The participants shared feelings, used their bodies to cope with anxiety, and talked about embodied ways of doing identity work. I extend what embodiment can do in our thinking about identity and organizations. In this dissertation I position embodiment as a key element in understanding the identity management process. Embodiment refers to:

the experiential body [that is] both a representation of self (a "text") as well as a mode of creation in progress (a "tool"). [...] Embodiment is a state that is contingent upon the environment and the context of the body (Perry \& Medina, 2011, p. 63).

Additionally, I respond to Mirza's (2013) call to researchers to study “embodied intersectionality", to make sense of the gendered and raced experiences and their implications in organizational settings. Intersectionality was originally defined by Crenshaw (1989) in a way analogous to an accident in a four-way intersection. If a Black woman is harmed at such a conceptual intersection, "her injury could result from sex discrimination or race discrimination" (p. 149).

In my dissertation I heard participants discuss embodied effects of identity management sense of loss, trauma, grief, experiences with weight loss and gain, use of coping strategies that numbed the body, and the embodied feeling of being seen in spaces that felt dangerous. Identity work is body work. The bodies are not mere containers for ourselves/our identities. Ellingson wrote: "traumatized body-selves resist the body-mind dichotomy with embodied memories, visceral emotions, and fleshy responses" (2017, p. 74). This identity/embodiment became apparent in the interviews. When transcribing I noticed that the sections of the interviews where the participants were certain of their identity management strategies were clear and coherent. The ones where they were not sure of their identity management process came out as confused and 
jumbled. This jumbled speech (embodied enactment of confusion) demonstrates that embodiment is an active part of identity management. This moment of confusion connects material, discursive, and embodied in a way that demonstrates how meaning is produces by connecting all three. Further, identity management cannot be fully understood without thinking about what the body is doing. What materiality offers us is a connection to all ways that "matter" matters in our understanding of the world. Embodiment allows us for a specific focus on bodyselves in relation to spaces, processes, organizations, objects, discourses.

Additionally, thinking about embodiment constructs the impact of the script of silence in new ways. The script of silence got entangled in bodies in a way that many participants still experience. I saw this ongoing entanglement in participants' expression of sadness, frustration, and other emotions that communicated their embodied discomfort during the interviews. The bodies seem to be paying a physical cost when we disrupt a script of silence.

\section{Rhizomatic nature of identity.}

A rhizome ceaselessly establishes connections between semiotic chains, organizations of power, and circumstances relative to the arts, sciences, and social struggles. A semiotic chain is like a tuber agglomerating diverse acts, not only linguistic, but also perceptive, mimetic, gestural, and cognitive: there is no language in itself, nor are there any linguistic universals, only a throng of dialects, patois, slangs, and specialized languages.

Deleuze and Guattari, 1987, p. 7.

The final identity contribution I want to discuss is theorizing identity as rhizomatic. In discussing the theoretical contributions above, I kept considering the interconnectedness of the identity management process. In chapter 2 , I described identity as "a communicative process and 
a site of struggle constantly negotiated through interaction with others and retroactive sensemaking about one's self" (Norander, Mazer, \& Bates, 2011, p. 60). I provided my definition of identity as a context-sensitive dynamic construction situated in communicative practice. Poststructuralist theorists see identity as a site of disunity and conflict that is influenced by power relations (Jackson \& Mazzei, 2012). A key contribution that poststructuralism makes in this context is that identity is conceptualized as an ongoing state of becoming ${ }^{16}$, rather than a fixed state of being in the world (Weedon, 1997). Tracy and Trethewey (2005), poststructuralist scholars, contributed to the literature on identity as related to the organizational discourses, by pushing back on the real-self $\leftrightarrow$ fake-self dichotomy and developing the metaphor of "crystalized self." The crystalized selves are neither real, nor fake and "have different shapes depending on the various discourses through which they are constructed and constrained" (Tracy \& Trethewey, 2005, p. 186). This metaphor is offered as a useful tool for an "individual in their everyday lives [to be] able to take advantage of the (micro)political space offered by structuralist theorizing"(Tracy \& Trethewey, 2005, p. 187). In sum, poststructuralist theorizing on identity offers us the following frameworks: identity as a site of disunity and conflict, identity as becoming, identity as crystalized. I offer another metaphor for understanding identity.

I add to the conversation about the current definitions of identity by discussing identity as rhizomatic. In the previous chapters, I have discussed the following parts of identity work: organizational identification, competing scripts and discourses, managerial control, materiality, embodiment, historical and societal contexts. I do not believe that the original definition of

\footnotetext{
${ }^{16} \mathrm{Becoming}$ is conceptualized as a line that passes between two points, a state of in between, the "continual production of difference immanent within events" (Deleuze and Guattari, 1997, p. 293).
} 
identity I provided encompasses all of these ideas. Here I discuss identity as rhizomatic and share how this concept can produce new knowledge in our thinking about identity. It is important to point out that thinking about identity as rhizomatic requires an epistemological shift.

Poststructuralist thinking, where the notion of the rhizome originates, has different assumptions about truth, power, and stability of categories than the critical assumptions that can be evident in the first half of this chapter. In chapter two I positioned myself as a "theoretical nomad" (Dougherty, 2011). Furthermore, Deleuze and Guattari take on a specific project of creating a new language to rupture our old ways of thinking (Jackson \& Mazzei, 2012). I discuss this change in assumption here as a way to signal to myself and any other readers that the concept of a rhizome signifies not only a new concept, but also a different set of epistemological assumptions. In order to introduce the concept of identity as rhizomatic, I start with discussing the characteristics of a rhizome, lay out how the concept of a rhizome can fit with the parts of identity work I have identified, and then I will theorize what thinking with rhizomes can produce in our understanding of identity.

I am not merely introducing a metaphor, but inviting a new way of thinking about identity. The concept of the rhizome is an a-centered multiplicity. This concept helps us see how everything is interrelated and helps us question hierarchies and categorization. It does not have a beginning or an end and goes in all directions. Here I tie the concept of the rhizome to identity. In my analysis I found that scripts that animate identity management connect and re-produce each other and are connected to such assemblages as managerial control, materiality, embodiment, historical and societal structures. A rhizome is often described as crabgrass or ginger: interconnecting and reinforcing parts that create a limitless whole. If we have the image of crabgrass when we think about identity work, we can see identity as a collection of scripts and 
assemblages that are connected to biological, political, and economic forces, which, in turn, are also connected to and produce scripts in creating what we understand as identity.

Deleuze and Guattari (1987) started their conversation about the rhizome by contrasting it to a tree. A tree has roots that can embed themselves in soil in a particular way and a trunk that produces leaves, blooms, and branches in a specific way. There is specificity to a tree. The leaves are connected to branches and not the roots, and the trunk is above ground and not below. A tree (whether it is a Martian - looking Joshua tree or a California sequoia) looks familiar and can be easily identified. One can easily divide a tree into familiar categories (trunk, branches, roots). Rhizome opposes this certainty. In introducing the Deleuzian concept of a rhizome, Todd May (2005) invites us to think about the training, coiling, climbing vines of Kudzu: "it can shoot out roots from any point, leaves and stems from at any point" (p.133). It is always in the middle. There is no particular shape that Kudzu has to take. It can connect to other plants, fences, or the ground:"The difference in the tree and the rhizome is the difference between the verb "to be" and the notion of becoming (nonlinear, constant movement, without beginning of end)" (Deleuze \& Guattari, 1977, p. 25).

Now, armed with the image of Kudzu, let us consider the principles that Deleuze and Guattari (1987) used to conceptualize a rhizome: connection and heterogeneity, multiplicity, asignifying rupture, and cartography and decalcomania. I explain these in detail below. First, any point of a rhizome can be connected to any other point no matter how similar or different: “A rhizome ceaselessly establishes connections between semiotic chains, organizations of power, and circumstances relative to the arts, sciences and social struggles.” (p.7). In other words, discourses and scripts can connect to power structures, hierarchies, and historical contexts. Unlike a tree, and like Kudzu these connections happen constantly and without directions. 
Connection is an ongoing process where connection is not to alike categories, but to and between nonuniform groups, ideas, concepts (principle of heterogeneity). These principles help us think about identity as a series of connections between and across different categories: time, geography, history, body, and discourse.

Second, the principle of multiplicity refers to determinations, dimensions, and magnitudes that cannot change in number without changing in nature (e. g., temperature cannot change in degrees without changing in the feel). That is, "there are no points or positions in a rhizome, such as those found in a stricture, tree, or root. There are only lines" (p. 8). Simply put, this metaphor works to illustrate that unlike a tree, that has a main truck, a rhizome is a collection of interconnected lines (imagine crabgrass). The principle of asignifying rupture suggests that "a rhizome may be broken, shattered at a given spot, but it will start up again on one of its old lines or roots.” (p. 9). If we carry this principle to thinking about identity, we can see how a disruption can shift, but not stop the identity building process, identity is always evolving. Finally, the principle of cartography and decalcomania suggests that we think of rhizomes as a map, as always open, and something that can be entered at any point:

The map is open and connectable in all of its dimensions; it is detachable, reversible, susceptible to constant modification. It can be torn, reversed, adapted to any kind of mounting, reworked by an individual, group, or social formation. It can be drawn on a wall, conceived of as a work of art, constructed as a political action or as a meditation. (p.12)

To apply this principle to identity is to think about identity as not having a set starting point. While some theorizing asks about primacy of identity categories (are you a woman, or a scholar, 
or a cat enthusiast first?), rhizomatic thinking upends this primacy of categories in favor of a process that can be entered at any point.

The principle of asignifying rupture when applied to identity would show how lines of identity are tied to one another. If a script is ruptured, a new one takes its place; if a body moves away from familiar geographical space, the lines of identity building continue. Finally, identity (in relation to cartography and decalcomania) is not something that can be entered from a specific direction. It can be entered and seen from multiple directions. Rhizome is not

One nor the multiple. It 1s not the One that becomes Two or even directly three, four, five, etc. It is not a multiple derived from the One, ... composed not of units but of dimensions, or rather directions in motion. It has neither beginning nor end, but always middle (milieu) from which it grows and which it overspills.

(Deleuze and Guattari, 1987, p. 21)

Identity follows this multiplicity. It grows and overspills not linearly, but constantly moving across all dimensions. Next, I show how this metaphor helps us build new understanding of the identity management process.

I have mentioned that I see identity work as being composed of the following: identity negotiation, competing scripts and discourses, managerial control, materiality, embodiment, and historical and societal contexts. If we see identity as a rhizome, we can see these parts of identity not as hierarchical, nested, or crystalized, but as flat, that is, anti-hierarchical. They are always entangled together, and are always in motion. If we do not pull pieces of identity apart, in an effort to create nestings, or hierarchies, but understand identity as rhizomatic, then it is possible to both see and value all of the parts of identity listed above as equally important. By not 
elevating organizational control over history, for example, we can see deeper richness and complexity in identity management. We can see a way to create newly complicated scripts.

One may ask, with so many conceptualizations of identity, what use is another one? What does a rhizome-focused understanding of identity produce? To understand identity by applying a lens of a rhizome is to understand identity as a complex process that involves and flattens scripts, discourses, bodies, historical, geographical, and cultural backgrounds, as well as power relations. This flattened interconnectivity allows for a more nuanced understanding of identity management as a process that can be entered from any point, restarted after a rupture. This identity process encapsulates history, geographical contexts, embodiment, and scripts and sees those as equally important mines in the creation of identity. This identity process is not aimed at a specific goal or a direction, but is in movement.

Considering identity as rhizomatic accomplishes several theoretical and epistemological moves. Theorizing identity with the concept of rhizome invites us to rethink subjectivity and destabilize identity categories. This theorizing pushes forward the idea of intersectionality and invites us to think beyond intersectionality. Intersectionality is a key concept in understanding ways race, ethnicity, class, and culture are integrated (Dill \& Kolman, 2012) as it discusses oppression on personal, group, and communal levels (Hill Collins, 1990). Epistemologically intersectionality views these levels as connected to specific material and discursive practices. Identity is viewed through the perspective of layering of the group, personal, and communal levels in ways that have specific material consequences. However, rhizomatic thinking does not occupy the same epistemological space. Rhizomatic thinking about identity considers identity as always becoming and not a fixed point where identity categories are pinned and static. Rhizomatic thinking about identity does not directly set out to answer questions about power and 
oppression in the way that Crenshaw's (1991) Stanford Law Review piece that introduced the idea of intersectionality does. Instead, rhizomatic thinking about identity invites us to consider identity as a movement through time, materiality, history, and physical space. It is creation of newness rather than reduction to familiar identity categories.

\section{Resilience literature.}

This research also extends our understanding of resilience as a communicative practice. In their research on resilience, Buzzanell and Turner (2003) discussed the process of constructing resilience as animated by anchoring identity anchors. These identity anchors are "managerial, masculine, and family discourses intersected to enhance formation of particular identities" (Buzzanell \& Turner, 2003, p. 4). Buzzanell points out a specific issue with this process: because the identity anchors rely on certain restrictive discourses (e.g., religion, masculinity, gender norms), not all members' best interests are served through these identity constructions. For example, in her study of unemployment, wives of men who lost jobs downplayed their own contributions to the family.

My research on scripts opens a new opportunity in theorizing on identity anchors. My research reveals that those identity anchors can also be found in professional identities. Specifically, participants relied on their professional identities and related scripts to construct resilience and manage their identity. This reliance on scripts provides a new direction to Buzzanell's (2010) theorizing of identity anchors. My research suggests that it is possible to build identity anchors without reliance on restrictive discourses. For example, the participants in my study did not center masculinity as important identity anchor like the participants in Buzzanell's study. They focused on a much broader set of discourses and scripts. For example, participants relied on their occupations and their cultural backgrounds to trouble and disrupt the 
organizational script of silence. This is important because resilience can be seen as going back to (restrictive) norms, in part because the participants rely on discourses that produce those norms.

Some participants in my study relied on the construct of motherhood. While that script can be seen as a rooted in a restrictive discourse as it heavily relies on gender norms, the participants used to challenge the organizational script of silence. This script was used as resilience that opened micro opportunities for resistance. My research demonstrates that resilience can rely on discourses that are less restrictive, thus, making "going back to the norm" into an opportunity for social progress.

\section{Methodological implications}

This dissertation also makes a notable methodological contribution; it engages the body as a site of knowledge production. This dissertation is guided by feminist embodied practices and suggests a path for embodied grounded theory. Embodied grounded theory believes that knowledge is carried in the discourse and the body and rich data can be generated by helping participants think not only of discourses but of their bodily memories, experiences, ways of knowing. Grounded theory is already aligned with the feminist research practices in accounting for the material and embodied. The material world is constructed by both us the researchers and the participants that we study. This material world includes both nonhuman bodies and our own embodiment (McCarthy 1984). Furthermore, knowledge production is an embodied process, "a holistic understanding of embodied knowledge centers on being in the world through our bodies" (Ellingson, 2017, p. 17). In this view "grounded theory leads us to attend to what we hear, see, and sense while gathering data" (Charmaz, 2014, P. 3).

In my dissertation I make embodiment explicit by asking the participants to bring objects that represent their identity. In doing that I was able to create experiences and collect data 
through ways that were more than speech and text. I paid attention and incorporated into analysis tone, expression of emotion (crying or laughter), and recollection of body sensation during the process and in the interview. I paid attention to my own body - feelings of anxiety and fear and "not enoughness" of carrying the weight of the interviews. In one conversation with my advisor we discussed how this dissertation (my writing and her reading) produced new experiences of prolonged anxiety for us as members of the campus community in Fall 2015. We sat with those feelings as we discussed what new knowledge this feeling produced.

My focus on embodiment invited me to consider a specific ethical question focused on speech manipulation and representation. Epistemologically, this was a question of "embodied intersectionality", which seeks to make sense of the gendered and raced experiences and their material implications in organizational settings (Mirza, 2013). Practically some of my participants are non-native English speakers. I too am a non- native speaker. One of the things that happens to me, and happened to these participants was a switching of words in speaking. While I was able to follow the conversation during the interview, once I transcribed those interviews, they became less coherent. I faced a dilemma in changing the words to make the interviews reader friendly, as I viewed that as an act erasure of that speaker's voice. On the other hand, some word choices and phrases followed a particular flow that would make those participants easily identifiable. The act of translating this speech into mainstream English seemed to be a very non-feminist, pro-colonizing, anti-embodiment move. I saw this as a tension and discussed this with the participants, letting them see the transcripts and discussing their preferences with them. 


\section{Implications for Practice}

My project carries value for any organization that is experiencing internal turmoil or internally generated uncertainty. While I focus my dissertation on a university in the Midwest, I believe the suggestions I give here could be transferred to many organizational contexts. In my dissertation I discuss organizational practices that shape ways employees construct their identities. I suggest communicative and policy-based practices that would allow the organizations to create scripts that allow for historical and embodied protocol of communication. Here I mean a systemic, negotiation-based communicative practice that allows for and invites acknowledgement of historical precedents and embodied impacts of organizational disruptions.

Contributions to organizational practice. This dissertation is making several practical contributions for organizations. Based on my findings, I address how organizations regulate and maintain policies, practices, and staffing structures. Simply stated, organizations should acknowledge and respond to the fact that employees rely on organizations for scripts that include a nuanced understanding of cultural, historic, and material realities. Such scripts benefit the employees and the organization. Existence of such scripts (when they are grounded in cultural norms, historical realities and focus on inclusion of many voices) allow the organizational members to show more consistent support to the organization. From the data analysis, I have learned that contextual scripts were created (Dakota specifically talked about her efforts in making one), but not followed. Historical and contextually relevant scripts would allow the employees to manage identity in ways that are less disruptive of their wellness and sense of trauma many of my interview participants have described.

Disruption of communication protocols: Script management. A key contribution that I am making to organizational practice is recommending that organizations have communication 
protocols in place that allow for processing, care, and narrative making before, during and after a disruptive event. This recommendation mirrors crisis communication protocols that many organizations have. Some may say that disruptive events like student protests are not predictable, thus a pre-protest communication protocol may not be not possible. I disagree with that argument for two reasons. First, a historical overview of higher education reveals that protests are an expected norm on a college campus. I make that argument in chapter 2. Second, multiple participants shared that they knew that student dissatisfaction was high and that a protest or other disruptive action was likely. Thus, an organizational script that allows for pre-event communication would have been possible.

Once we see that protocols that address script creation that focus on pre, during, and post event are valuable and feasible, I suggest that organizations explore the value of such protocols for organizational health. Implementation of these protocols would provide an action and forward movement focused script and help the organizations with employee wellbeing. When an organization evaluates its culture, history, and material conditions and creates a script that acknowledges those, and provides a set of practices that employees may engage in, this may help the organization as a whole experience disruption in a way that produces less trauma. My analysis suggests that employees pulled from other scripts precisely because the organizational only provided two unsatisfactory options. Deetz theorized that 'the modern business of management is often managing the "insides" - the hopes, fears, and aspirations - of workers, rather than their behaviors directly' $(1995$, p. 87). Therefore, the modern organization can, and I argue, should provide employees with scripts that allow for more embodied and historical understanding of a trauma. 
As a part of post-disruption employee care, I also recommend an implementation of shared sensemaking opportunities for and with the university community. These can take the form of listening sessions, policy and university history workshops, and heightened publicity around the need for mental health support. I follow Kevin Barge (2014) in recommending that all responses are scalable. The practice of sensemaking sessions can serve the organization and the employees. The act of creating these opportunities communicates care and the employees can utilize the space provided to create shared scripts. Furthermore, sensemaking sessions can allow the employees to engage in crafting scripts in a way that allows for them to see and hear shared history, institutional context, and create a script that invites organizational change.

Organizational history markers. It is not likely that organizations (universities and others) will stop experiencing protests and other disruptions. Therefore, it is important for organizations to create scripts that allow for reflection of (often) racist history and acknowledge and disrupt ways in which scripts are gendered and racialized. I do not suggest that scripts alone can change the material conditions. Thus, my second contribution is a suggestion for material integration of organizational history as a part of creating scripts. This integration can include material markers of both events that create organizational pride and events that discuss history not as blemish-free, but as complex and at times troubled by events that uphold existing privileges such as whiteness. For example, organizational scripts that include what the institution is learning as a result of the Fall 2015 protests may offer a less disruptive way forward. The result of telling such a history can be that the organization would have to engage in scripts that produce rather than silence. this historical and contextual integration can invite employees with various levels of power into the organizational script creation. 
Additionally, the organization may benefit from connecting history to the community it takes place in. Functionally it may benefit organizations to understand and leverage communal and familial relationships. The university, like any organization, benefits from having employees with strong identification and clear narratives that can be shared in their communities. Cocreating a clear script that includes community values, university values, and university history can benefit both the university and the employees. We organize around our work, communities, and values. This script making is both a communal process and identity managing process.

Role evaluation and support. The third contribution I am making to practice is suggesting that organizations evaluate the position compensation and promotion process to include a deeper and more nuanced understanding of ways certain roles are systemically disadvantaged and made invisible. My analysis demonstrates that organizational roles shape the lived experiences of the workers. Specifically, those in a staff role seemed to be carrying the most burden. Staff members reported doing a lot of labor with low compensation and recognition. Organizations can do more to bring equality in pay and status to those unseen overworked roles. Furthermore, I recommend that organizations develop a more nuanced understanding or roles that provide emotional labor, administrative support, and management of logistics and find ways to provide adequate support, training, and recognition for individuals in those roles.

\section{Strengths}

I can identify three key strengths in this project: the diversity of the participants, the need this project filled, and the focus on embodiment that this project has. First, participant diversity is a strength of this dissertation. It was important for me to include a variety of voices and experiences. I was initially concerned that I may lack participation because of the nature of the 
topic and the silencing script that I identified through my analysis. However, through informal networks, university wide recruitment, and snowball sampling I was able to recruited a diverse set of participants (e.g., positions, race/ethnicity, gender, age) who provided a rich set of narratives and experiences. Regardless of their experiences or backgrounds, the participants were speaking to the existence of both organizational and personal scripts that they were engaging to manage their identity during a period of upheaval.

The second clear strength of this project was the social need that it filled in at least two ways. First, the participants have shared that the ability to reflect on the experience allowed then to make sense of the experience and start establishing a narrative that functioned better in their lives. Second, early in the interview process the participants have commented that there was a need for such a project to take place. A number of projects, articles, and research pieces have been published already, and adding one that focuses on identity management files an important gap in existing literature (Johnston, 2018, McElderry \& Rivera, 2017, Trachtenberg, 2018). I am committed to disrupting the silencing script, and plan on presenting this work to a wide variety of audiences.

The third strength that this project has is that it actively brings embodied practices into grounded theory work. In chapter three I discussed how thinking with embodiment can inform the research process. In this dissertation I was able to illustrate knowledge production as an embodied process. In this chapter I have offered suggestions for ways grounded theory scholars can use embodiment in the research process.

\section{Limitations}

While this research has several strengths, there are also limitations that should be addressed. Although my recruitment protocol offered me a diverse participant base, the 
sensitivity, relative recency of Fall 2015, and possible adherence to the script of silence made this topic challenging for potential participants. I reached out repeatedly to many senior administrators and have not been able to secure those interviews. The ongoing silence of senior level administrators has raised many questions that I address in the future directions section. Furthermore, my research questions focused on a specific population, which narrowed my participant base. Specifically, in my initial conceptualization of the study I wanted to interview individuals (administrators, faculty, and staff) who have engaged with the campus social movements and protests and have identities that are in conflict. While not all the participants supported the movement, a large majority sympathized with the students involved. Additionally, while this project used grounded theory, the population led itself to a case study nature within the project.

This project relied on memories and observations. I think that including more university generated documents and asking participants to share any forms of memory keeping (journals, social media posts, pictures) created during Fall 2015 would help me generate richer data. Moreover, although my research design asked the participants to bring in three objects that reflected their identity before, after, and during the protests of Fall 2015, not every participant complied with those directions. I realized that that task was a challenging one to ask all participants to do. Having more consistency in this area would provide richer and more illustrative data.

\section{Future Directions}

The strengths and limitations of this project invited me to consider ways I can continue this work in the future. A clear theme that I could see traces of in every interview was the impact of the organization on the overall identity management of the employees and the violence that 
this encompasses. In chapter four I discuss the script that the university had for the student protest. Throughout the data analysis process, I had questions about how this script was produced and who is responsible for producing it. Research exists that tackles similar questions in the sexual harassment and violence realm. In her work on sexual harassment, Kate Lockwood Harris (2013) discussed organizational standpoints and ways organizations facilitate violence. She makes a case that organizations can produce violence and how "discourse is used to excuse organizations from complicity with violence" (p. 587). I saw traces of this violence in the interviews, but my interview protocol did not focus on the organization. Future directions of this work can include an exploration of what and how organizational scripts are produced and how any harm they produce can be disrupted.

Furthermore, this dissertation established an organizational script of silence as a script that organizations rely on as a response to student organizing. I want to expand this research and explore ways in which silence is doing work as a tool for sensemaking, resistance, and identity building. First, I want to explore how organizational silence impacts the process of sensemaking throughout the organization. Previous research has demonstrated that silence is used by organizations and employees to maintain often harmful norms at work around sexual harassment (Clair, 1998; Dougherty, 1999) and assumed heterosexuality (Compton \& Dougherty, 2017). Silence works at macro and micro levels and has organizing capacity with both oppressive and emancipatory power (Clair, 1998). Additionally, I want to explore how organizational silence creates and closes discursive opportunities for resistance among various levels of employees. I conceptualize organizational silence as created by the organization, not an individual actor. Individual actors have agency in interacting with, reproducing, and resisting the script of silence. I want to further explore these topics. Lastly, I have remaining questions about how the 
organizational script of silence impacts identity management. This project revealed that employees pull from other scripts to supplement what an organizational script of silence is not providing. However, I want to further explore how silence impacts the identity management process.

Additionally, I want to explore how (re)construction of an identity during a student-led social process is a continuous process that can have lasting impacts. For example, one participant discussed how the identity she constructed during the fall of 2015 impacted her role as a parent. Alia shares that she sees parenting as resistance:

At their age, resistance is raising a child that is aware. And you know, thats my resistance to society and (pause) to my husband. And my in-laws. Because when he, yeah, he thinks like: " Why does she need to know that?" I know like I will have conversations that make them very uncomfortable. Shes a smart kid and she was very empathetic and aware and he just has to deal with it.

Alia's comments underscore the importance of understanding how individual employees manage their identities during a campus student protest. Identity management during a time of turmoil has lasting impacts on identity management after the organization gets to a place stability. This quote also demonstrates a larger point that I am making - identity is a complex construct that is animated by multiple scripts (in this particular example, mothering and social resistance) and material and embodied realities, constructed in relation to others.

I would like to revisit the assumption I made in the beginning of this process and think about the broad question of identity and social change. That is: how do we make change happen? I will continue this work by conducting a similar study across college campuses to see if the 
organizational scripts would be similar and what responses they produce. I am aware that the university setting is a specific and unique space. Thus, I also will expand this research into community spaces. A place like Ferguson ${ }^{17}$, Missouri or other similar communities that experience protests and disruptions to everyday living.

My research demonstrated that the process of reliance on scripts that participants engaged in was imbued with power. In chapter 2 I theorize that moments of social change produce a number of acts of both resistance and resilience and that identity management is entangled in this struggle. This struggle occurs in the "web of power" (Dougherty, 2011) and is done in embodied ways. The participants leverage a number of resources to manage identity and do so in ways that engage resistance and resilience strategies: (1) the participants use scripts to open up the discursive closures that are created by the organizational script of silence; (2) the participants enact micro-resistance within their professional roles (see Alia speech writing \& Forrest informing staff via students); and (3) they engage with the discourse and embodiment of whiteness to make changes. Here resistance and resilience strategies are entangled and complex. I was able to see this entanglement throughout the chapter, and I will focus future research on better understanding the interconnections among resistance, resilience, and power.

In this research I encountered scripts that reaffirmed discourses about whiteness in unpredictable ways. One of my dissertation readers pointed out that the discourse around mothering reaffirmed whiteness and positioned the (mostly) white women as capable saviors of (mostly) nonwhite student protestors. Thus, I would like to gather more data around the theme of

${ }^{17}$ Ferguson is a community in St Louis that saw a shooting of a black teen Michael Brown by a white police officer Darren Wilson on August 9, 2014. This event, and the response of the local police led to a series of protests in the surrounding communities. 
mothering and scripts and develop a more nuanced understanding of ways discourses of the white savior interact with the script of mothering.

Finally, I want to further explore the idea of the rhizome. While empirical testing of a rhizome is not consistent with poststructural assumptions, I will consider other work in using rhizomes (ex., Freitas, 2012; Honan, 2007; Wilson, 2003) in thinking about how I can further develop the concept of identity as rhizomatic.

\section{Conclusion}

This study started with me thinking about how we make progress happen. It was clear that protests serve as disruptions that can rip apart and rewrite the existing scripts, and I wanted to learn more about this process. I wanted to understand how organizational members make sense of themselves in a world that is rocky with tension. How do they manage visibility and invisibility? How do they/we think about what is right? The process of identity management that I theorize here reveals scripts that are created by organizations and other social identities. This dissertation also asks questions that I am eager to explore. These questions focus on how organizational scripts are produced. What values do they uphold? I believe that communication, as a discipline that values theory and praxis, is uniquely positioned to answer these questions in a way that helps build equality. I believe that within organizational communication we have the capacity and the duty explore ways and share practices of how to be critical consumers of organizations, to encourage disruption in power structures, and to bring feminist embodied ethos into everyday working and living practices.

I will finish this dissertation with the same words I started with "To keep the spirit of democracy alive requires a continuous revolution" ( Griffin, 2008, p. 49). It is up to all of us to contribute to the scripts that continue those revolutions. 


\section{Coda}

1. The experience of bodies in space.

You are looking at a sea of tents - blue, black, gray. Standing side to side

And you see her frame: big pregnant belly, a halo of red hair, all frizz and curls.

The minister holds an open a big box of glazed doughnuts that she is sharing.

How does one decide what to bring to a protest?

2. On (in)visibility.

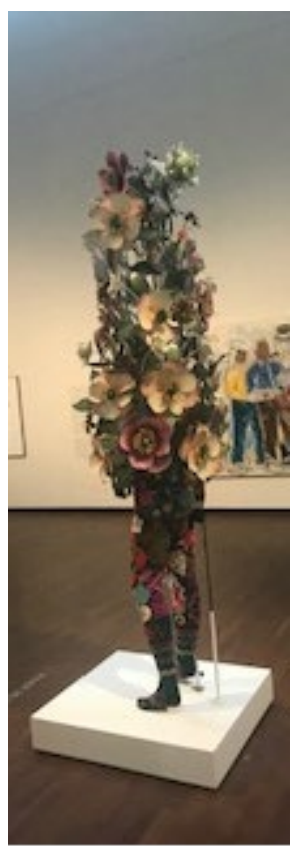

Nic Cave, an artist born in Fulton MO, who now lives in Chicago thinks a lot about visibility and invisibility of Black bodies. He builds wearable sculptures that reveal and conceal. They obscure race, gender, and class and yet they are hyper visible - colorful, loud, in movement.

He thinks about his being in the world - a Black man who navigates (in) visibility in a colorful sculpture.

Nick Cave tells his audience that the first Soundsuit came to be in 1992.

In response to killing of Rodney King.

The pieces are designed to be seen

3. The experience of carbon and change.

My coworker told me about carbon. And I thought, well I am like carbon too. Carbon has different forms, right? There's the natural carbon and then theres carbon as a mineral. And so natural carbon is, it doesnt change, right? But mineral carbon does change. It turns into a 
diamond. And I was like, oh, thats such a corny thing to say like diamonds, right. But its more the process that happens.

4. Heartbreak.

The hardest thing for her was not that she had to forget about her own body. Not that she had to keep folding the tents and packing the supplies. Or that her body was pained and sore. The camp needed to be picked up because the storm was coming and the students were hiding out ever since the threat on their lives was made. So she kept the body moving.

The hardest thing was to look at the Latina students, who looked just like her and say: "Hey, visually from afar we dont look a certain skin tone, you p otentially could be pass - pass off as white and so, let's keep packing."

And their eyes when she said that. 


\section{References}

Aburn, G., Gott, M., \& Hoare, K. (2016). What is resilience? An integrative review of the empirical literature. Journal of Advanced Nursing, 72(5), 980-1000. doi: 10.1111/jan. 12888

Acker, J. (1990). Hierarchies, jobs, bodies: A theory of gendered organizations. Gender \& society, 4(2), 139-158.

Acker, J. (2006). Inequality regimes: Gender, class, and race in organizations. Gender \& Society, 20(4), 441-464. doi:10.1177/0891243206289499

Acker, J., \& Van Houten, D. R. (1974). Differential recruitment and control: The sex structuring of organizations. Administrative Science Quarterly, 19(2), 152-163. doi:10.2307/2393886

Ackroyd, S., \& Thompson, P. (1999). Organizational misbehavior. Thousand Oaks, CA: SAGE Publications.

Agarwal, V., \& Buzzanell, P. M. (2015). Communicative reconstruction of resilience labor: Identity/identification in disaster-relief workers. Journal of Applied Communication Research, 43(4), 408-428. doi:10.1080/00909882.2015.1083602

Albert, S., \& Whetten, D. A. (1985). Organizational identity. Research in Organizational Behavior, 7, 263-295.

Allen, B. J. (1998). Black womanhood and feminist standpoints. Management Communication Quarterly, 11(4), 575-586. doi:10.1177/0893318998114004

Alvesson, M., Ashcraft, K., \& Thomas, R. (2008). Identity matters: Reflections on the construction of identity scholarship in organization studies. Organization, 15(1), 5-28. doi: $10.1177 / 1350508407084426$ 
Alvesson, M., \& Willmott, H. (2002). Identity regulation as organizational control: Producing the appropriate individual. Journal of Management Studies, 39(5), 619-644.

$\underline{\text { doi:10.1111/1467-6486.00305 }}$

Amenta, E., Caren, N., Chiarello, E., \& Su, Y. (2010). The political consequences of social movements. Annual Review of Sociology, 36, 287-307. doi:10.1146/annurev-soc-070308$\underline{120029}$

Ashcraft, K. L. (2005). Resistance through consent? Occupational identity, organizational form, and the maintenance of masculinity among commercial airline pilots. Management Communication Quarterly, 19(1), 67-90. doi:10.1177/0893318905276560

Ashcraft, K. L. (2007). Appreciating the 'work' of discourse: Occupational identity and difference as organizing mechanisms in the case of commercial airline pilots. Discourse \& Communication, 1(1), 9-36. doi:10.1177/1750481307071982

Ashcraft, K. L. (2013). The glass slipper: "Incorporating” occupational identity in management studies. Academy of Management Review, 38(1), 6-31. doi:10.5465/amr.2010.0219

Ashcraft, K., \& Allen, B. J. (2003). The racial foundation of organizational communication. Communication Theory, 13(1), 5-38. doi:10.1111/j.1468-2885.2003.tb00280.x

Ashcraft, K. L., \& Harris, K. L. (2014). Meaning that matters': An organizational communication perspective on gender, discourse, and materiality. In S. Kumra, R. Simpson, \& R.J. Burke (Eds.), The Oxford handbook of gender in organizations, (pp. 130-150).

doi:10.1093/oxfordhb/9780199658213.013.001

Ashcraft, K. L., \& Mumby, D. K. (2004). Organizing a critical communicology of gender and work. International Journal of the Sociology of Language, 166, 19-44.

doi:10.1515/ijs1.2004.012 
Ashforth, B. E. (1998). Becoming: How does the process of identification unfold. In D. A. Whetten \& P. C. Godfrey (Eds.), Identity in organizations: Building theory through conversations (pp. 213-222). Thousand Oaks, CA: SAGE Publications.

Ashforth, B. E., \& Mael, F. (1989). Social identity theory and the organization. Academy of Management Review, 14(1), 20-39.

Ashforth, B. E., \& Johnson, S. A. (2001). Which hat to wear. In M. Hogg (Ed.), Social identity processes in organizational contexts (pp. 32-48). Florence, KY: Psychology Press.

Baldwin, J. (1984). On being white... and other lies. Essence, 14(12), 90-92.

Barad, K. (2003). Posthumanist performativity: Toward an understanding of how matter comes to matter. Signs: Journal of Women in Culture and Society, 28(3), 801-831.

Barker, J. R. (1993). Tightening the iron cage: Concertive control in self-managing teams. Administrative Science Quarterly, 38(3), 408-437.

Bourdieu, P. (1990). The logic of practice, Palo Alto, CA: Stanford University Press.

Bourdieu, P. (1991). Language and symbolic power. Cambridge, MA: Harvard University Press.

Britt, L., \& Heise, D. (2000). From shame to pride in identity politics. In S. Styker, T. J. Owens, \& R. W. White (Eds.), Self, identity, and social movements (pp. 252-68). Minneapolis, MN: University of Minnesota Press.

Broadhurst, C. J. (2014). Campus activism in the 21st century: A historical framing. New Directions for Higher Education, 167, 3-15. doi: 10.1002/he.20101

Broadhurst, C., \& Martin, G. L. (2014). Part of the "establishment"? Fostering positive campus climates for student activists. Journal of College and Character, 15(2), 75-86.

Bryant, A., \& Charmaz, K. (Eds.). (2007). The Sage handbook of grounded theory. Thousand Oaks, CA: SAGE Publications. 
Butler, J. (1996). Imitation and gender insubordination. In D. Fuss (Ed.), Inside/Out (pp 13-32). London: Routledge.

Butler, J. (1997). Gender is burning: Questions of appropriation and subversion. Cultural Politics, 11, 381-395. Retrieved from http://artsites.ucsc.edu/faculty/gustafson/FILM\%20165A.W11/film\%20165A\%5BW11\% 5D\%20readings\%20/butlerburning.pdf

Buzzanell, P. M. (2010). Resilience: Talking, resisting, and imagining new normalcies into being. Journal of Communication, 60(1), 1-14. doi:10.1111/j.1460-2466.2009.01469.x

Buzzanell, P. M., \& Turner, L. H. (2003). Emotion Work Revealed by Job Loss Discourse: Backgrounding-Foregrounding of Feelings, Construction of Normalcy, and (Re)instituting of Traditional Masculinities. Journal of Applied Communication Research, 31(1), 27-57. https://doi.org/10.1080/00909880305375

Carter, N. (2018). The politics of the environment: Ideas, activism, policy. Cambridge, UK: Cambridge University Press.

Charmaz, K. (2006). Constructing grounded theory: A practical guide through qualitative analysis. Thousand Oaks, CA: SAGE Publications.

Charmaz, K. (2014). Constructing grounded theory. Thousand Oaks, CA: SAGE Publications.

Cheney, G., Christensen, L. T., \& Dailey, S. (2014). Communicating identity and identification in and around organizations. In SAGE handbook of organizational communication (pp. 695716). Thousand Oaks, CA: SAGE Publications. 
Cheng, C. Y., Sanchez-Burks, J., \& Lee, F. (2008). Connecting the dots within: Creative performance and identity integration. Psychological Science, 19(11), 1178-1184. doi:10.1111/j.1467-9280.2008.02220.x

Clair, R. P. (1998). Organizing silence: A world of possibilities. SUNY Press.

Clarke, A. E. (2012) Feminism, grounded theory, and situational analysis revisited", in A. N. Hesse-Biber, The Handbook of Feminist Research (2nd ed.), Los Angeles: Sage.

Cloud, D. L. (1994). The materiality of discourse as oxymoron: A challenge to critical rhetoric. Western Journal of Communication 58(3), 141-163.

Cohen, N., \& Richards, J. (2015). 'I didnt feel like I was alone anymore': evaluating selforganized employee coping practices conducted via Facebook. New Technology, Work and Employment, 30(3), 222-236. doi:10.1111/ntwe.12051

Collins, P. H. (1990). Black feminist thought: Knowledge, consciousness, and the politics of empowerment. Abingdon, UK: Routledge.

Compton, C. A., \& Dougherty, D. S. (2017). Organizing sexuality: Silencing and the push-pull process of co-sexuality in the workplace. Journal of Communication, 67(6), 874-896.

Crenshaw, K. (2018). Demarginalizing the intersection of race and sex: A Black feminist critique of antidiscrimination doctrine, feminist theory, and antiracist politics [1989]. In K. Bartlett (Ed.), Feminist legal theory (pp. 57-80). New York, NY: Routledge.

Crenshaw, K. (1991). Mapping the margins: Identity politics, intersectionality, and violence against women. Stanford Law Review, 43(6), 1241-1299. Retrieved from https://www.racialequitytools.org/resourcefiles/mapping-margins.pdf

Creswell, J. W. (2013). Qualitative inquiry: Choosing among five approaches. Los Angeles, CA. Crisler, R. M. (1948). Missouris Little Dixie.. Missouri Historical Review, 42, 130-39. 
Crisp, R. J., Turner, R. N., \& Hewstone, M. (2010). Common ingroups and complex identities: Routes to reducing bias in multiple category contexts. Group Dynamics: Theory, Research, and Practice, 14(1), 32. doi:10.1037/a0017303

Curtis, W. J., \& Cicchetti, D. (2003). Moving research on resilience into the 21st century: Theoretical and methodological considerations in examining the biological contributors to resilience. Development and Psychopathology, 15(3), 773-810. doi:10.1017/S0954579403000373

D Emilio, J. (2003). Lost prophet: The life and times of Bayard Rustin. New York, NY: Simon and Schuster.

Deetz, S. (1995). Transforming communication, transforming business: Stimulating value negotiation for more responsive and responsible workplaces. International Journal of Value-Based Management, 8(3), 255-278.

Deleuze, G., \& Guattari, F. (1997). Rethinking architecture: A reader in cultural theory. London: Routledge.

DeVault, M. L., Gross, G., \& Hesse-Biber, S. N. (2012). Handbook of Feminist Research: Theory and Praxis. Thousand Oaks, CA: SAGE Publications.

Dick, P. (2008). Resistance, Gender, and Bourdieu's Notion of Field. Management Communication Quarterly, 21(3), 327-343. doi:10.1177/0893318907309930

Dill, B. T., \& Kohlman, M. H. (2012). Intersectionality: A transformative paradigm in feminist theory and social justice. Handbook of feminist research: Theory and praxis, 2, 154-174.

Dougherty, D. S. (1999). Dialogue through standpoint: Understanding women's and men's standpoints of sexual harassment. Management Communication Quarterly, 12(3), 436468. 
Dougherty, D. S. (2011). The reluctant farmer: An exploration of work, social class, and the production of food. Liesc, UK: Troubador.

Dougherty, D. S., Schraedley, M. A., Gist-Mackey, A. N., \& Wickert, J. (2018). A Photovoice study of food (in) security, unemployment, and the discursive-material dialectic. Communication Monographs, 1(24). doi:10.1080/03637751.2018.1500700

Dougherty, D. S., Kramer, M. W., Klatzke, S. R., \& Rogers, T. K. (2009). Language convergence and meaning divergence: A meaning centered communication theory. Communication Monographs, 76(1), 20-46. doi:10.1080/03637750802378799

Dubois, P. (1979). Sabotage in industry. New York City, NY: Penguin books.

Duff, S. E. (2012). 'Education for every son and daughter of South Africa': Race, class, and the compulsory education debate in the cape colony. In L. Brockliss \& N. Sheldon (Eds.), Mass Education and the Limits of State Building, c. 1870-1930 (pp. 261-282). London, UK: Palgrave Macmillan.

Edwards, P., Collinson, D., \& Della Rocca, G. (1995). Workplace resistance in Western Europe: A preliminary overview and a research agenda. European Journal of Industrial Relations, 1(3), 283-316.

Ellingson, L. L. (2017). Embodiment in qualitative research. Abingdon, UK: Routledge.

Ferguson, M. (1993). Colonialism and gender relations from Mary Wollstonecraft to Jamaica Kincaid: East Caribbean connections. New York, NY: Columbia University Press.

Fleming, P. (2005). Metaphors of resistance. Management Communication Quarterly, 19(1), 4566. doi:10.1177/0893318905276559 
Fleming, P., \& Sewell, G. (2002). Looking for the good soldier, Švejk: Alternative modalities of resistance in the contemporary workplace. Sociology, 36(4), 857-873. doi:10.1177/003803850203600404

Fleming, P., \& Spicer, A. (2007). Contesting the corporation: Struggle, power and resistance in organizations. New York, NY: Cambridge University Press.

Fleming, P., \& Spicer, A. (2008). Beyond power and resistance: New approaches to organizational politics. Management Communication Quarterly, 21(3), 301-309. $\underline{\text { doi:10.1177/0893318907309928 }}$

Foucault, M. (1979). Discipline and Punish. New York, NY: Vintage Books.

Forbes, D. A. (2002). Internalized masculinity and womens discourse: A critical analysis of the (re) production of masculinity in organizations. Communication Quarterly, 50(3-4), 269291. doi:10.1080/01463370209385664

Forbes, D. A. (2009). Commodification and co-modification: Explicating black female sexuality in organizations. Management Communication Quarterly, 22(4), 577-613. doi:10.1177/0893318908331322

Ford, J. S. (2018). (Dis) identification as resilience in dirty volunteer work. Corporate Communications: An International Journal, 23(2), 242-256. doi:10.1108/CCIJ-04-20170035

Foust, C. R. (2010). Transgression as a mode of resistance: Rethinking social movement in an era of corporate globalization. United Kingdom: Lexington Books.

Freeman, C. (2000). High tech and high heels in the global economy: Women, work, and pinkcollar identities in the Caribbean. North Carolina: Duke University Press. 
Friedman, D., \& McAdam, D. (1992). Collective identity and activism. In A. D. Morris \& C. M. Mueller (Eds). Frontiers in social movement theory (pp. 156-173). New Haven, CT: Yale Press

Gaston-Gayles, J. L., Wolf-Wendel, L. E., Tuttle, K. N., Twombly, S. B., \& Ward, K. (2005). From disciplinarian to change agent: How the civil rights era changed the roles of student affairs professionals. NASPA Journal, 42(3), 263-282.

Gherardi, S. (1994). The gender we think, the gender we do in our everyday organizational lives. Human Relations, 47(6), 591-610.

Giddens, A. (1991). Modernity and self-identity: Self and society in the late modern age. Redwood City, CA: Stanford University Press.

Giddings, L. S. \& Pringle, J. K. (2011). Heteronormativity at work: Stories from two lesbian academics. Womens Studies Journal, 25 (2), 91-100. Retrieved from www.wsanz.org.nz/

Gilligan, C. (1994). In a different voice: Women's conceptions of self and of morality. Moral Development: A Compendium, 6, 1-37. Retrieved from http://sfonline.barnard.edu/sfxxx/documents/gilligan.pdf

Gioia, D. A., Schultz, M., \& Corley, K. G. (2000). Organizational identity, image, and adaptive instability. Academy of Management Review, 25(1), 63-81. doi:10.2307/259263

Glaser, B., \& Strauss, A. (1967). The discovery of grounded theory. London, UK: Weidenfeld and Nicholson.

Goldstein-Hode, M., \& Meisenbach, R. J. (2012). Naming, framing, and blaming: Rhetorical public responses to racial incidents on campus. In D. Waymer (Ed.), Culture, social class, and race in public relations: Perspectives and applications. Lanham, MD: Lexington Books. 
Goodchild, P. (1996). Deleuze and Guattari: An introduction to the politics of desire. Thousand Oaks, CA: SAGE Publications.

Granter, E., McCann, L., \& Boyle, M. (2015). Extreme work/normal work: Intensification, storytelling and hypermediation in the (re) construction of 'the New Normal'. Organization, 22(4), 443-456. doi:10.1177/1350508415573881

Griffin, S. (2008). Wrestling with the angel of democracy: On being an American citizen. Boulder, Colorado: Shambhala Publications.

Guattari, F., \& Deleuze, G. (2000). A thousand plateaus: capitalism and schizophrenia. London, UK: Athlone Press.

Haney Lopez, I. (1996). White by law. New York, NY: NY Press

Haraway, D. (1988). Situated knowledges: The science question in feminism and the privilege of partial perspective. Feminist Studies, 14(3), 575-599. doi:10.2307/3178066

Hesse-Biber, S. N. (Ed.). (2011). Handbook of feminist research: Theory and praxis. Thousand Oaks, CA: SAGE Publications.

Hensmans, M. (2003). Social movement organizations: A metaphor for strategic actors in institutional fields. Organization Studies, 24(3), 355-381.

Hochshild, A. R. (1983). The managed heart. Retrieved from https://caringlabor.files.wordpress.com/2012/09/the-managed-heart-arlie-russellhochschild.pdf

Hoel, N. (2013). Embodying the field: A researcher's reflections on power dynamics, positionality and the nature of research relationships. Fieldwork in Religion, 8(1), 27-49. doi:10.1558/firn.v8i1.27 
Hoffman, M. F., \& Ford, D. J. (2010). Organizational Rhetoric: Identifying rhetorical strategies in organizational rhetoric. Thousand Oaks, CA: SAGE Publications.

Hogg, M. A., \& Mullin, B. A. (1999). Joining groups to reduce uncertainty: Subjective uncertainty reduction and group identification. Basic and Applied Social Psychology, 21(2), 91-102.

Hondagneu-Sotelo, P. (1994). Gendered transitions: Mexican experiences of immigration. Berkeley, CA: University of California Press.

Horne, J.F., \& Orr, J.E. (1998). Assessing behaviors that create resilient organizations. Employment Relations Today, 24, 29-40.

Hu-DeHart, E. (2007). Latin America in Asia-Pacific perspective Evelyn Hu-DeHart. In R. S. Parrenas \& L.C. D. Siu (Eds.), Asian diasporas: New formations, new conceptions (pp. 29-42). Palo Alto, CA: Stanford University Press.

Hyman, R. (1972). Strikes. Glasgow: Fontana/Collins.

Jackson, A. Y., \& Mazzei, L. A. (2012). Thinking With Theory in Qualitative Research. Abingdon, United Kingdom: Taylor \& Francis.

Jenks, C. (1995). In C. Jenks (Ed.), Visual Culture (pp. 1-25). London, UK: Routledge. Johnston, A. (2015, November 15). History of Student Activism [Video file]. Retrieved from https://www.c-span.org/video/?400341-4/washington-journal-angus-johnston-historystudent-activism

Jorgenson, J. (2002). Engineering selves: Negotiating gender and identity in technical work. Management Communication Quarterly, 15(3), 350-380. doi:10.1177/0893318902153002 
Kahlenberg, R. D. (1996). Class-based affirmative action. Retrieved from https://scholarship.law.berkeley.edu/cgi/viewcontent.cgi?article=1642\&context=californi alawreview

Kerr, E. (2018, April 16). Student occupation, Coming to a campus near you. The Chronicle of Higher Education. Retrieved from https://www.chronicle.com/

King, D. (1988). Multiple jeopardy, multiple consciousness: The context of a black feminist ideology. Signs, 14 (1), 42-72.

Kuhn, T. (2006). A 'demented work ethic'and a 'lifestyle firm': Discourse, identity, and workplace time commitments. Organization Studies, 27(9), 1339-1358. doi:10.1177/0170840606067249

Lather, P. A., \& Smithies, C. S. (1997). Troubling the angels: Women living with HIV/AIDS. Boulder, CO: Westview Press.

Larson, G. S., \& Tompkins, P. K. (2005). Ambivalence and resistance: A study of management in a concertive control system. Communication Monographs, 72(1), 1-21. doi:10.1080/0363775052000342508

Lewis, L. (2011). Organizational change: Creating change through strategic communication $\left(4^{\text {th }}\right.$ ed.). Hoboken, NJ: John Wiley \& Sons.

Lorde, A. (1984). Sister outsider. Berkley, California: Crossing Press

Loseke, D. R. (2007). The study of identity as cultural, institutional, organizational, and personal narratives: Theoretical and empirical integrations. The Sociological Quarterly, 48(4), 661-688. 
Lucas, K., \& Buzzanell, P. M. (2011). Its the cheese: Collective memory of hard times during deindustrialization. In J. M. Cramer, C. P. Greene, \& L. M. Walters (Eds.), Food as Communication/ Communication as Food (pp. 95-113). New York: Peter Lang.

Mael, F., \& Ashforth, B. E. (1992). Alumni and their alma mater: A partial test of the reformulated model of organizational identification. Journal of Organizational Behavior, 13(2), 103-123.

Marchand, R. (1998). Creating the corporate soul. Berkeley, CA: University of California Press.

Mark, G. J., Al-Ani, B., \& Semaan, B. (2009, April). Resilience through technology adoption: merging the old and the new in Iraq. In Proceedings of the SIGCHI conference on human factors in computing systems (pp. 689-698). 27th International Conference Extended Abstracts on Human Factors in Computing Systems, CHI 2009. Boston, MA, United States

Mars, G., \& Gerald, M. (1982). Cheats at work: An anthropology of workplace crime. London, United Kingdom: Unwin Paperbacks.

Massumi, B. (1992). A users guide to capitalism and schizophrenia: Deviations from Deleuze and Guattari. Boston, MA: MIT press.

May, T. (2005). Gilles Deleuze: an introduction. Cambridge, United Kingdom: Cambridge University Press.

McCall, L. (2008). The complexity of intersectionality. In E. Grabham, D. Cooper, J. Krishnaas, \& D. Herman (Eds.), Intersectionality and Beyond (pp. 65-92). New York, NY: Routledge. 
McElderry, J. A., \& Rivera, S. H. (2017). "Your agenda item, our experience": Two administrators' insights on campus unrest at Mizzou. The Journal of Negro Education, 86(3), 318-337. doi:10.7709/jnegroeducation.86.3.0318

Mead, M. (1962). A cultural anthropologists approach to maternal deprivation. Public Health Papers, 14, 45-62.

Meisenbach, R. J., \& Kramer, M. W. (2014). Exploring nested identities: Voluntary membership, social category identity, and identification in a community choir. Management Communication Quarterly, 28(2), 187-213. doi:10.1177/0893318914524059

Meyer, D. S. (2007). The politics of protest: Social movements in America. Oxford, United Kingdom: Oxford University Press.

Milk. H. (1978). Thats What America Is . Speech given on Gay Freedom Day. Retrieved from http://voicesofdemocracy.umd.edu/milk-youve-got-to-have-hope-speech-text/

Mirza, H. S. (2013). ‘A second skin': Embodied intersectionality, transnationalism and narratives of identity and belonging among Muslim women in Britain. Womens Studies International Forum, 36, 5-15. doi:10.1016/j.wsif.2012.10.012

Mitra, R. (2018). Communicative management of tensions by MSIs for water resilience. Corporate Communications: An International Journal, 23(2), 257-273. doi:10.1108/CCIJ-04-2017-0041

Mongin, O. (1982). La democratie a corps perdu. Esprit.

Mumby, D. K. (2005). Theorizing resistance in organization studies: A dialectical approach. Management Communication Quarterly, 19(1), 19-44. doi:10.1177/0893318905276558 Mumby, D. K., \& Putnam, L. L. (1992). The politics of emotion: A feminist reading of bounded rationality. Academy of Management Review, 17(3), 465-486. 
Nkomo, S. M. (1992). The emperor has no clothes: Rewriting "race in organizations." Academy of Management Review, 17(3), 487-513.

Norander, S., Mazer, J. P., \& Bates, B. R. (2011). "D.O. or die”: Identity negotiation among osteopathic medical students. Health Communication, 26(1), 59-70. doi:10.1080/10410236.2011.52762

Oktay, J. S. (2012). Grounded theory. Oxford, United Kingdom: Oxford University Press.

Olesen, V. L. (2007). Feminist qualitative research and grounded theory: Complexities, criticisms, and opportunities. In A. Bryant \& K. Charmaz (Eds.), The SAGE handbook of grounded theory (pp. 417-435). Los Angeles, CA: Sage.

Olsen, T. (1995). Tell me a riddle. New Jersey, NY: Rutgers University Press.

Orbe, M., \& Harris, T. M. (2001). The history of race. In M. Orbe \& T. Harris (Eds.), Interracial communication: Theory into practice (25-43). Thousand Oaks, CA: SAGE Publishing.

Pfafman, T. M., \& Bochantin, J. E. (2012). Negotiating power paradoxes: Contradictions in womens constructions of organizational power. Communication Studies, 63(5), 574-592. doi:10.1080/10510974.2012.681100

Perry, M., \& Medina, C. (2011). Embodiment and performance in pedagogy research: Investigating the possibility of the body in curriculum experience. Journal of Curriculum Theorizing, 27(3). Retrieved from http://journal.jctonline.org/index.php/jct/article/view/100

Piven, F. F. (2006). Challenging authority: How ordinary people change America. Lanham, MD: Rowman \& Littlefield Publishers.

Poole, P. P., Gray, B., \& Gioia, D. A. (1990). Organizational script development through interactive accommodation. Group \& Organization Studies, 15(2), 212-232. 
Pullen, A., Rhodes, C., \& Thanem. T. (2017). Affective politics in gendered organizations:

Affirmative notes on becoming-woman. Organization, 24, 105-123. doi: $10.1177 / 1350508416668367$

Putnam, L. L., \& Bochantin, J. (2009). Gendered bodies: Negotiating normalcy and support. Negotiation and Conflict Management Research, 2(1), 57-73. doi:10.1111/j.1750-4716.2008.00028.x

Remedios, J. D., \& Snyder, S. H. (2015). How women of color detect and respond to multiple forms of prejudice. Sex Roles, 73(9-10), 371-383. doi:10.1007/s11199-015-0453-5

Rickford, R. (2016). Black lives matter: Toward a modern practice of mass struggle. New Labor Forum, 25(1), 34-42. doi:10.1177/1095796015620171

Rogers, R. (2003). A critical discourse analysis of family literacy practices: Power in and out of print. New York, NY: Routledge.

Rudolph, F. (1990). The American college and university: A history. Athens, GA: University of Georgia Press.

Sani, F., Bowe, M., Herrera, M., Manna, C., Cossa, T., Miao, X., \& Zhou, Y. (2007). Perceived collective continuity: Seeing groups as entities that move through time. European Journal of Social Psychology, 37(6), 1118-1134. doi:10.1002/ejsp.430

Schrock, D. P., \& Padavic, I. (2007). Negotiating hegemonic masculinity in a batterer intervention program. Gender \& Society, 21(5), 625-649.

doi: $10.1177 / 0891243207304975$

Scott, K. D. (2013). Communication strategies across cultural borders: Dispelling stereotypes, performing competence, and redefining black womanhood. Womens Studies in Communication, 36(3), 312-329. 
Scott, C. R., Corman, S. R., \& Cheney, G. (1998). Development of a structurational model of identification in the organization. Communication Theory, 8(3), 298-336.

Shim, J. K. (2005). Constructing 'race'across the science-lay divide: Racial formation in the epidemiology and experience of cardiovascular disease. Social Studies of Science, 35(3), 405-436. doi:10.1177/0306312705052105

Simmonds, F N. (1997). My body myself: How does a black woman do sociology? In H. Mirza (Ed.), Black British Feminism, (pp. 226-39). New York, NY: Routledge.

Singhal, A., Harter, L. M., Chitnis, K., \& Sharma, D. (2007). Participatory photography as theory, method and praxis: Analyzing an entertainment-education project in India. Critical Arts: A Journal of South-North Cultural Studies, 21(1), 212-227. doi:10.1080/02560040701398897

Snow, D. A., \& McAdam, D. (2000). Identity work processes in the context of social movements: Clarifying the identity/movement nexus. In S. S. Owens \& R. W. White (Eds.), Self, identity, and social movements, 13. doi:10.1002/9780470674871

Stewart, C. J., Smith, C. A., \& Denton Jr, R. E. (2012). Persuasion and social movements. Long Grove, IL: Waveland Press.

Stohl, C. (1986). The role of memorable messages in the process of organizational socialization. Communication Quarterly, 34(3), 231-249.

Strauss, A. (1993). Continual permutations of action. New York, NY: Aldine de Gruyter

Sturdy, A., Schwarz, M., \& Spicer, A. (2006). Guess whos coming to dinner? Structures and uses of liminality in strategic management consultancy. Human Relations, 59(7), 929-960.

Stryker, S., Owens, T. J., \& White, R. W. (Eds.). (2000). Self, identity, and social movements (Vol. 13). Minneapolis, MN: University of Minnesota Press. 
Synnott, M. G. (2008). African American women pioneers in desegregating higher education. Higher education and the civil rights movement. In P. Wallenstein (Ed.), White supremacy, Black southerners, and college campuses, (pp. 199-228). Gainesville, FL: University Press of Florida

Tarrow, S. G. (2011). Power in movement: Social movements and contentious politics. New York, NY: Cambridge University Press.

Taylor, I. (1996). Fear of crime, urban fortunes and suburban social movements: some reflections from Manchester. Sociology, 30(2), 317-337.

Taylor, V., \& Raeburn, N. C. (1995). Identity politics as high-risk activism: Career consequences for lesbian, gay, and bisexual sociologists. Social Problems, 42(2), 252-273.

Tempest, S., \& Starkey, K. (2004). The effects of liminality on individual and organizational learning. Organization Studies, 25(4), 507-527.

Thomas, R., \& Davies, A. (2005). Theorizing the micro-politics of resistance: New public management and managerial identities in the UK public services. Organization Studies, 26(5), 683-706. doi:10.1177/0170840605051821

Tracy, S. J. (2005). Locking up emotion: Moving beyond dissonance for understanding emotion labor discomfort. Communication Monographs, 72(3), 261-283. doi:10.1080/03637750500206474

Tracy, S. J. (2013). Qualitative research methods. Oxford, UK: Wiley-Blackwell.

Tracy, S. J., \& Scott, C. (2006). Sexuality, masculinity, and taint management among firefighters and correctional officers: Getting down and dirty with "Americas heroes" and the "scum of law enforcement”. Management Communication Quarterly, 20(1), 6-38. doi:10.1177/0893318906287898 
Tracy, S. J., \& Trethewey, A. (2005). Fracturing the real-self $\leftrightarrow$ fake-self dichotomy: Moving toward "crystallized" organizational discourses and identities. Communication Theory, 15(2), 168-195. doi:10.1111/j.1468-2885.2005.tb00331.x

Trujillo, N. (1991). Hegemonic masculinity on the mound: Media representations of Nolan Ryan and American sports culture. Critical Studies in Media Communication, 8(3), 290-308.

Turner, V. (1969). Liminality and communitas. The Ritual Process: Structure and Antistructure, 94, 358-374.

Tye-Williams, S., \& Krone, K. J. (2017). Identifying and re-imagining the paradox of workplace bullying advice. Journal of Applied Communication Research, 45(2), 218-235. doi:10.1080/08824090701831875

Van Dijk, T. A. (1993). Principles of critical discourse analysis. Discourse \& Society, 4(2), 249283.

Waheed, N. (2013). Salt. Scotts Valley, CA: CreateSpace Independent Publishing Platform Watson, T. J. (2008). Managing identity: Identity work, personal predicaments and structural circumstances. Organization, 15(1), 121-143. doi:10.1177/135050840708448

Watson, T. J., \& Watson, D. H. (2012). Narratives in society, organizations and individual identities: An ethnographic study of pubs, identity work and the pursuit of 'the real'. Human Relations, 65(6), 683-704. doi:10.1177/0018726712440586

Weedon, C. (1997). Feminist practice \& poststructuralist theory. Hoboken, NJ: Wiley-Blackwell

Weick, K. E. (1979). The social psychology of organizing (Topics in social psychology series). Columbus, OH: McGraw-Hill Humanities.

West, C., \& Fenstermaker, S. (1995). Doing difference. Gender \& Society, 9(1), 8-37. 
Wieland, S. M. (2010). Ideal selves as resources for the situated practice of identity. Management Communication Quarterly, 24(4), 503-528. doi:10.1177/0893318910374938

Wolkomir, M., \& Powers, J. (2007). Helping women and protecting the self: The challenge of emotional labor in an abortion clinic. Qualitative Sociology, 30(2), 153-169. doi:https://link.springer.com/article/10.1007/s11133-006-9056-3

Wood, J. T., \& Conrad, C. (1983). Paradox in the experiences of professional women. Western Journal of Speech Communication, 47(4), 305-322. doi:10.1080/10570318309374128

Ybema, S., Yanow, D., Wels, H., \& Kamsteeg, F. H. (Eds.). (2009). Organizational ethnography: Studying the complexity of everyday life. Thousand Oaks, CA: SAGE Publications. 


\section{Appendix A: Recruitment Script}

\section{MU Info blurb}

Title: Are you a faculty member, staff member or an administrator? Participants are needed for an identity management study.

Text: I am currently interviewing university administrators, faculty and staff about their experiences negotiating identity during social movements and student led protests. I would love to hear your stories! The interview will be audiotaped but identifying information will be kept strictly confidential. For more information, contact Anna Valiavska at valiavskaa@missouri.edu.

\section{Participant email prompt}

Thank you for agreeing to the interview. This interview will focus on identity management during social movements so some of the questions will focus on your thoughts and feelings as various events unfolded. As a part of the research process I wanted to ask you to think about and bring a few objects with you that represent your thoughts, feelings, state of being before, during, and after your involvement in a social movement. 


\section{Appendix B: Interview Protocol}

Thank you for agreeing to the interview. This interview will focus on identity management during social movements so some of the questions will focus on your thoughts and feelings as various events unfolded. As a part of the research process I want to ask you to think about and bring a few objects with you that represent your thoughts, feelings, state of being before, during, and after your experience with the 2015 campus social movement.

Let's take a look at this object you brought

1. Tell me a story about this photo.
a. What does it depict?
b. What does it mean to you?
c. How did you choose it?

2. How does this connect to your role in the social movement?

3. What does it say about who you are/ your identity?

4. Describe your involvement in a social movement.

5. What was your professional title at that time? What were your professional responsibilities?

6. In terms of your role around the social movement, what were the obligations you felt strongly about that did not fall into the realm of your professional responsibilities?

7. Describe how your colleagues or peers participate in this social movement?

a. What conversations did you have with them?

b. Did you talk about your involvement in this social movement with your colleagues? Peers?

8. Describe what conflicts you felt?

a. If so, when?

b. What physical sensations do you recall? What emotions do you recall?

9. What are some of the identities that you hold that feel especially important to you?

a. Prompts: gender, race, social class

10. What identities were important to you as the movement was unfolding? 
11. How did you experienced sense of internal or interpersonal conflict as the movement was unfolding?

12. Tell me a story about being resilient as the social movement was unfolding.

a. Did you ever feel like you had to persevere? If so, when?

13. Did you see any documents, internal memos about this? How did those shape your experiences?

14. How do you feel now as we talk about this?

15. How has this impacted your work? 


\section{Appendix C: Demographic Survey}

What is your occupation and job title?

What is your age?

What is your race?

What is your gender?

What is your sexuality?

What is your social class status?

In what city do you live? 


\section{Vita}

Anna Valiavska was born in Kiev, Ukraine and lived in several places in the Midwest before settling in Columbia, Missouri. After graduating with a BA in International Relations and a minor in Philosophy, Anna pursued a MS degree in Student College Personnel. Anna moved to Columbia MO, where she worked as a Hall Coordinator, and a Coordinator for First Year Interest Groups at the University of Missouri. She started taking classes as a non-degree seeking student and became interested in questions about gender, embodiment, and organizing. Throughout her doctoral program, Anna was interested in thinking about connections between theory and practice. She was thrilled to discover poststucturalist work and integrated thinking with theory into her scholarship. Anna is excited about her next professional adventures. 